\author{
UNIVERSIDADE DE SÃO PAULO \\ INSTITUTO DE FÍSICA \\ FACULDADE DE EDUCAÇÃO
}

FABIO GARCIA GATTI

\title{
FILOSOFIA DA MECÂNICA ESTATÍSTICA \\ E ENSINO DE FÍSICA: REDUÇÃO VERSUS EMERGÊNCIA E A IMPORTÂNCIA DOS MODELOS
}




\author{
UNIVERSIDADE DE SÃO PAULO \\ INSTITUTO DE FÍSICA \\ FACULDADE DE EDUCAÇÃO
}

FABIO GARCIA GATTI

\title{
FILOSOFIA DA MECÂNICA ESTATÍSTICA E ENSINO DE FÍSICA: REDUÇÃO VERSUS EMERGÊNCIA E A IMPORTÂNCIA DOS MODELOS
}

Tese apresentada ao Programa de Pós-Graduação Interunidades em Ensino de Ciências da Universidade de São Paulo para a obtenção do título de Doutor em Ensino de Ciências (Modalidade Física).

Área de Concentração: Ensino de Ciências

Orientador: Prof. Dr. Osvaldo Frota Pessoa Jr.

São Paulo

2016 
FICHA CATALOGRÁFICA

Preparada pelo Serviço de Biblioteca e Informação do Instituto de Física da Universidade de São Paulo

\section{Gatti, Fábio Garcia}

Filosofia da Mecânica Estatística e Ensino de Física: Redução versus emergência e a importância dos modelos. São Paulo, 2016.

Tese (Doutorado) - Universidade de São Paulo. Faculdade de Educação, Instituto de Física, Instituto de Química e Instituto de Biociências

Orientador: Prof. Dr. Osvaldo Frota Pessoa Jr.

Área de Concentração: Ensino de Ciências e Matemática

Unitermos: 1. Filosofia da Ciência; 2. Reducionismo; 3. Emergentismo; 4. Modelos; 5. Mecânica Estatística.

USP/IF/SBI-045/2016 


\section{Resumo}

Gatti, F. G. Filosofia da mecânica estatística e ensino de física: redução versus emergência e a importância dos modelos. 113 pp. Tese (Doutorado em Ensino de Física). Instituto de Física, Instituto de Química, Instituto de Biociências, Faculdade de Educação. Universidade de São Paulo, São Paulo, 2016.

Esta tese explora tópicos de Filosofia da Mecânica Estatística e sua inserção no Ensino de Física. Levanta-se inicialmente a discussão filosófica entre o reducionismo e o emergentismo. Esta questão permeia os debates científicos em Mecânica Estatística e em outras áreas, mas costuma ficar fora dos currículos escolares e universitários. Defendemos que esta discussão tem grande valor educacional para a formação do futuro professor e dos futuros cidadãos, mostrando como a ciência de fato é construída, e revelando aspectos da ciência para os quais não há uma visão de consenso único. Além disso, a natureza de modelos e aproximações foi estudada, sendo explorados diversos modelos de Mecânica Estatística, visando seu uso em sala de aula. Ao final da tese, apresenta-se uma proposta de curso onde essas questões poderão ser discutidas em sala de aula, contribuindo para um enriquecimento dos estudos sobre a Natureza da Ciência.

Palavras chave: Filosofia da física, mecânica estatística, reducionismo, emergentismo, modelos. 


\section{Abstract}

Gatti, F. G. Philosophy of statistical mechanics and physics teaching: reduction versus emergence and the importance of models. $113 \mathrm{pp}$. Thesis (Doutorate in Physics Teaching). Institute of Physics, Institute of Chemistry, Institute of Biosciences, School of Education. University of São Paulo, São Paulo, Brazil, 2016.

This thesis explores topics in the Philosophy of Statistical Mechanics and their use in Physics Teaching. It begins with the philosophical discussion between reductionism and emergentism. This issue is present in the scientific debates in Statistical Mechanics and other fields, but is usually not treated in high school and university courses. We argue that this discussion has great educational value for the future teachers and citizens, showing how science is constructed and revealing aspects of science about which there isn't a consensus. The nature of models and approximations is also studied, and various models in Statistical Mechanics are explored, in connection to their use in the classroom. At the end, a proposal for a course syllabus is presented, in which the issues explored in this thesis can be discussed in the classroom, contributing to the enrichment of the studies on the Nature of Science.

Keywords: Philosophy of physics, statistical mechanics, reducionism, emergentism, models. 


\section{Agradecimentos}

Primeiramente gostaria de agradecer a minha esposa Sandra e por extensão a minha filha Larissa, pois na alegria e na tristeza, na saúde e na tese, elas contribuíram passando-me incentivo, crédito, confiança e apoio nos momentos de maior turbulência.

Aos meus pais e meu irmão Eduardo, que desde o início de minha peregrinação pelo mundo acadêmico, sempre acreditaram em mim, apesar da escolha da carreira.

A minha irmã Gisele e ao meu cunhado Adriano, que acolheram-me durante 48 meses em sua casa, tornando minha estada a mais agradável. Não sei se a recíproca é verdadeira.

Ao grupo REDUX, Luis Rigolin, Nelson Bejarano, Yara Kulaif, Fábio Leite e Douglas Slaughter, pelas inúmeras discussões que serviram de semente para a elaboração desta tese. Se não der frutos, valeu pela sombra das folhas.

A meu orientador de mestrado, Luis Vicente de Andrade Scalvi, pela paciência de conduzir-me pelo caminho da pesquisa.

Ao professor Pablo Venegas, pelos momentos de descontração em sua sala no departamento de física tornando a viagem mais agradável.

Ao meu professor de graduação Renato Ghiotto, não somente pelas críticas e discussões do trabalho, mas principalmente por mostrar que caminhos comuns, nos levam a lugares comuns.

Aos professores Cristiano Mattos, Vera Henriques, Eduardo Henriques, Jesuína Pacca e Silvio Salinas pelas leituras atentas da tese e críticas construtivas.

Finalmente gostaria de reconhecer a figura ímpar de meu orientador, professor Osvaldo Frota Pessoa Jr. Poderia começar por agradecê-lo pela sua paciência, conselhos, críticas, lisura acadêmica e confiança no trabalho. Ou então, pelas inúmeras noites de orientação em que fui recebido em sua residência. Entretanto, não há como mensurar meu agradecimento por ter sido ele a estender-me as mãos e retirar-me de um sono profundo. 


\section{Sumário}

INTRODUÇÃO

CAPÍTULO 1 - EMERGÊNCIA VS REDUÇÃO

1.1 A Face Política da Discussão 4

1.2 Analisando o Reducionismo 6

$\begin{array}{ll}1.3 & \text { Analisando a Emergência } \\ 1.3 .1 & 16\end{array}$

1.3.1 Modelo da Flambagem 22

CAPÍTULO 2. TEORIA CINÉTICA DA MATÉRIA E REDUÇÃO DA ENTROPIA

2.1 O Conceito de Entropia e Versões da 2 $2^{\underline{a}}$ Lei 28

2.2 Modelos Moleculares para a 2a Lei 34

2.3 A Equação de Boltzmann e o Teorema H 43

2.4 Concepção Probabilista de Entropia 51

2.5 Novas Aproximações: a Hierarquia BBGKY 59

2.6 A Hipótese do Caos Molecular 65

CAPÍTULO 3 - FILOSOFIA DA CIÊNCIA E MODELOS

$\begin{array}{lll}3.1 & \text { Filosofia da Física } & 70\end{array}$

3.2 Sobre Modelos e Aproximações 72

3.3 Filosofia da Ciência e Modelos 75

3.4. Três Modelos de Física Térmica 80

3.4.1 Modelo dos Fônons na Barra 81

3.4.2 Modelo da Urna dos Ehrenfest 84

3.4.3 Modelo do Vento e da Árvore dos Ehrenfests 87

CAPÍTULO 4 - IMPLICAÇÕES PARA O ENSINO DE CIÊNCIAS

4.1 História e filosofia no ensino de ciências 90

$\begin{array}{lll}4.2 & \text { Uma proposta de curso } & 94\end{array}$

4.3 As implicações para o Ensino de Ciências 100

$\begin{array}{lr}\text { CAPÍTULO 5 - CONCLUSÕES } & 101\end{array}$

$\begin{array}{ll}\text { REFERÊNCIAS BIBLIOGRÁFICAS } & 103\end{array}$

$\begin{array}{ll}\text { APÊNDICE A } & 113\end{array}$

$\begin{array}{lr}\text { APÊNDICE B } & 115\end{array}$ 


\section{Introdução}

Buscar o entendimento do mundo que nos cerca certamente não é uma exclusividade de nossa sociedade contemporânea. Os primeiros atomistas gregos, já no século $\mathrm{VI}$ a.C., elaboraram modelos que se propunham a reduzir os fenômenos do mundo macroscópico a blocos fundamentais e indivisíveis de matéria, os "átomos" que se movem no espaço vazio.

A proposta de uma entidade física microscópica e indivisível era o início do chamado "materialismo", que busca reduzir até a mente humana à matéria. Um dos maiores desafios que os seguidores desta concepção filosófica teriam de enfrentar era a explicação de como substâncias inanimadas, quando organizadas, resultavam em algo extremamente complexo, tal como a vida (LANGE, 1957).

Mas será que podemos explicar o universo tratando-o somente como um local cheio de energia, átomos e campos, que em determinado momento gerou vida? Mais ainda, podemos dizer que somos somente um agrupamento de átomos e moléculas, que graças a uma complexidade muito grande, resultou naquilo que chamamos de consciência? Seria possível prever as propriedades optoeletrônicas de um semicondutor, por exemplo, somente a partir de uma teoria detalhada da mobilidade eletrônica e transmissão óptica? Poderíamos prever o comportamento das reações químicas apenas a partir da equação de Schrödinger da Mecânica Quântica? Poderíamos prever a maneira como uma colônia de abelhas interage apenas a partir do conhecimento de uma única abelha?

Tais questões poderiam ser consideradas excessivamente complexas e filosóficas para serem tratadas no contexto do Ensino de Física. Porém a prática em sala de aula indica que essas questões despertam em muito o interesse do aluno. A resposta positiva a essas perguntas admitiria um reducionismo; por outro lado, se negarmos a possibilidade de tais reduções, temos aquilo que é chamado de emergentismo.

Nesta tese discutiremos algumas formas de redução, lembrando que as definições de "redução" variam conforme o autor (ver DUPRÉ, 2001). O mesmo 
vale para os diferentes conceitos de emergência, sendo que ambos os assuntos são tratados no Capítulo 1.

Tal discussão se dá principalmente na área de Filosofia da Ciência, mas na verdade elas sempre fizeram parte também da discussão dos cientistas. Veremos a seguir que elas ainda orbitam a atividade científica, gerando disputas e interesses, como no debate entre Weinberg e Anderson, que envolvem até aspectos sociológicos da ciência. Ainda no Capítulo 1, examinamos um modelo bastante simples, da flambagem de uma barra, para contrastar as explicações reducionista e emergentista.

A segunda parte da tese é focada num estudo detalhado da abordagem mecânico-estatística relacionada com a Segunda Lei da Termodinâmica. Examinaremos os principais obstáculos encontrados na tentativa de reduzir a lei da entropia à Mecânica Clássica, feita por Clausius, Maxwell e Boltzmann. Esta discussão é apresentada no Capítulo 2, onde enfocamos o período 18501900, que inclui o debate entre os chamados "energeticistas" e os atomistas. É neste período da história da ciência que se iniciou a busca pela redução interteórica da física macroscópica à física dos átomos e moléculas. Descrevemos as duas abordagens de Boltzmann a esta questão: o teorema $\mathrm{H}$ e a concepção probabilista de entropia. $\mathrm{O}$ teorema $\mathrm{H}$ foi uma tentativa de derivar a irreversibilidade apenas a partir da Mecânica Clássica, mas críticas como os paradoxos da reversibilidade e da recorrência mostraram que uma hipótese adicional teria que ser usada para justificar a utilidade do teorema $\mathrm{H}$. Discutiremos esta hipótese, chamada de "independência estatística" (Stossanzahlansatz) ou, com ligeiras modificações, "caos molecular".

Analisaremos alguns outros episódios do debate sobre o reducionismo no século $X X$, em especial a chamada abordagem BBGKY, explorando assim uma estratégia físico-matemática adotada para se tentar fundamentar a redução, com base em um método de aproximações sucessivas.

No Capítulo 3, tratamos inicialmente da posição fundamental que a filosofia possui no ensino de ciências, posição esta que é assumida por pesquisadores de ensino e filósofos de várias partes do mundo. Subsequentemente, exploramos o papel dos modelos na ciência, e em especial na Física Estatística. Discorremos sobre três diferentes modelos, dentre eles o 
"modelo da urna", o modelo das barras e o "modelo da árvore e do vento", que fornecem subsídios para o ensino da teoria mecânico-estatística da matéria.

A partir da síntese envolvendo capítulos anteriores, buscamos desenvolver no capítulo 4 uma proposta de ensino, cujo objetivo foi o de integrar elementos físicos a aspectos de História e Filosofia da Ciência (HFC), e suas aproximações para a compreensão da Natureza da Ciência ( $\mathrm{NdC})$. Essa proposta consiste da elaboração de um minicurso com um total de dez encontros, onde apresentaremos as discussões levantadas por esta tese.

A questão de pesquisa teve o proposito de investigar de que maneira uma proposta de formação baseada na HFC, tendo como pano de fundo as discussões sobre modelos e filosofia da física, pode contribuir para a construção de uma visão adequada da NdC.

Em muitos momentos atuaremos de forma interdisciplinar no tratamento dos temas aqui apresentados, fazendo uma leitura históricofilosófica do assunto. Julgamos que este procedimento interdisciplinar possa trazer boas contribuições à formação dos propedeutas. 


\section{CAPÍTULO 1 \\ Emergência vs. redução}

\section{1- A Face Política da Discussão}

A tentativa de explicar o mundo visível a partir de entidades microscópicas esteve presente nas principais escolas filosóficas da Antiguidade, seja com os antigos jainistas, na Índia do séc. IV a.C. (McEVILLEY, 2002, p. 317-321,) ou com os chamados atomistas (Leucipo e Demócrito) nos sécs. V e IV a.C.

Muitos séculos depois, conforme analisaremos no cap. 2, veremos outra tentativa de entender o macro através do micro, com a implantação da Mecânica Estatística como método de se reduzir teoricamente a Teoria Termodinâmica.

Mas foi no século $X X$ que o chamado projeto reducionista se intensificou e se expandiu para além das fronteiras científicas, ganhando proporção de política de estado.

Com a descoberta de novas partículas elementares, a partir da década de 1930, após a 2a Guerra Mundial, aceleradores de partículas cada vez maiores passaram a ser construídos, exigindo somas cada vez mais vultosas de dinheiro, consequentemente atraindo muitos jovens para a física nuclear e de altas energias.

No entanto, outra grande área da física expandia-se paralelamente à Física Nuclear após a 2ª Guerra: a Física da Matéria Condensada. Esta área estava mais próxima de aplicações tecnológicas, como a pesquisa em dispositivos semicondutores, essencial para a microeletrônica e, assim, sofisticadasteorias foram desenvolvidas para descrever seus fenômenos macroscópicos, enquanto área autônoma da Física.

Tentando manter uma independência, esta área argumenta que a explicação completa de determinados fenômenos ocorridos em seus campos, não podem ser reduzidos (pelo menos epistemologicamente) à Física de 
Altas Energias (partículas elementares), afinal, alguns fenômenos "emergentes", que ali aparecem, fugiriam ao escopo do projeto reducionista almejado pela física de partículas (SCHWEBER, 1993, p. 34).

Em meados dos anos 1980, no governo Reagan, o congresso dos EUA decidiu investir 4,4 bilhões de dólares na construção de um imenso acelerador de partículas, o Superconducting Super Collider (Super Colisor Supercondutor). A construção se iniciou em 1991, e após o investimento de US $\$ 2$ bilhões, o custo total projetado passou para US\$ 12 bilhões. Em 1993, vários grupos passaram a argumentar que os custos eram muito elevados e que as verbas estavam sendo mal administradas, o que levou a intensos debates no Congresso, resultando no cancelamento do projeto.

A comunidade dos físicos se dividiu em lados opostos nesta discussão. Por um lado, físicos de partículas como Steven Weinberg, Prêmio Nobel de 1979, apoiavam o projeto, salientando a importância da pesquisa em Física de Partículas, que forneceria o arcabouço teórico geral para se entender todos os fenômenos da ciência. O mesmo Weinberg publicou em 1992 o livro Sonhos de uma teoria final, hasteando a bandeira de uma concepção reducionista da física, argumentando que a Física de Partículas seria "mais fundamental" (WEINBERG,1996).

Do outro lado, físicos que trabalhavam com a matéria condensada, como Philip Anderson, Prêmio Nobel de 1977, puseram em cheque a viabilidade do chamado projeto reducionista. Segundo ele, a ênfase da física da matéria condensada está em descrever e explicar propriedades "emergentes", com conceitos e leis próprias de escalas mais macroscópicas.

A tentativa de reduzir essa teoria a conceitos e leis da Física de Partículas seria um projeto inviável, por motivos práticos e teóricos. Esta concepção emergentista difundiu-se bastante entre os físicos, tendo como influência também as teses do químico llya Prigogine (ZYLBERSZTAJN, 2003).

Em 1993, Weinberg e Anderson foram convidados a darem seus pareceres em sessão do congresso americano, e enquanto Weinberg apoiara entusiasticamente o projeto do Super Colisor, Anderson e seu colega James Krumhansl argumentaram que o dinheiro poderia ser melhor investido se distribuído entre muitos projetos menores. Anderson negou que a Física de 
Partículas fosse "mais fundamental", articulando sua concepção emergentista da física (ANDERSON, 1972).

Este debate que aconteceu dentro da física certamente tem paralelos com debates análogos ocorrendo internamente em outras áreas da ciência, como a química e a biologia. Obviamente em paralelo as posições científicas e metodológicas estavam marcando forte presença os interesses ideológicos e de cunho econômico.

Como consequência, o Congresso Norte-Americano arquivou o projeto do Super Colisor (CAT, 1998), propondo que o mesmo deveria ser debatido com a sociedade num momento futuro.

\subsection{Analisando o Reducionismo}

O apelo reducionista na ciência no início do século XX é inegável, uma vez que a ciência já havia presenciado uma redução bem sucedida através da Mecânica Estatística no final do século XIX, conforme detalharemos a seguir.

O físico Milton Rothman o resume o ambiente do seguinte modo:

Uma peculiar reviravolta ocorreu durante o curso do século XX. Através do trabalho dos físicos, a teoria atômica tornou-se tão bem estabelecida, que já não era possível atacá-la chamando-a de antirreducionista. Os filósofos tiveram que inverter a posição do reducionismo para fazer a teoria atômica parte da visão aceita. O reducionismo agora congregava a ideia de que tudo é feito de átomos. Como resultado disso, o conceito de reducionismo agora tornou-se alvo de crítica daqueles que não poderiam aceitar a ideia de que seres humanos são feitos de átomos, e seguem os princípios físicos como todo o resta da natureza. (ROTHMAN, 1998, p.222)

Em que sentido explicar um fenômeno macroscópico através de uma dinâmica microscópica faz de alguém um reducionista? Analisando o que 
disse Rothman, notamos primeiramente que o fato de alguém alegar que toda a matéria conhecida é constituída de átomos e que estes são explicados por outras áreas da física por si só não representa um reducionismo radical, apenas é uma colocação em sincronia com os fatos, o que costuma ser chamado de "reducionismo ontológico" ou "ôntico". No entanto, caso esta mesma pessoa passe a expandir este conceito, e supor que já que tudo é feito de átomos, e estes são de domínio íntimo da Física, logo todas as áreas da ciência podem ser reduzidas à teoria física, aí teremos uma posição extremada, chamada de "reducionismo epistemológico" ou "teórico".

A visão de que o reducionismo ôntico é verdadeiro e o epistemológico é falso tem sido chamado de "visão tradicional" do reducionismo.

O quadro a seguir consiste de uma representação da hierarquização da estrutura da ciência, onde, segundo o físico Philip Anderson, as entidades elementares da ciência, da coluna $X$, obedecem às leis da ciência Y (ANDERSON, 1972, p.393).

\begin{tabular}{|c|c|}
\hline $\mathrm{X}$ & $\mathrm{Y}$ \\
\hline $\begin{array}{c}\text { Física da matéria } \\
\text { condensada ou de muitos } \\
\text { corpos }\end{array}$ & $\begin{array}{c}\text { Física das partículas } \\
\text { elementares }\end{array}$ \\
\hline Química & Física de muitos corpos \\
\hline Biologia molecular & Química \\
\hline Biologia celular & Biologia molecular \\
\hline$\ldots$ & $\ldots$ \\
\hline Psicologia & Fisiologia \\
\hline Ciências sociais & Psicologia \\
\hline
\end{tabular}

Tabela 1.1 - Ciências relacionadas na coluna $X$ seguiriam as leis das ciências da coluna $Y$. 
Esta tabela aparece num artigo seminal escrito por Anderson, em 1972, onde é discutida a hipótese reducionista de ciência. Anderson apresenta algumas contestações referentes a esta questão, não exatamente à tese de que um conjunto de leis fundamentais rege o mundo inorgânico e orgânico, mas ao que ele chama de hipótese construcionista. O que ele nega é que tudo que existe no universo pode ser reconstituído a partir de partículas, campos e suas interações.

Caso houvesse uma "desconstrução" de um sistema mais complexo ao nível microscópico, um reducionista iria argumentar que em princípio a construção do mesmo se daria sem nenhum problema, desde que as leis básicas aonível microscópico fossem conhecidas em detalhe. Mas Anderson nega que seja factível a reconstrução de um sistema de matéria condensada a partir de suas moléculas. Ele apresenta um argumento contra esta manobra, baseado na noção de "quebra de simetria".

Especulando-se um pouco, poderíamos considerar que um ser dotado de um conhecimento profundo das leis universais, cuja capacidade de computação fosse também superlativa, pudesse a partir das subpartículas promovera construção de átomos e moléculas, já prevendo seu comportamento nos diversos níveis de complexidade. Este é o raciocínio de Laplace, ao defender o determinismo do Universo, e este é o raciocínio comum aos reducionistas (ou construcionistas, na terminologia de Anderson). Estes dizem que não existe nenhum impedimento teórico relatado na ciência até agora que impeça tal manobra. Para Steven Weinberg:

Reducionismo não é uma prescrição geral para o progresso da ciência, mas uma afirmação da ordem da natureza, que penso ser correta.

Ernest Nagel caracteriza a redução em seu famoso livro The structure of science, publicado em 1961, da seguinte maneira: 
Redução no sentido em que a palavra é aqui usada, é a explicação de uma teoria ou de uma série de leis experimentais estabelecidas em uma área de pesquisa, por outra teoria geralmente, masnem sempre formulada para algum outro domínio.

[...] chamamos o conjunto de teorias ou leis experimentais que é reduzida para outra teoria de ciência secundária, e a teoria que efetua ou propõe a redução de ciência primária.

Nagel também estabelece a diferença entre dois tipos de reducionismo,que chamou de homogêneo e heterogêneo. Segundo o autor, a redução que não gera desconforto intelectual poderia ser chamada de homogênea. Por exemplo, no livro As Duas Novas Ciências de Galileu, é tratado o conceito de queda livre referente a corpos terrestres. No entanto esta teoria é absorvida pela mecânica celeste newtoniana, mais abrangente, ocorrendo aí o que Nagel chama de reducionismo homogêneo.

Já no caso da redução envolvendo o conceito de temperatura com energia cinética média das moléculas, certas lacunas aparecem quanto à análise da interpretação, envolvendo o conceito de calor e entropia. Nestes casos podemos considerar que houve uma redução heterogênea, pois incômodos intelectuais estão presentes (NAGEL, 1961,p.161).

Posteriormente 0 autor trata da hierarquia envolvendo proposições dentro de uma teoria geral que chama de T. Podemos dizer que uma dada subclasse teórica denominada de T1, contém uma maior capacidade de generalização que uma subclasse T2, mais específica para um determinado sistema. Por exemplo, na Teoria Cinética dos Gases T, os axiomas da mecânica newtoniana $T 1$ são mais gerais que a suposição de que todas as moléculas de um gás têm a mesma probabilidade de ocupar um dado estado no espaço de fase T2 (teorema das iguais probabilidades a priori), cujo escopo é bem menos geral.

Nagel também tenta estabelecer aquilo a que chama de condições formais necessárias para uma redução:

1. Conectabilidade (entre campos, teorias ou áreas)

2. Derivabilidade (implicação lógica) 
A proposta de Nagel para definir a redução tem sido contestada por vários autores. entre eles Kim (1999) e Sklar (1967). Este último argumenta que o exemplo de redução homogênea proposto por Nagel é extremamente particular, não ocorrendo em quase nenhum momento na ciência. Como caso particular, considera que alguns conceitos existentes na Teoria Galileana não aparecem na Teoria Newtoniana, de maneira que a primeira não seria derivável da segunda, violando o item 2 de Nagel citado acima. Por exemplo, para Galileu a aceleração gravitacional é constante ao longo da queda de um corpo, ao passo que na lei da gravitação de Newton ela varia continuamente, mesmo que de maneira bastante suave. Reducionistas consideram que tal aproximação pode ser incluída no item da derivabilidade, ao passo que autores como Kuhn e Feyerabend (usados por Sklar) veem aí uma lacuna.

Não há um consenso para tipificar os diferentes tipos de reducionismo existentes. Adotarei aqui três tipificações de reducionismo que parecem suficientes para expor a ideia geral da tese aqui apresentada:

Reducionismo Ôntico: $\mathrm{Na}$ realidade, independentemente de nossas teorias e observações, um corpo macroscópico é um montede moléculas organizadas, assim um inseto é constituído de um certo número de moléculas disponibilizadas (organizadas) de certa maneira, e nada mais.

Reducionismo Teórico: Redução de uma teoria a outra. Podendo conter a redução de uma área a outra, num caso limite. Por exemplo, as leis biológicas que regem um inseto seriam deriváveis de leis físico-químicas de suas partes.

Reducionismo Metodológico: Buscar reduzir um domínio macroscópico a seus elementos microscópicos é um bom métodopara a pesquisa científica. Decompor um sistema complexo seria uma maneira "rica" de analisá-lo. Não há necessariamente um comprometimento com o reducionismo ôntico. 
Por estas definições, pode-se dizer que um químico que utilizasse um espectrógrafo de massa para analisar sua amostra estaria agindo como um reducionista metodológico, já que procurou decompor sua amostra através do espectrômetro.

O debate a respeito do reducionismo de forma geral, ocorreu de maneira marcante nas ciências no final do século XIX, embora os primeiros passos para estabelecer diferenças internas entre os vários tipos de reducionismo já tivessem começado com John Stuart Mill em 1843.

Naquela época, físicos como Clausius, Maxwell e Boltzmann propuseram que todas as leis e propriedades termodinâmicas macroscópicas de um gás poderiam ser explicadas por meio de uma redução teórica às leis e propriedades das moléculas componentes, ou seja, através da Mecânica Newtoniana.

Nesta tese pretende-se explorar a redução interteórica envolvida na Mecânica Estatística elaborada por Boltzmann,

O debate se tornou agudo com relação à possibilidade de se reduzir teoricamente a $2^{\mathrm{a}}$ Lei da Termodinâmica, expressa por Clausius como a tendência de um sistema isolado entrar no estado de equilíbrio termodinâmico que maximiza a entropia.

A maneira mais usual de exemplificar a atuação da entropia, é lançarmos mão do didático exemplo de um gás confinado por um anteparo na metade de uma caixa. Caso retiremos este fator limitador, o gás irá se expandir de maneira uniforme pela caixa toda, assumindo um estado de equilíbrio, que num sistema isolado é o de máxima entropia.

Certamente o relato do experimento mental proposto acima, e sua conclusão, não é uma novidade seja para um estudante de física. $O$ problema está na tentativa de justificar mecanicamente o porquê de o gás ocupando toda a caixa não ficar concentrado somente numa de suas metades, e depois de estar ocupando a caixa integralmente, o porque de não voltar à primeira metade novamente.

A Termodinâmica, considerada uma das áreas mais sólidas da física até o século XIX, é uma teoria fenomenológica. A lei zero e primeira lei 
serviram de apoio para elaboração de uma teoria construtiva apoiada inteiramente no sucesso da Mecânica Newtoniana. Em contraste com as teorias fenomenológicas, as teorias construtivas envolvem proposições referentes a entidades e processos inacessíveis à observação direta, que são postulados com o objetivo de explicar os fenômenos por sua "construção" a partir dessa suposta estrutura fundamental subjacente. Podemos citar alguns exemplos característicos desse tipo de teoria como a Mecânica Quântica, a Mecânica Estatística, o Eletromagnetismo, a Genética Molecular e grande parte das teorias químicas (CHIBENI, 1999).

Considerar temperatura como a energia cinética média das moléculas e pressão como transferência do momento das partículas por unidade de volume à parede dos recipientes, fizeram parte daquele que foi conhecido como o projeto mecanicista da Teoria Cinética dos Gases do final do século XIX. A redução desses conceitos e das primeiras leis da Termodinâmica à Mecânica Estatística não é considerada problemática.

Além disso, a confirmação experimental da existência dos átomos no início do século XX, a partir dos experimentos de Jean Perrin, foi um sucesso para a abordagem reducionista. Porém, o que é controvertido até os dias de hoje é a questão da redução da $2^{\text {a }}$ Lei da Termodinâmica (SKLAR, 1993), que será um dos principais focos de análise desta tese.

Na visão reducionista de Weinberg, áreas mais macroscópicas como a Química se reduzem (teoricamente) as teorias microscópicas como a Física Quântica, já que os princípios que regem as reações químicas envolvem elétrons e núcleos atômicos, que são descritos adequadamente pela física quântica. Isso foi expresso na bem conhecida citação feita pelo físico Paul Dirac (1929, p.714):

As leis físicas subjacentes necessárias para a teoria matemática de uma grande parte da física e de toda a química estão, portanto conhecidas completamente, e a dificuldade é apenas que a aplicação exata dessas leis leva a equações complicadas demais para serem solúveis.

O astrofísico inglês, Stephen Hawking, em seu livro best-seller, 
traduzido para o português com o nome de Uma Breve História do Tempo, também tem uma visão consistente com reducionismo, e escreve:

[...] se a carga elétrica do elétron tivesse sido apenas ligeiramente diferente, teria estragado o equilíbrio da força eletromagnética e gravitacional nas estrelas, e elas teriam sido incapazes de queimar o hidrogênio e o hélio, ou então não teriam explodido (HAWKING, 1998, p. 126).

Explicitou assim a estreita relação entre o micro e o macro. Ou seja, se a carga de todos os elétrons, por exemplo, sofresse uma alteração mínima, isso conduziria a um universo totalmente diferente do que conhecemos hoje. Mais recentemente HAWKING (2002) tem expressado dúvidas contra a viabilidade de uma "teoria de tudo", por conta do teorema de Gödel, o que pode ser considerado uma visão antirreducionista.

Pode-se argumentar que há uma concepção de emergência envolvida na análise dos reducionistas, mas ela pode ser chamada de "fraca". Neste caso ela apenas reconhece que há propriedades coletivas, como por exemplo elasticidade ou a propriedade de estar molhado, que não se manifestam no nível da molécula individual. Isto é distinto da concepção de Anderson e de outro emergentista "forte".

Refinando sua concepção anterior, WEINBERG (2001, p. 111-2) defende uma redução a princípios (grand reductionism), deixando de lado uma redução a entidades (petty reductionism), que não é tão rigorosa no contexto da Teoria Quântica de Campos. Para Weinberg, não há uma "satisfação" científica advinda de explicações envolvendo fenômenos que não envolvam uma redução. A partir das reflexões acima temos algumas questões de difícil resolução:

- $\quad$ É possível obtermos uma equação geral do universo partindo do modelo padrão?

- A dificuldade seria apenas a nossa limitação técnica para um modelo que simule o universo integralmente?

- Fará sentido, ou será razoável considerarmos a explicação do funcionamento de uma célula através de suas ligações químicas? 
- $\quad$ Existirá alguma regra universal que nos proíba de tal feito?

O fato é que não podemos negar a estreita relação que há entre a explicação científica e a redução, relação que envolve também atributos lógicos e dedutivos. Parece-me que não há uma fundamentação científica sem que elementos redutivos sejam "evocados", independente da área que estamos tratando.

Somos tentados então a observar mais proximamente os elementos que contêm uma explicação, e para tal se faz necessário relacionarmos uma "causa" para o fenômeno. Neste caso, para que haja uma explicação de um fato é necessário que se conheça essa causa.

Popper defende que:

oferecer uma explicação causal de certo acontecimento significa deduzir um enunciado que o descreva, utilizando, como premissa da dedução, uma ou mais leis universais. (POPPER, 1962, p. 62)

No entanto não podemos desconsiderar a opinião de Bertrand Russell que em um texto de 1913, faz uma séria ressalva à palavra "causa":

a palavra causa está tão inexplicavelmente presa a associações enganosas que sua completa exclusão do vocabulário filosófico se faz desejável (RUSSELL, 2002, p. 76).

Weinberg aceita que haja fenômenos emergentes de maneira fraca na química e na física da matéria condensada, mas "as regras que eles obedecem não são verdades independentes, elas surgem de princípios científicos em um nível mais profundo". Para Weinberg, quando os físicos afirmam que encontraram uma explicação, é porque esta pode ser deduzida de princípios mais fundamentais. (WEINBERG, 2001, p. 115), ou seja, há uma causa para tal.

Em 1948 Carl Hempel escreveu um famoso artigo, junto com Paul Oppenheim, intitulado "Studies in the logic of explanation". Deste artigo é 
derivado o conhecido método dedutivo-nomológico, onde defende que a explicação de um evento é somente possível quando podemos deduzi-lo a partir das condições iniciais e de alguma lei:

A explicação de um fenômeno regular mais geral, consiste em subordiná-la a outra regularidade mais abrangente, ou seja, a uma lei mais geral (HEMPEL, 1948, p. 48).

Esta frase claramente vai ao encontro da posição de Weinberg quanto a explicação. Para Hempel explicar um evento é deduzi-lo a partir das condições iniciais e de uma lei, caso contrário, a explicação conterá lacunas.

Veja o exemplo a seguir:

Explanans - Todos os pedaços de cobre que são aquecidos dilatam.(Lei da natureza)

Explanans - Este pedaço de cobre foi aquecido. (Condição inicial)

Explanandum - Logo, este pedaço de cobre dilatou. (Dada a lei ou regularidade, e verificada a condição inicial, o acontecimento ocorre.)

O discurso reducionista é comum em artigos científicos, por exemplo, num artigo publicado pela revista Scientific American Brasil, escrito por Christopher Crockett em outubro de 2013, com o título: "Fluorescência celular mostra o avanço da morte pelo corpo":

Acompanhar a morte de vermes pode não ser particularmente empolgante exceto se quando morressem começassem a brilhar em um tom azul.

É o que uma equipe de biólogos observou no nematódeo Caenorhabditis elegans. Uma "onda de morte" azul se propagou pelos corpos das criaturas durante até seis horas, à medida que a vida se esvai neles, um fenômeno que está fornecendo insights sobre como a morte se espalha por um organismo.

"A morte na realidade se propaga", diz David Gems, um biogerontólogo do University College London (UCL) e coautor desse estudo. "A presença de uma célula morta desencadeia a destruição de outra vizinha". Gems e seus colegas descreveram suas descobertas na edição de 23 de julho de PLoS Biology.

A sequência da morte celular no C. elegans se dá por uma onda de íons de cálcio que viaja através do verme da parte anterior para a posterior. O influxo de cálcio na célula desencadeia processos que destroem estruturas celulares.

Os chamados lisossomos, os centros de processamento de resíduos das células, entram em colapso e "tudo vira um inferno", explica Gems. O extravasamento dos lisossomos faz com que a própria célula se consuma.[...] 
Ao neutralizar proteínas chamadas de inexinas, essenciais para transferir 0 cálcio de uma célula para outra, os pesquisadores foram capazes de interromper a propagação da morte no verme, mas apenas no caso de lesão.

"Bloquear a necrose não expande a longevidade", observa Gems. No caso de envelhecimento "outras coisas acontecem paralelamente e contribuem para a morte".

Isso quer dizer que determinados medicamentos podem impedir ou retardar amorte vinculada a lesões em seres humanos?

Ainda não. "Somos muito mais complicados que isso", diz Cassandra Coburn, também do UCL e principal autora do artigo. "Não creio que se possa fazer essa comparação".

Aqui neste exemplo, explicar é claramente reduzir; o texto exibe também caráter interdisciplinar, uma vez que o biogerontólogo utiliza-se de conceitos químicos para fundamentar a explicação da morte biológica de um organismo menos complexo.

Porém, para a primeira autora do artigo, não podemos ainda expandir essas explicações feitas para os organismos mais elaborados, como o homem. Isso pode ser apenas uma limitação prática, como diria o reducionista, ou pode ser uma limitação mais fundamental, conclusão consistente com o emergentismo, que defende a autonomia de áreas em relação as outras.

\subsection{Analisando a Emergência}

O conceito de emergência é parte importante de abordagens antirreducionistas, como o fisicalismo não-redutivo. Além dessas esse conceito é geralmente associado ao holismo cuja principal ideia é que a soma das partes é diferente do todo. Esses termos são utilizados largamente em áreas da ciência como química e biologia, pois fundamentam princípios que garantem a autonomia das mesmas.

Um exemplo de abordagem holista são os vitalistas na biologia (Driesch, 1914), que apregoavam a existência de uma "força criadora" responsável por diferenciar matéria viva de inanimada e cujos fundamentos estavam além da compreensão humana. Posteriormente, os filósofos da biologia e da mente fundamentaram o conceito de emergência de modo mais 
consiste. Já no tocante à química, Roald Hoffmann (1995, p. 185) salienta que: "reduzir é hierarquizar a ciência, comum a definição correspondente de entendimento e um juízo de valor implícito acerca da qualidade desse entendimento".

Outro conceito utilizado pelo emergentismo é o de "causação descendente", em que o nível superior, como a mente é capaz de exercer causalidade sobre o nível inferior, como o cérebro.

Lombardi \& Labarca (2005) defendem a autonomia da química em relação aos fenômenos quânticos, pois orbitais e estruturas moleculares não poderiam ser preditos adotando somente cálculos envolvendo a escala nanoscópica. Mais tarde, Labarca \& Bejarano (2013) justificam que apesar do cálculo proximal (de aproximações) Born-Oppenheimer para o cálculo de estruturas em Química Quântica atingir excelentes resultados, ele por si só não é capaz de explicar a estrutura química como um todo.

Como já vimos, um dos artigos mais citados quanto à defesada autonomia das ciências veio do físico da matéria condensada, Philip Anderson, intitulado "Mais é diferente" (More is different). Anderson salientou que "a habilidade para reduzir tudo a leis fundamentais simples não implica a habilidade de partir dessas leis e reconstruir o universo" (ANDERSON, 1972, p. 393). Defendeu que ocorre uma "hierarquização" dos níveis de escala do mundo físico, e as leis epropriedades de cada hierarquia são efetivamente autônomas em relação às escalas mais baixas.

A Figura 1.1 a seguir traduz o modelo proposto por Anderson:

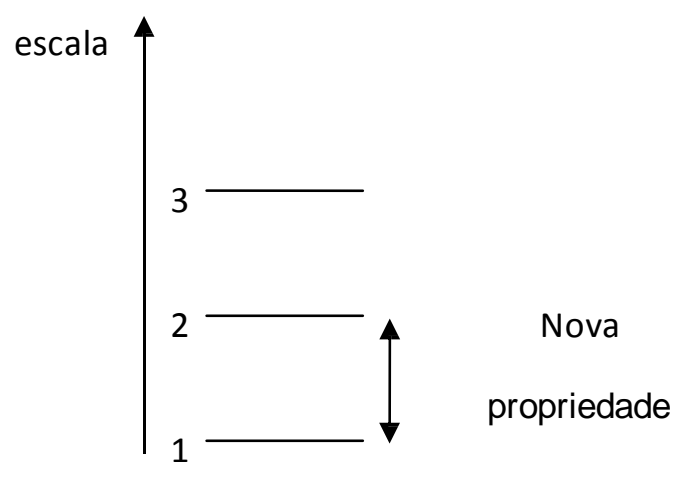

Figura 1.1 - Com o aumento da escala, surgiriam novas propriedades. 
O aumento da escala é seguido por um aumento da complexidade do fenômeno. Assim, quando passam os do degrau 1 para o 2, assumimos que este último possui características não previstas quando a referência era 0 nível 1. Novas e autônomas propriedades surgirão, ou emergirão.

A partir de então, os físicos da matéria condensada refinaram e radicalizaram o discurso emergentista. Anderson ainda admitia que, em algum sentido, a física de escalas superiores se reduz onticamente à física de escalas mais fundamentais. Assim, abriu seu artigo escrevendo que "a hipótese reducionista" é aceita pela maioria dos cientistas, ou seja, "supõe-se que o funcionamento das nossas mentese corpos, e de toda a matéria animada e inanimada da qual temos algum conhecimento detalhado, é controlado pelo mesmo conjunto de leis fundamentais" (ANDERSON, 1972, p.393).

O fisicismo (ou materialismo) de Anderson pode assim ser classificado como um reducionismo ontológico (ou “ôntico"), porém, em um domínio epistemológico (teórico) ou metodológico ele é claramente um emergentista, negando o que chamou de "construcionismo". Lombardi \& Labarca (2005, p.126) chamam estade "suposição tradicional", presente também em Dirac.

Lembrando novamente que construcionismo, aqui, refere-se a um possível experimento mental, onde em última análise poderíamos "desconstruir" uma célula a níveis basais e posteriormente montá-la novamente, construindo-a.

$\mathrm{O}$ argumento de Anderson fundamenta que uma molécula de amônia isolada $\left(\mathrm{NH}_{3}\right)$ não tem dipolo elétrico, pois se encontra em uma superposição de dois estados com polaridade elétrica. Ao ser preparada em um estado de polarização definida, ela oscilará entre os dois estados, por meio de uma inversão, que Anderson descreve como um "tunelamento" do átomo de nitrogênio pelo plano dos átomos de hidrogênio. Ocorre que, à medida que moléculas maiores são consideradas, a inversão descrita ocorre com frequências de oscilação cada vez menores, até chegar em uma molécula grande como a sacarose, cuja simetria é completamente quebrada, consequentemente não oscilando mais.

Este comportamento ocorre por conta do ambiente à sua volta, e a escolha de polaridade adotada é um processo aleatório. Em suma, são 
processo de quebra de simetria como esses que impediram a manobra de reconstruir uma macromolécula a partir de seus átomos.

Mas será que o comportamento coletivo de muitos átomos, por exemplo, em uma molécula de sacarose (com 45 átomos), pode ser derivado das propriedades individuais dos átomos de carbono, oxigênio e hidrogênio? Sua resposta é não: essa tentativa de construção fracassa por causa da ocorrência de "quebras espontâneas de simetria", que faz com que a molécula se oriente de maneira dextrógira ou levógira (como a mão direita ou como a mão esquerda), sem que se possa prever qual orientação será escolhida pela natureza. Ou seja, na tentativa de construir o complexo a partir do simples, surgem novas propriedades emergentes.

Mas o que vem a ser simetria? Há diversas simetrias na natureza, e muitas podem se quebrar espontaneamente. A simetria de paridade $(P)$ argumenta que uma lei física permanece inalterada caso haja a troca de sinais das coordenadas, no entanto, aplicada à molécula de sacarose, a paridade pode ser quebrada espontaneamente, mesmo que moléculas menores, como a de amônia, mantenham a simetria, em um estado de sobreposição quântica (ANDERSON, 1972, p.394).

É interessante notar que uma questão semelhante, relacionada a como as propriedades "escalam", ou seja, como as propriedades se transformam ao passar de um nível ou escala para outro, já tinha sido apontada por Galileu, em seu Discurso sobre duas novas ciências [1638].

Neste trabalho Galileu argumentou que, caso um cavalo pudesse ser aumentado para um tamanho maior, seus ossos não teriam condições de sustentar seu próprio peso, a não ser que a resistência dos ossos também aumentasse. De fato, se o tamanho do cavalo aumentasse $2 x$, a área transversal de um osso aumentaria $4 x$, e seu volume $8 x$, e isso impossibilitaria tal indivíduo de se sustentar. Quando semelhante aumento ocorre na natureza, o aumento das partes não é proporcional, como Galileu exemplificou na Fig.1.2. 


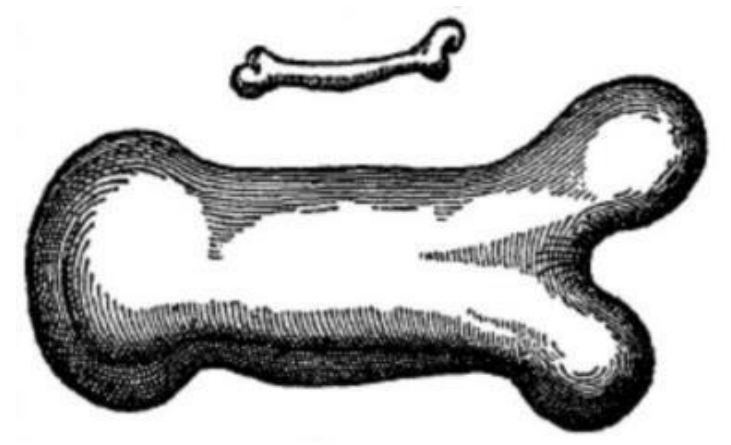

Figura 1.2: Desenho apresentado por GALILEU (1985, p. 105) para ilustrar que se um osso fosse simplesmente aumentado três vezes, ele se tornaria mais frágil, sendo preciso que ele ficasse proporcionalmente mais grosso para exercer as mesmas funções que o osso menor.

Mas assim como fizemos com a redução, é importante agora mostramos o espectro de definições que há no que refere-se a emergência. $\mathrm{Na}$ passagem do século XIX ao século XX, alguns autores como John Stuart Mill e Samuel Alexander já propunham definições relativas a tipificação da emergência (O'CONNOR \& WONG, 2012).

Para o filósofo coreano-americano Jaegwon $\operatorname{Kim}$ (1999, p. 95) podemos classificar a emergência de cinco maneiras:

1. Emergência de entidades de alto nível de complexidade: Sistemas altamente complexos emergem de sistemas menoscomplexos, resultando em uma nova configuração estrutural. (EMERGÊNCIA FRACA)

2. Emergência de propriedades alto nível: Todas as propriedades de um entidade de alto nível surgem das propriedades e relações que caracterizam suas partes constituintes. (EMERGÊNCIA FRACA)

3. Propriedades imprevisíveis da Emergência: Apesar de exaustivas informações basais, não é possível prever as propriedades emergentes. (EMERGÊNCIA FORTE) 
4. Irredutibilidade das Propriedades Emergentes: As propriedades emergentes não podem ser explicadas nem reduzidas em termos das condições basais. (EMERGÊNCIA FORTE)

5. A eficácia causal da emergência: Propriedades emergentes possuem poderes próprios, e são irredutíveis aos poderes dosseus constituintes básicos. (EMERGÊNCIA FORTE)

SCHWEBER (1993, p. 38) chama atenção ao papel desempenhado pela teoria da supercondutividade nessa nova maneira de ver a natureza física, em termos de hierarquias de níveis estáveis e quase-autônomos. A teoria de Bardeen, Cooper \& Schrieffer (BCS), de 1957, mostrou ao mesmo tempo que a mecânica quântica não se limita a escalas nanométricas, mas que sua extensão para o domínio macroscópico, no caso da supercondutividade, não pode ser feito $a b$ initio, a partir da descrição quântica exata dos elétrons e cristais envolvidos, pois o modelo envolve aproximações que constituem uma teoria "efetiva". Não é coincidência que dois grandes teóricos da supercondutividade, Anderson e Anthony Leggett, tenham escrito contra o reducionismo epistemológico.

LEGGETT (1992) argumenta que mesmo uma lei simples como a lei de Ohm, usada para descrever circuitos elétricos, não pode ser rigorosamente derivada de leis microscópicas. As derivações que encontramos nos livros (lei de Drude) envolvem aproximações e suposições auxiliares, que só podem ser introduzidas porque se sabe de antemão qual é a forma da lei de Ohm que se quer derivar.

Um argumento semelhante é apresentado por LAUGHLIN \& PINES(2000), para quem os esquemas para realizar cálculos aproximados não são deduções de primeiros princípios, mas requerem dados experimentais e detalhes locais. Robert Laughlin é ganhador do Prêmio Nobel de 1998, e defende a concepção emergentista em seu livro $A$ different universe (LAUGHLIN, 2005).

Vários campos têm contribuído para a concepção emergentista da física, e para a noção de estratificação da realidade em níveis quaseautônomos. A área do caos determinista deixou clara a importância da não- 
linearidade das leis da física, levando a uma imprevisibilidade derivada da extrema sensibilidade que a evolução do sistema tem em relação às suas condições iniciais.

\subsubsection{Modelo da Flambagem}

Com o intuito de analisarmos uma teoria já sedimentada cujo vetor aponte em direção ao emergentismo, poderíamos expor algumas características da teoria da renormalização. Tal teoria foi usada com extremo sucesso na área de fenômenos críticos da física da matéria condensada, especialmente por Kenneth Wilson (1974), que ganhou o Prêmio Nobel de Física de1982. Uma característica marcante desta teoria é apontar para o caminho da "universalidade", ou seja, para a existência de propriedades de materiais que independem dos detalhes de seus substratos. Esta característica da universalidade pode ser usada como um argumento a favor do emergentismo. Deixaremos o aprofundamento deste tópico para outra oportunidade (ver PFEUTY \& TOULOUSE, 1977)

Este tema é explorado pelo filósofo da ciência Robert Batterman, no livro The devil in the details. Ele fornece um modelo bastante simples e ilustrativo que pode servir para comparar abordagens reducionista e emergentista.

Considere uma barra metálica em forma de paralelepípedo com os três lados de tamanho diferente. A Fig. 1.3 mostra esta barra em pé, virada com o lado mais fino para nós. Se uma carga for adicionada ao topo da barra, exercendo uma força vertical e apontada para baixo, e sua intensidade for lentamente aumentando, de início a barra permanece imóvel, mas a partir de um certo valor crítico da carga, a barra irá "flambar", ou seja, irá se dobrar, ou para a esquerda ou para a direita. 


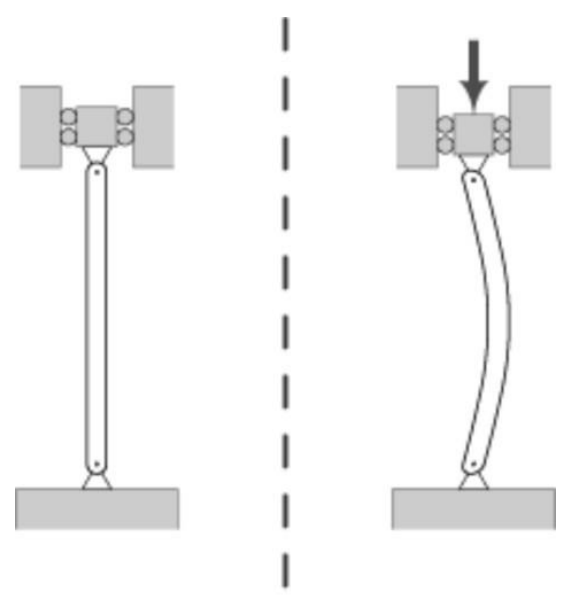

Figura 1.3. Flambagem de uma barra metálica: o aumento constante da carga chega a um ponto crítico em que a barra se dobra, ou para a esquerda ou para a direita (figura de domínio público obtido da Wikipédia).

A questão é explicar para qual lado se dará a flambagem. Os métodos assintóticos da teoria dos fenômenos críticos irão ignorar os detalhes microscópicos do sistema e simplesmente estipular qual é o ponto crítico, e qual é a probabilidade de o sistema seguir diferentes caminhos possíveis. Esta é a abordagem emergentista, e a flambagem para cada sentido (esquerda ou direita) pode ser considerada uma propriedade emergente.

Este fenômeno determina uma classe de universalidade, que é a ampla classe de sistemas que tem comportamento semelhante, independente da constituição material das barras.

A explicação reducionista apresenta um outro relato para esta situação. Ela precisa levar em conta as posições de todos os átomos da barra metálica, todas as imperfeições microscópicas da barra, e também as posições e velocidades de todas as moléculas do gás que circunda a barra. Se a barra for perfeitamente simétrica, pode-se talvez identificar qual foi a molécula individual de oxigênio que forneceu, num determinado instante, o impulso que foi determinante para o início da flambagem. Esta seria então a análise mecânico-causal feito pela abordagem reducionista (BATTERMAN, 2002, p.10).

BATTERMAN (2002, p. 11) argumenta que a explicação emergentista é superior, por ser mais econômica, desprezando detalhes inacessíveis para 
nós, e por fornecer uma explicação de porque outras barras se comportam de maneira semelhante.

O reducionista concede que sua explicação é mais complicada, mas discorda que a abordagem mecânico-causal não possa explicar a existência da classe de universalidade. Para o reducionista, o que as diferentes barras têm em comum (para fazer em parte da mesma classe de universalidade) é sua estrutura microscópica global, sua organização, envolvendo o arranjo dos átomos e os campos (campos de força, interações) gerados por cada um dos átomos. No caso das transições de fase, o que coloca um gás e um ferromagneto na mesma classe é a estrutura geral das interações entre suas partes microscópicas.

Se aceitarmos esta análise, vemos que a grande vantagem da abordagem emergentista é ser pragmática: ela ignora o que é irrelevante e inobservável (os detalhes microscópicos, que se tornam especialmente irrelevantes nos pontos críticos), e descreve um fenômeno imprevisível a partir de uma teoria indeterminista.

O relato reducionista não é refutado por esses exemplos, mas se torna claro que a explicação envolvida não pode ser verificada. Sua utilidade na ciência não está em ser usada para descrever fenômenos críticos macroscópicos, mas em entender os fundamentos microscópicos que unificam esta teoria a todos os outros fenômenos físicos conhecidos. Tratase de uma interpretação realista, que poder ser concatenada em uma versão consistente com a mecânica clássica, ou em uma versão consistente com uma versão realista da mecânica quântica.

Batterman considera que as duas primeiras emergências propostas por Kim (emergência de entidades e propriedades de alto nível), referem-se a diferentes níveis de organização, cabendo ai uma pergunta: pode ocorrer fenômenos emergentes relativos ao mesmo nível de organização?

Podemos ver que emergência e redução estabeleceram-se em trincheiras claramente opostas, e ambos os lados possuem uma quantidade de munições.

Talvez num futuro, o homem consiga delimitar até onde termina a redução e começa a emergência, ou pelo contrário, possa surgir um 
"caminho do meio", quem sabe uma terceira via.

No próximo capítulo estudaremos o mais citado e conhecido exemplo de uma redução na ciência (NAGEL, 1961), a redução da Termodinâmica de Equilíbrio à Mecânica Estatística de Equilíbrio, onde tentarei esboçar os caminhos que foram percorridos pela teoria cinética molecular. 


\section{CAPÍTULO 2 \\ Teoria cinética da matéria e redução da entropia}

\section{1 - O Conceito de Entropia e Versões da 2ª Lei}

Minha intenção nesta tese não é fazer uma análise histórica detalhada da Termodinâmica, uma vez que já existem muitos trabalhos historiográficos e livros retratando-a (ver, por exemplo, BRUSH, 1986). A seguir abordarei os principais pontos que serviram de sustentáculo para a teoria cinética dos gases, para então estudar aspectos da Mecânica Estatística de interesse para o ensino de ciência.

Não é exagero considerar a $2^{\underline{a}}$ Lei da Termodinâmica, envolvendo 0 conceito de entropia, como uma das mais abrangentes leis universais da Física, além do Princípio de Conservação de Energia. É possível calcular a entropia tanto para algumas poucas moléculas presas dentro de uma pequena caixa, quanto para buracos negros. Mas afinal o que ela é?

Antes de a definirmos, vamos recuperar o panorama científico em que 0 conceito de Entropia foi derivado. Com a revolução industrial e o advento das máquinas térmicas, era necessário um maior entendimento do rendimento das mesmas, era importante que a ciência estabelecesse qual seria o princípio ao qual estava submetido a realização de trabalho dessas máquinas.

Em 1824, Sadi Carnot generalizou o conhecimento empírico relacionado às máquinas a vapor e examinou o rendimento de um ciclo ideal, reversível, posteriormente chamado de "ciclo de Carnot", cuja eficiência é máxima. A distinção entre processos reversíveis e irreversíveis tornou-se muito importante, sendo análoga à diferença entre um sistema mecânico conservativo (reversível) e um sistema mecânico com atrito ou sujeito a forças dissipativas (irreversível).

Carnot trabalhava porém com a noção de um fluido de calor, chamado "calórico". Segundo escreveu, o trabalho realizado em uma máquina térmica 
resulta "não de um consumo de calórico, mas de seu transporte de um corpo quente para um corpo frio". Tinha em mente a analogia com um moinho d'água, cuja potência motriz depende da altura da fonte d'água (análogo à temperatura) e da quantidade de água (análogo ao calórico) (CHALLEY, 2007, p. 416).

O livro publicado por Carnot teve pouca repercussão, mas em 1834 seu compatriota Émile Clayperon publicou uma reformulação matemática do seu trabalho, apresentando o ciclo de Carnot em um gráfico de pressão versus volume, mostrado na Fig. 2.1.

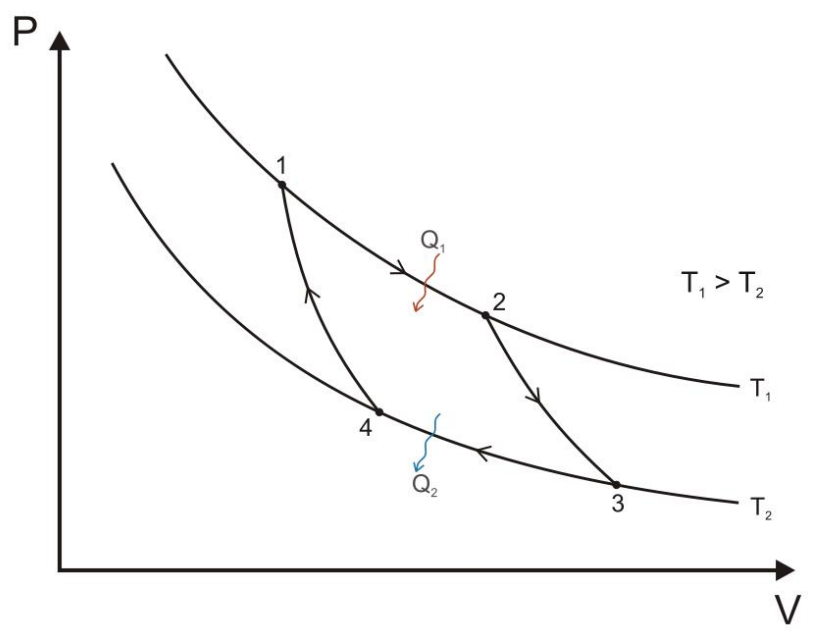

Figura 2.1 - Ciclo de Carnot, em um gráfico de pressão versus volume $(p \times V)$. Em $1 \rightarrow 2$, tem-se uma isoterma, em que o gás expande à temperatura constante $T_{1}$. Para que não ocorra esfriamento nesta expansão, é preciso que o sistema receba energia térmica, indicada pelo acréscimo de calor $+Q_{1}$. Em $2 \rightarrow 3$, o processo é adiabático, sem trocas de energia térmica com o reservatório (sistema isolado); como há expansão, a temperatura cai para $\mathrm{T}_{2}$. Em $3 \rightarrow 4$, tem-se outra isoterma, sendo que trabalho é aplicado ao sistema para diminuir seu volume. Para evitar o aquecimento do sistema (mantendo $\mathrm{T}_{2}$ constante), há uma saída de energia térmica, resultando na troca de calor $Q_{2}$ (onde $Q_{2}$ tem valor negativo). Em $4 \rightarrow 1$, novo processo adiabático de compressão, retornando para o estado inicial, à temperatura $T_{1}$.

Independentemente disso, o médico alemão Julius Mayer (1842) e o físico inglês James Joule (1843) exploraram a ideia de que o trabalho mecânico pode ser convertido em calor, e vice-versa, e encontraram o valor numérico que exprime o equivalente mecânico do calor. Isso levou Hermann Helmholtz a formular o princípio de conservação de "força", o que hoje chamamos "energia", incluindo aí também as formas de energia elétrica. 
O trabalho de Carnot era inconsistente com o princípio de Mayer-Joule, mas a partir de 1850 William Thomson (futuro Lorde Kelvin) e Rudolf Clausius começaram a unificar os dois princípios. A Primeira Lei da Termodinâmica diz que a mudança na energia interna de um sistema $(\Delta C)$ é igual ao calor adicionado ao sistema $(Q)$, menos o trabalho realizado pelo sistema $(W)$. Esta lei de conservação de energia pode ser expressa da seguinte maneira:

$$
\Delta U=Q-W .
$$

Vimos que Carnot não tinha percebido que uma parte do calor gerado era convertida em trabalho mecânico. Foram Thomson e Clausius que adaptaram o princípio de Carnot para a situação em que uma parte do calor é convertido em trabalho mecânico. Para Carnot, o trabalho estaria relacionado apenas à diferença de temperatura entre os reservatórios, ou seja, ele estaria relacionado com uma variável "intensiva" (como temperatura e pressão). Para a nascente Termodinâmica, o trabalho produzido era proporcional à quantidade de calor envolvida no processo, ou seja, o trabalho estava relacionado a uma grandeza "extensiva" (como volume, massa ou energia) (BORGES, 1999, p. 455).

A eficiência $\varepsilon$ de uma máquina térmica é definida como a razão do trabalho realizado $W$ e do calor $Q_{1}$ que entra no sistema. Em um ciclo, a variação da energia interna é nula, então, pela eq. (2.1), $W=Q_{1}-\left|Q_{2}\right|$, e portanto:

$$
\varepsilon=\frac{W}{Q_{1}}=1-\frac{\left|Q_{2}\right|}{Q_{1}}=1+\frac{Q_{2}}{Q_{1}} .
$$

O princípio de Carnot transformou-se então na Segunda Lei da Termodinâmica, o que foi feita em torno de 1850, sem o conceito de calórico, mas com a noção de que o calor é uma forma de movimento molecular. De início, a $2^{\mathrm{a}}$ Lei foi enunciada de maneira qualitativa, por exemplo, pelo enunciado de Thomson (posteriormente chamado de "enunciado de KelvinPlanck"), segundo o qual não há nenhum processo cíclico possível, cujo único resultado seja a conversão integral de calor em trabalho.

Notando que a Primeira Lei da Termodinâmica não dava conta de estabelecer a ordem causal dos fenômenos, ou seja, se a energia flui de um 
corpo quente para um frio ou se o ocorreria o inverso, Clausius conseguiu exprimir o sentido correto do processo, a partir de uma expressão matemática envolvendo o conceito de entropia. Segundo seu enunciado, num processo espontâneo, em um sistema isolado, a entropia nunca pode decrescer (ver BRUSH, 1986, p. 569).

Em 1865, Clausius resume a primeira e segunda leis da Termodinâmica com a seguinte frase: "1. A energia do universo é constante. 2. A entropia do universo tende a um máximo" (ver CLAUSIUS, 1867, p. 365).

A entropia com Clausius assume caráter de Lei Universal, ultrapassando a barreira da Termodinâmica e invadindo os mais variados campos da Física, e mesmo fora (ver, por exemplo, na economia, GEORGESCU-ROEGEN, 1971). A seguir temos duas figuras que apresentam modelos didáticos ilustrando 0 conceito de entropia.
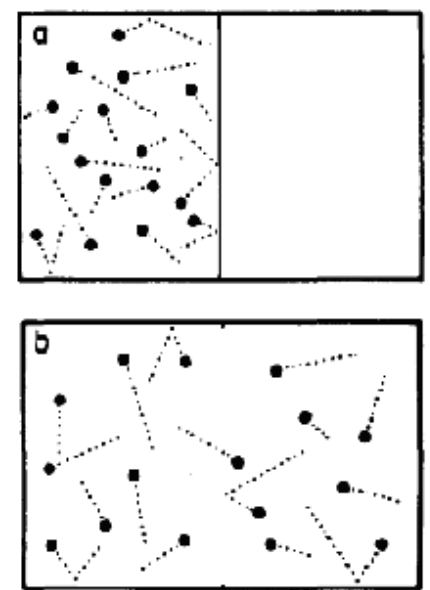

Figura 2.2

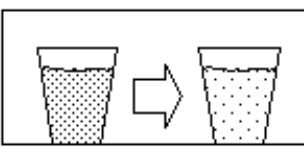

Caixa Isolada

Fluxo de calor do quente para o frio

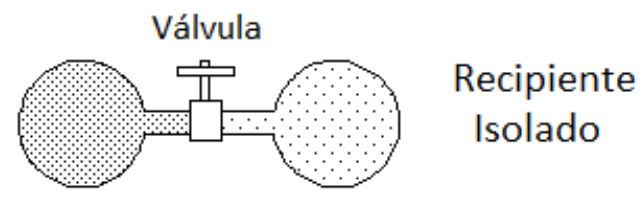

Fluxo gás da alta para a baixa pressão

Figura 2.3

Figuras 2.2 e 2.3 - À esquerda temos um gás confinado na primeira metade de uma caixa e, num momento posterior, o mesmo gás sem a separação. O processo envolve aumento de entropia. Na figura à direita (2.2), mostra-se que o caminho natural seguido pelo calor e por um gás entre recipientes a diferentes pressões, processos envolvendo aumento de entropia.

Pela definição proposta por Clausius, podemos identificar o sentido (direção) em que o calor flui, do corpo quente para o mais frio, sendo 
impossível, de maneira espontânea, o caminho inverso. O conceito de entropia permitiu também distinguir processos reversíveis e irreversíveis.

Para realizar a sua análise, Clausius partiu do ciclo de Carnot (Fig. 2.1). Com a definição de escala absoluta de temperatura, Clausius pôde exprimir as propriedades ideais do ciclo de Carnot (processo reversível) da seguinte maneira:

$$
\frac{Q_{1}}{T_{1}}+\frac{Q_{2}}{T_{2}}=0
$$

Lembremos que $Q_{1}$ exprime a energia térmica que sai do sistema (tendo valor positivo), e $Q_{2}$ a que entra no sistema, a partir do reservatório (tendo valor negativo). A partir disso, Clausius (1854) definiu a grandeza entropia $S$ como uma função de estado, de tal forma que a variação de $S$ em um caminho adiabático é nula, e sua variação em um caminho isotérmico de temperatura $T$ do ciclo de Carnot (como $1 \rightarrow 2$ da Fig. 2.1) é $\Delta S_{1 \rightarrow 2}=S_{2}-S_{1}=Q / T$. Esse resultado vale para quaisquer dois estados do diagrama $p V$, que podem sempre ser ligados por uma isoterma de temperatura $T$ e uma adiabática:

$$
\Delta S=\frac{Q}{T}
$$

Levando em consideração a eq.(2.3), a variação da entropia em um ciclo reversível é nula.

Para fins didáticos, vamos repetir a análise do ciclo de Carnot. No processo $1 \rightarrow 2$ deste ciclo (à temperatura constante $T_{1}$ ), a variação de entropia é $\Delta S_{1}=Q_{1} / T_{1}$, sendo positiva. Nos processos adiabáticos a entropia mantémse constante. No processo $3 \rightarrow 4$ do ciclo (à temperatura $T_{2}$ ), a variação de entropia é negativa: $\Delta S_{2}=-\left|Q_{2}\right| / T_{2}$. Tendo em vista a eq.(2.3), a variação total da entropia no ciclo reversível é nula.

Clausius percebeu que os resultados acima podem ser estendidos para qualquer ciclo reversível, substituindo o ciclo por pequenos ciclos de Carnot, juntados pelas adiabáticas (onde não há trocas de calor). Desta forma, a partir das eqs.(2.3) e (2.4), obtém-se a seguinte expressão para processos reversíveis, onde a integral de linha ao longo do caminho do ciclo é fechada: 


$$
\oint \frac{d Q}{T}=0
$$

O problema agora é obter uma expressão para processos irreversíveis. Nestes casos, será que a integral da eq.(2.5) deve ser maior ou menor que zero? Para analisar este processo, considere-se um ciclo em que um caminho é reversível e o outro não (Fig. 2.4).

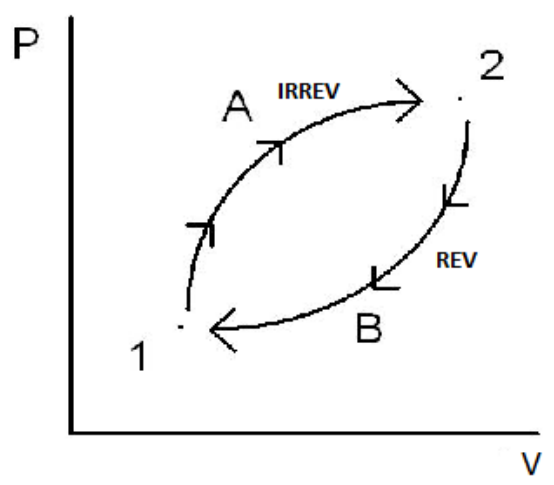

Figura 2.4 - Ciclo composto por um caminho irreversível (A) e reversível (B).

A rigor, um processo irreversível não pode ser representado por um caminho contínuo em um diagrama $p V$, pois ele não passa por uma série de estados de equilíbrio. No entanto, pode-se fazer uma aproximação com pequenos ciclos de Carnot (OLENICK et al., 1985, p. 333).

Considere um desses pequenos ciclos, a ser denotado por $j$. Como por hipótese ele é irreversível, pode-se estipular que sua eficiência $\varepsilon_{j}$ será menor do que a da máquina ideal (reversível) $\varepsilon_{\text {rev. }}$, pelo princípio de Carnot. A definição de eficiência é dada pela eq.(2.2), de tal modo que $\varepsilon_{j}=1+\frac{Q_{2 j}}{Q_{1 j}}$. Da eq.(2.3) temos que para o ciclo mais eficiente (reversível), $Q_{2} / Q_{1}=-T_{2} / T_{1}$, de forma que a eficiência do ciclo reversível é: $\quad \varepsilon_{r e v}=1+\frac{Q_{2 j}}{Q_{1 j}}$. Assim, $\varepsilon_{j}<$ $\varepsilon_{\text {rev. }}$ exprime-se a partir da eq.(2.2) como $1+\frac{Q_{2 j}}{Q_{1 j}}<1-\frac{T_{2 j}}{T_{1 j}}$, de maneira que $\frac{Q_{1 j}}{T_{1 j}}+\frac{Q_{2 j}}{T_{2 j}}<0$. Somando sobre todos os pequenos ciclos, e levando ao limite, Clausius obteve, para processos irreversíveis: 


$$
\oint \frac{d Q}{T}<0
$$

Por que esta integral deu negativa? Isso não iria contra a conclusão de que, em processos irreversíveis, $\Delta S>0$ ? Na verdade, não. O que acontece é que a parte irreversível do ciclo gerou mais calor do que ele faria se fosse reversível, de maneira análoga a um sistema mecânico que gera calor por atrito. Para retornar ao estado inicial do ciclo, é preciso remover este calor adicional do sistema, de maneira que a integral se torna negativa (OLENICK et al., 1985, p. 334).

Para exprimir isso matematicamente, vamos considerar o ciclo da Fig. 2.4. De acordo com a eq.(2.6):

$$
\oint \frac{d Q}{T}=\int_{1}^{2} \frac{d Q_{I R R}}{T}+\int_{2}^{1} \frac{d Q_{R E V}}{T}<0
$$

Podemos escrever:

$$
\int_{1}^{2} \frac{d Q_{I R R}}{T}<-\int_{2}^{1} \frac{d Q_{R E V}}{T} \text {, ou } \quad \int_{1}^{2} \frac{d Q_{I R R}}{T}<\int_{1}^{2} \frac{d Q_{R E V}}{T}
$$

Dado que:

$$
\int_{1}^{2} \frac{d Q_{R E V}}{T}=S_{2}-S_{1}=\Delta S_{21}
$$

então:

$$
\int_{1}^{2} \frac{d Q_{I R R .}}{T}<S_{2}-S_{1}
$$

Ou seja, em um processo irreversível, o estado final tem entropia maior do que o estado inicial. Isso ocorre mesmo para processos adiabáticos, nos quais $Q=0$, que são sistemas isolados. Nestes, $\Delta S>0$, ou seja, mesmo em um sistema isolado a entropia aumenta para processos irreversíveis.

Tomemos um exemplo para ilustrar esta fórmula (OLENICK et al., 1985, p. 336). Um corpo frio à temperatura $T_{1}$ é conectado momentaneamente a outro mais quente, à temperatura $T_{2}$ (Fig. 2.5). Uma certa quantidade de calor $Q$ (que tem valor positivo) passa do corpo quente para o frio, sem que as temperaturas se alteram significantemente. A variação de entropia do corpo 
quente é $-Q / T_{2}$, ao passo que a do corpo frio é $Q / T_{1}$. Somando as duas contribuições, obtemos a variação total de entropia: $\Delta S=Q / T_{1}-Q / T_{2}$. Como $T_{2}>T_{1}$, vemos que $\Delta S$ é positivo, conforme requerido.

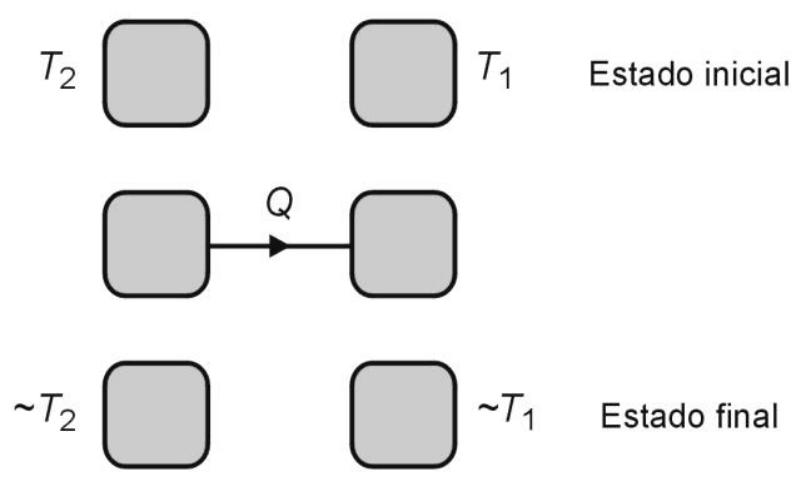

Figura 2.5 - Partindo do estado inicial, com cada um dos dois sistemas em equilíbrio, a temperaturas $T_{2}>T_{1}$, faz-se uma conexão entre os dois sistemas, de forma que passe um calor $Q$. Após desconectar, as temperaturas serão praticamente as mesmas dos valores iniciais, mas a entropia do estado final é maior do que a do estado inicial (figura obtida de PESSOA, 2014a, p. 134).

Notemos que este aumento de entropia foi calculado comparando-se dois estados em equilíbrio, ou seja, estados que não se modificam com o tempo (que são os estados antes da conexão e depois da conexão). Essa definição termodinâmica de entropia não se aplica para situações fora do equilíbrio (por exemplo, quando o calor está passando de um corpo para outro).

Este segundo principio, que fora esboçado por Carnot e cristalizado por Clausius, não fala em "perdas" de energia, pois isso iria contradizer a $1^{\text {a }}$ Lei $d a$ Termodinâmica (conservação de energia), mas pode ser enunciado em termos de "dissipação" ou "degradação" de energia.

Dentre as outras formas de definição de entropia, uma das mais citadas é que ela é a medida de desordem do sistema. Mas tal caracterização só fará sentido após introduzirmos os modelos moleculares de entropia, na seção seguinte. Outra versão é interpretar entropia como a medida de nossa incerteza a respeito de um sistema. 
A partir na noção de fenômenos irreversíveis, William Thomson propôs pela primeira vez a ideia de que o Universo seguiria em direção ao estado de entropia máxima, em que energia seria uniformemente distribuída (considerando que o Universo é um sistema isolado), levando a uma "morte térmica" do Universo. Estas ideias mostravam não só o caráter universal desta lei, assim como sua abrangência filosófica.

Para completar, vale dizer que há um princípio usado implicitamente na Termodinâmica, que veio a ser chamada de "Lei Zero": se dois sistemas estão em equilíbrio térmico com um terceiro, então cada um deles está em equilíbrio térmico com os demais. Além disso, a $3^{3}$ Lei da Termodinâmica, enunciada por Nernst (1912), estipula que a entropia de um cristal perfeito à temperatura de zero graus absoluto é igual a zero.

\section{2 - Modelos Moleculares para a $2^{\underline{a}}$ Lei}

Uma vez estabelecida a $2^{\text {a }}$ Lei da Termodinâmica, Clausius e Maxwell se voltaram para sustentá-la por um modelo cinético-molecular, cuja base fosse formada pela mecânica newtoniana (BRUSH, 1986). A Primeira Lei e algumas de suas variáveis como pressão e temperatura já haviam passado pelo processo de redução à mecânica.

$E$ os exemplos mais didáticos para entender o que é uma redução aparecem quando relacionamos temperatura como energia cinética média das moléculas e pressão como a transferência de momento das partículas por unidade de volume às paredes de um recipiente. Veja as seguintes Figs. $2.6 \mathrm{e}$ 2.7 a seguir: 


\section{Temperatura de um gás}

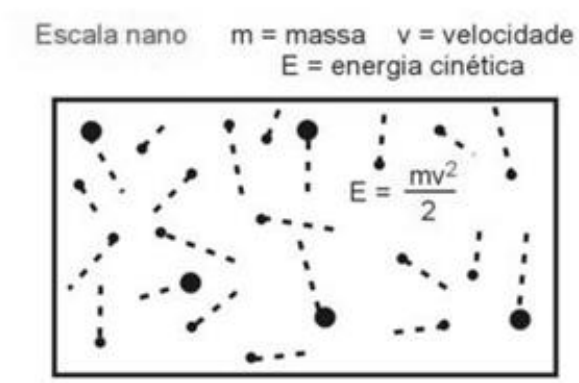

A temperatura è uma medida da energia cinética média de translaçăo de moléculas de um gás.

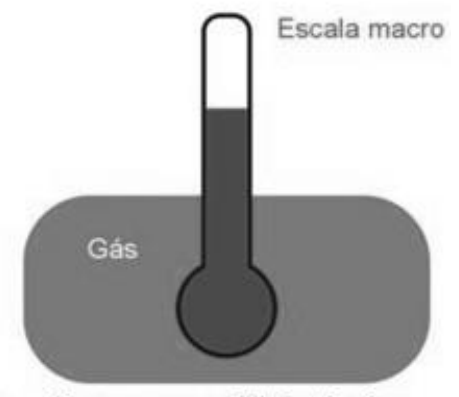

Corpos em equilibrio térmico têm a mesma temperatura.

Figura 2.6 - Modelo microscópio referente à temperatura, e à direita um termômetro.

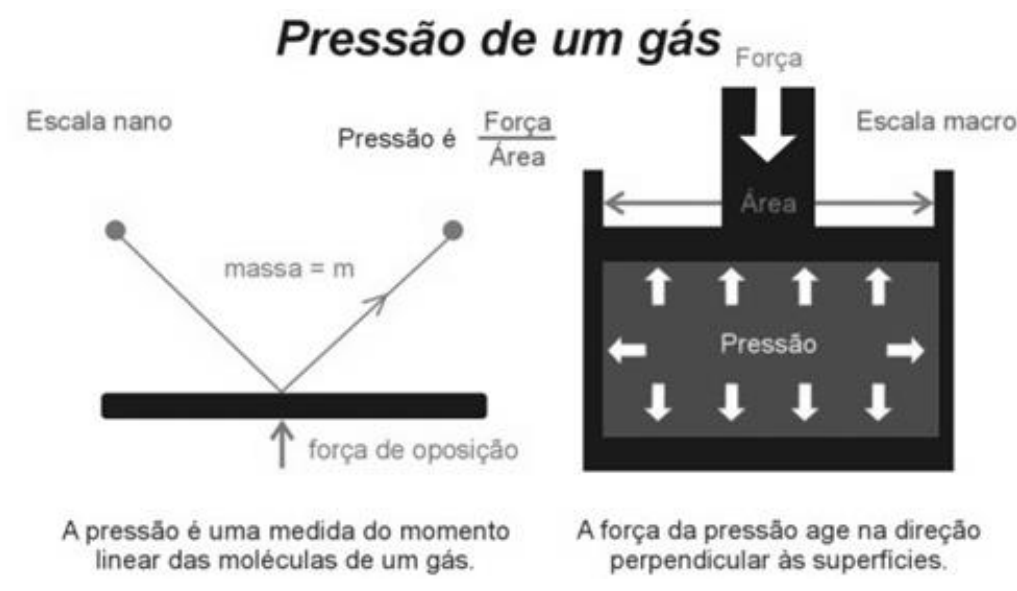

Figuras 2.7.- Modelo microscópico referente a pressão (adaptado de http://www.grc.nasa.gov/WWW/k-12/airplane/temptr.html)

O primeiro relato que se tem notícia a propor uma teoria cinética para a matéria aparece no livro de Daniel Bernoulli, chamado de Hidrodinâmica (1738), onde era proposto um modelo para o gás constituído de partículas microscópicas em alta velocidade. O trabalho foi ignorado na época, pois a teoria do calórico era dominante. Bernoulli obtém a seguinte expressão ligando a pressão $P$ de um gás com a velocidade $v$ de suas moléculas, onde $V$ é $o$ volume do gás, $m$ a massa das moléculas e $N$ o número de moléculas: 


$$
P=\frac{N m v^{2}}{3 V}
$$

No ano de 1820, John Herapath submete um trabalho à Royal Society propondo o movimento de moléculas num gás movendo-se a velocidade constante, obtendo de maneira independente a eq.(2.6). Segundo Brush (1986, p.130), ele foi o pioneiro em identificar calor com movimento interno. O seu artigo foi recusado para publicação, pois os membros da Academia o consideraram muito especulativo.

Em 1843, John Waterson publicou um livro contendo propostas de uma teoria cinética da matéria, onde expunha que a temperatura de equilíbrio dependeria do comportamento das moléculas, entretanto diferentes tamanhos moleculares teriam a mesma energia cinética. Mas novamente a hipótese fora ignorada. Propôs que a temperatura seria proporcional à energia cinética média $m v^{2}$ das moléculas do gás.

Um trabalho publicado por Krönig em 1856, na revista alemã Poggendorfs Annalen der Physik, teve um papel fundamental para a aceitação e justificativa microscópica da Teoria do Calor, mesmo que este não contivesse novas hipóteses, não consideradas anteriormente, pois o que trouxe era aquilo já tratado por Bernoulli, Herapath e Waterson (BRUSH, 1986, p.165). O fato é que o artigo de Krönig influenciou muito fortemente aquele que iria trazer substanciais contribuições para a constituição da Teoria Cinética dos Gases: Rudolf Clausius.

Em 1857, Clausius escreveu um artigo cujo título era "Sobre a natureza do movimento que chamamos de calor", onde propôs um modelo mecânicomolecular para movimento do calor. Uma de suas maiores contribuições foi supor que a energia do gás era advinda não somente do movimento de translação das moléculas, mas também do movimento de rotação e vibração (CLAUSIUS, 1867).

A tentativa de exprimir a termodinâmica em termos de uma mecânica de moléculas gerou uma reação contrária de muitos cientistas, como Mach, Ostwald, Helm e Stallo. Dentre estes havia visões positivistas, que não admitiam falar de entidades inobserváveis, e também os energeticistas, que colocavam o conceito de energia como fundamental, ao invés do conceito de 
matéria. Dentre estes, Helm era mais positivista e Ostwald mais realista.

Em 1858, o meteorologista holandês Christoph Buys-Ballot formulou uma crítica que hoje é às vezes chamada de "paradoxo do perfume". Consiste de inquirir Maxwell e Clausius de por que não sentimos imediatamente o cheiro de um frasco de perfume sendo aberto no canto de uma sala, caso estejamos no outro canto, uma vez que as estimativas das médias de velocidade molecular passavam de $400 \mathrm{~m} / \mathrm{s}$.

A resposta foi dada utilizando-se o conceito de livre caminho médio. Clausius mostrou que haveria um intervalo de tempo não desprezível até que as moléculas contidas no recipiente chegassem à narina do observador, porque esta molécula iria chocar-se com outras presentes no ambiente, levando assim um certo tempo para sair de um determinado ponto da sala até outro canto (ver Fig. 2.8). Sua hipótese continha uma aproximação que apenas uma partícula se moveria, enquanto as demais estariam em repouso.

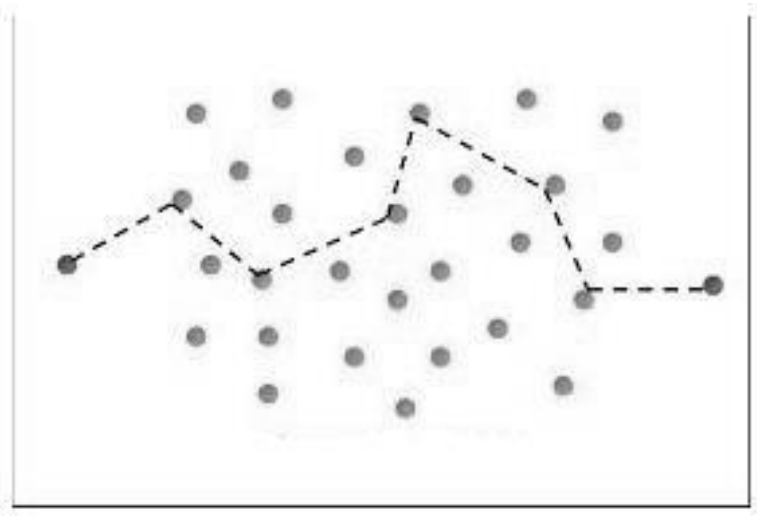

Figura 2.8 - Representação do caminho médio adotado por uma partícula.

Foi derivado de sua visão a respeito dos fenômenos irreversíveis que William Thomson propôs, pela primeira vez, a idéia da morte térmica do universo. Como o calor tende a ir de corpos quentes para corpos frios, o universo tenderia para uma situação futura em que sua temperatura seria uniforme, estando assim "condenado a um estado de repouso absoluto", nas palavras de Helmholtz. Clausius (1867) também defendeu a concepção de um "estado de morte sem mudança", ao passo que Rankine tentou dar argumentos contrários, com base na ideia de que o universo conteria fronteiras refletoras 
(Harman, 1982, pp. 66-71). Posteriormente, Arthur Eddington já influenciado por um conceito mais maduro de entropia, postularia a possibilidade do universo seguir um caminho definido, guiado pela chamada flecha do tempo.

Em 1860, James Clerk Maxwell iniciou suas importantes contribuições para a teoria cinética, estudando a natureza das possíveis colisões moleculares. Sua teoria também voltou atenção pela primeira vez ao caráter probabilístico destas colisões, estabelecendo uma distribuição (quase normal) estatística das velocidades moleculares em um gás, considerando como probabilisticamente independentes as velocidades nos eixos $\mathrm{X}, \mathrm{Y}$ e Z. Postulou que:

1. Haveria uma função $g$ que obedecesse

$$
f(v)=g\left(v_{x}\right) \cdot g\left(v_{y}\right) \cdot g\left(v_{z}\right)
$$

função que fundamenta a independência estatística do evento. Tal ideia advém da proximidade de Maxwell com a teoria das probabilidades (SKLAR, 1993, pp. 30-31). A independência dos eventos, situação em que um evento $A$ não influencia o outro $B$, é expresso na teoria das probabilidades a partir da seguinte equação:

$$
P(A \cap B)=P(A) \cdot P(B) .
$$

Nessa situação de independência, a probabilidade de ocorrer o evento $\mathrm{A}$ e o evento $B$ (expresso pela intersecção de conjuntos $A \cap B$ ) é igual ao produto das probabilidades em separado.

2. Não havendo direção preferencial, o espaço é isotrópico, pouco importando a direção e sentido da velocidade. Assim:

$$
f(\mathrm{v})=f(|\mathrm{v}|) .
$$

Abaixo, na Fig. 2.9 apresentamos o caminho aleatório seguido por uma partícula movimentando-se num plano cartesiano, corroborando o segundo postulado de Maxwell. 


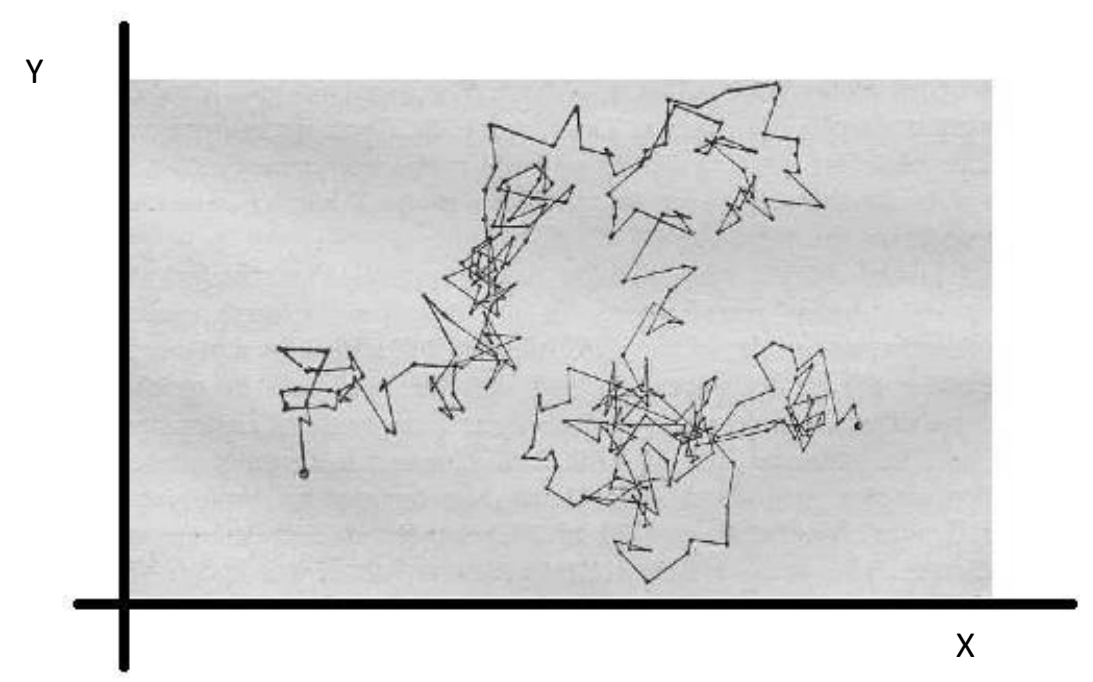

Figura 2.9 - Movimento aleatório molecular em 2 dimensões. Experimento feito por Jean Perrin em 1908, em seu estudo do movimento browniano. Perrin registrava aproximadamente 20 imagens por segundo (PHILIBERT, 2006, p. 14).

Maxwell aprimorou o modelo de Clausius, deixando de lado a suposição de que todas as partículas de um gás possuiriam a mesma velocidade:

Assim, após um certo tempo, a vis viva [energia cinética] estará dividida entre as partículas de acordo com alguma lei regular, o número médio de partículas cujas velocidades estejam entre certos limites sendo determinável, embora a velocidade de cada partícula mude a cada colisão (Maxwell, 1860, p. 360).

Supondo o espaço isotrópico, de forma que a pressão seja igual em todas as paredes do recipiente, temos que (NUSSENZVEIG, 1997, p. 272):

$$
\left\langle v_{x}^{2}\right\rangle=\left\langle v_{y}^{2}\right\rangle=\left\langle v_{z}^{2}\right\rangle=\frac{1}{3}\left\langle v^{2}\right\rangle
$$

Como vimos anteriormente, a conhecida expressão da pressão em função das velocidades das moléculas foi derivada por Daniel Bernoulli (1738) e Herapath (1820) considerando que todas as moléculas teriam a mesma 
velocidade. A expressão moderna considera a velocidade quadrática média $\left\langle v^{2}\right\rangle:$

$$
P=\frac{N m}{3 V}\left\langle v^{2}\right\rangle .
$$

Considerando a lei dos gases ideias, $P V=N k T$, onde $k$ é a constante de Boltzmann e $T$ a temperatura na escala absoluta, obtém-se:

$$
\frac{1}{2} m\left\langle v^{2}\right\rangle=\frac{3}{2} k T .
$$

A equação geral dos gases pode também ser escrita como $P V=n R T$. Neste caso, $n=N / N_{a}$ é o número de moles do gás considerado, ou seja, a razão entre o número $N$ de moléculas e a constante de Avogadro $N_{\mathrm{a}}$. Assim, a constante dos gases ideais $R$ é dado pelo produto da constante $k$ e de $N_{a}: R=$ $N_{\mathrm{a}} \cdot k$.

Tinha-se então todas as hipóteses necessárias para se determinar as distribuições microscópicas do sistema:

1. Isotropia do espaço. Caso escrevamos uma função de distribuição de velocidades, esta será igual em qualquer eixo: $f\left(v_{x}^{2}\right)=f\left(v_{y}^{2}\right)=f\left(v_{z}^{2}\right)$. Logo, suas funções de distribuição também devem ser as mesmas: $f\left(v_{x}^{2}\right) d v_{x}=$ $f\left(v_{y}^{2}\right) \mathrm{d} v_{y}=f\left(v_{z}^{2}\right) \mathrm{d} v_{z}$. Como nenhum sentido de movimento é privilegiado (ou seja, o sinal da velocidade é irrelevante), a função depende apenas dos quadrados das velocidades.

2. Independência das velocidades quanto aos eixos $x, y$ e $z$, de modo que $f\left(v_{x}, v_{y}, v_{z}\right)=f\left(v_{x}\right) f\left(v_{y}\right) f\left(v_{z}\right) d v_{x} d v_{y} d v_{z}$.

3. Equipartição de energia, ou seja, $1 / 2 k T$ para cada grau de liberdade do sistema.

Maxwell percebeu, em sua derivação de 1860, que uma função exponencial satisfazia as hipóteses 1 e 2 :

$$
f\left(v^{2}\right)=e^{-\alpha v^{2}}=e^{-\alpha\left(v_{x}^{2}+v_{y}^{2}+v_{z}^{2}\right)}=e^{-\alpha v_{x}^{2}} \cdot e^{-\alpha v_{y}^{2}} \cdot e^{-\alpha v_{z}^{2}} .
$$

Para considerarmos uma função de distribuição de velocidades num elemento de volume $\mathrm{d} v_{x} \mathrm{~d} v_{y} \mathrm{~d} v_{z}$, é mais conveniente trabalhar com 
coordenadas esféricas, onde o elemento de volume será: $d V=4 \pi v^{2} d v$. A função distribuição pode ser escrita como $f\left(v_{x}, v_{y}, v_{z}\right)=A \cdot 4 \pi v^{2} \cdot f\left(v^{2}\right) \cdot d v$, onde $A$ é uma constante obtida por normalização da dunção. Ou seja, a função distribuição de velocidades de Maxwell é (ver Fig. 2.10):

$$
f(v)=4 \pi N\left(\frac{m}{2 \pi k T}\right)^{\frac{3}{2}} v^{2} e^{\frac{-m v^{2}}{2 k T}} .
$$
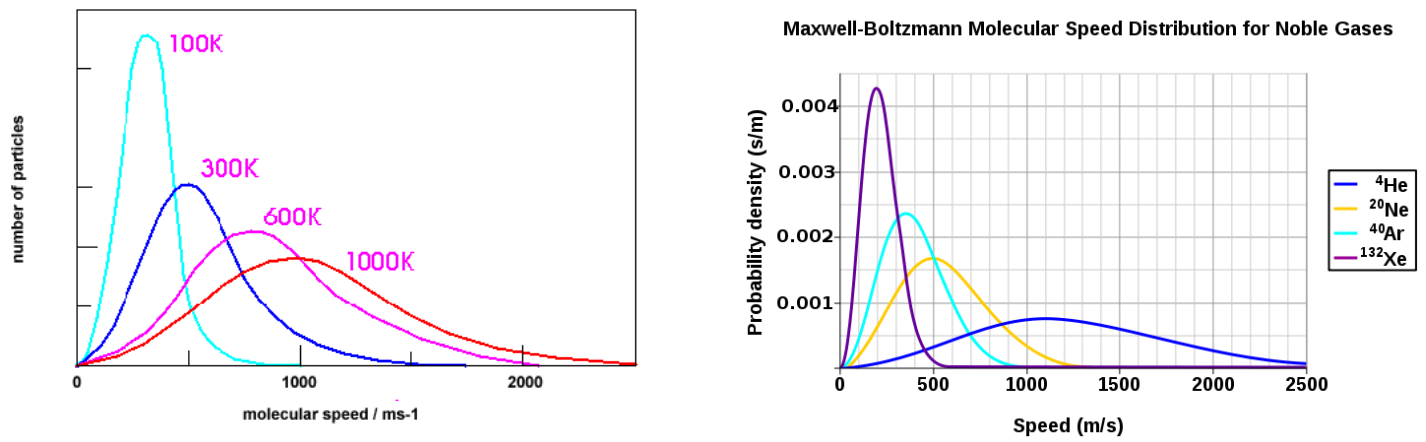

Fig. 2.10 - Distribuição de Maxwell-Boltzmann. (a) À esquerda, para diferentes temperaturas. (b) À direita, para diferentes massas moleculares. Fonte: wikipédia.

Maiores detalhes a respeito do caminho matemático seguido por Maxwell, e posteriormente por Boltzmann, podem ser consultados em NUSSENZVEIG (1997, p. 269-78). O livro Theory of heat de MAXWELL (1871 [2001]) também poderia ser consultado, sendo um livro muito rico e didático, apesar de sua primeira edição conter diversos erros relacionados ao conceito de entropia, o que seria corrigido nas edições posteriores, após conhecer o trabalho de Gibbs (ver PESIC, 2001, p. xviii).

O trabalho de Boltzmann de 1868 generalizou a derivação de Maxwell, trabalhando com moléculas poliatômicas interagentes, e levando em conta 0 efeito de forças externas na distribuição de velocidades. Não adentramos nos detalhes da derivação matemática, que é um tanto complicada, permanecendo como um desafio para o ensino de física básica. Com o trabalho de Maxwell e Boltzmann, a teoria cinética passou a um novo patamar de complexidade, lidando de maneira estatística com o comportamento coletivo de moléculas, abdicando da análise individual de cada uma das partículas.

A constatação experimental direta da Lei da Distribuição de Velocidades 
de Maxwell só foi obtida em meados do século XX. Um dos trabalhos mais conhecidos é o de Miller \& Kusch, publicado pelo periódico Physical Review em 1955 , onde o elemento usado para obter o famoso histograma de velocidades foi o gás de tálio.

A primeira aplicação da lei de distribuição de Maxwell foi com relação à viscosidade dos gases. A teoria cinética previa que a viscosidade seria independente da densidade, e os dados experimentais da época pareciam sugerir o contrário. Maxwell e O.E. Meyer realizaram experimentos que confirmaram essa independência. A teoria de Maxwell também foi usada para explicar os fenômenos da condução térmica (que, de maneira contraintuitiva, não depende da densidade) e a difusão (BRUSH, 1986, p. 191-2). Nota-se que tais fenômenos de transporte são casos de termodinâmica fora do equilíbrio. Em 1867, diante da crítica especialmente de Clausius, Maxwell teve que aperfeiçoar sua teoria, reconhecendo certa "precariedade" em suas hipóteses anteriores para obter a função de distribuição de velocidades. Agora seus argumentos envolviam a consideração de que há uma força central repulsiva entre as partículas, proporcional à quinta potência em relação a suas distâncias. E um dos mais importantes argumentos desta nova proposta é a troca da suposição de independência dos eixos ortogonais $(x, y, z)$ pela suposição de que há uma independência de movimentos entre cada colisão que as moléculas sofrem.

Maxwell preocupava-se com a distribuição de velocidades em equilíbrio, para tempos muito longos. Faltava saber como uma função distribuição mudava em direção ao equilíbrio, tarefa que seria levada a cabo por Boltzmann, conforme veremos na seção 2.3.

$\mathrm{Na}$ página seguinte, apresentaremos uma tabela com a síntese da evolução da Teoria Cinética e seus respectivos autores, que consideramos como aqueles que historicamente contribuíram para o desenvolvimento da Teoria, seguindo BRUSH (1986). A tabela apenas reflete o que está inserido no texto tratado até este momento. 


\begin{tabular}{|c|c|l|}
\hline CIENTISTA & ANO & \multicolumn{1}{c|}{ CONTRIBUIÇÃO } \\
\hline D. Bernoulli & 1750 & Primeiro a propor um modelo microscópico para gases. \\
\hline Herapath & 1820 & $\begin{array}{l}\text { A ele é atribuído a primeira relação entre movimento de } \\
\text { gases e temperatura. }\end{array}$ \\
\hline Waterson & 1843 & $\begin{array}{l}\text { Propõe diferentes tamanhos moleculares. A ele é atribuído } \\
\text { pela primeira vez a relação entre pressão e colisões } \\
\text { moleculares. }\end{array}$ \\
\hline Kronig & 1856 & $\begin{array}{l}\text { Propõe que as moléculas não oscilam em torno de uma } \\
\text { posição de equilíbrio e movem-se com velocidade constante. } \\
\text { "Popularizou" as idéias da Teoria Cinética, influenciando } \\
\text { Clausius e Maxwell. }\end{array}$ \\
\hline Mausius & $1857-$ & $\begin{array}{l}\text { Moléculas oscilam e possuem velocidade constante. Introduz } \\
\text { o conceito de livre caminho médio. Desenvolve e formaliza o } \\
\text { conceito de Entropia em seu livro Mechanical Theory of Heat. } \\
\text {... }\end{array}$ \\
\hline 1860 & $\begin{array}{l}\text { Influenciado pelas Teorias Probabilísticas, propõe que as } \\
\text { moléculas possuem não só diferentes velocidades, como } \\
\text { também estão distribuídas numa função de caráter } \\
\text { estatístico. } \\
\ldots \\
\text { A ele é atribuída a "comunhão" entre elementos mecânicos e } \\
\text { estatísticos. }\end{array}$ \\
\hline
\end{tabular}

Tabela 2.1. Síntese histórica da evolução da Teoria Cinética e seus respectivos autores

\section{3 - A Equação de Boltzmann e o Teorema H}

Na seção 2.2, fizemos um breve relato da busca por um modelo cinético molecular que pudesse explicar em termos microscópicos os fenômenos macroscópicos descritos pela Termodinâmica. Porém, faltava fundamentar adequadamente a $2^{\mathrm{a}}$ lei, ou seja, dar uma explicação microscópica a um fenômeno que somente fora observado pela fenomenologia termodinâmica: a irreversibilidade.

É neste ponto que se começou a pensar em uma mecânica estatística de não equilíbrio, que contemplasse, como um de seus objetivos, determinar as propriedades termodinâmicas em função das leis dinâmicas que governam o micromundo.

Antes de descrevermos os passos históricos percorridos a seguir, é 
fundamental lembrar que a mecânica newtoniana era um dos pilares da física no então século XIX, e um de seus maiores atributos era descrever a evolução do movimento dos corpos. Na ausência de atrito, suas equações apresentam a propriedade de invariância por inversão temporal. Como exemplo, consideremos a segunda lei de Newton, $F=m \cdot a$. Se exprimirmos a inversão temporal pela troca do sinal do tempo, o que acontece com a $2^{2}$ lei ante tal inversão?

Consideremos a definição de aceleração: $a=d v / d t$, como $v=d r / d t$, temos que $a=d^{2} r / d t^{2}$. Logo, caso troquemos $t$ por $-t$, a aceleração ficará invariante temporalmente, ou seja $(-t)^{2}=t^{2}$, e assim também a $2^{\underline{a}}$ lei de Newton ficará invariante.

Este é um dos exemplos de que, fundamentalmente, as leis de Newton não induzem a uma assimetria temporal. Outro fato é que as leis são simétricas via translação temporal, o que implica a conservação da energia (pelo teorema que seria demonstrado no começo do século XX por Emmy Noether).

Ludwig Boltzmann iniciou em 1866, aos 22 anos, seu desafio de escrever uma equação que conciliasse a simetria microscópica com a assimetria macroscópica. Inicialmente, Boltzmann tinha a ambição de obter um conjunto completo de variáveis que representasse o sistema. Sabe-se que seu ímpeto para completar tal objetivo diminuiria depois de seu contato mais próximo com o trabalho de Maxwell. Boltzmann explicitou suas ideias num artigo de 1866 (BOLTZMANN, 2005, p.186):

O objetivo do presente artigo é estabelecer uma prova puramente analítica e geral da segunda lei da termodinâmica, bem como descobrir o teorema da mecânica que a ela corresponde.

Seu primeiro passo foi desenvolver um modelo que contemplasse a evolução de um gás de um estado de equilíbrio a outro. Para tal foi levado a derivar a primeira equação cinética para os gases.

As considerações iniciais eram que um gás era formado por esferas rígidas que colidiriam com a parede do recipiente de maneira elástica. Tecnicamente, Boltzmann elaborou seu modelo com referência ao conceito de 
espaço de fase em 6 dimensões ( 3 de espaço e 3 de momento), assim a função distribuição de probabilidades fica dependente de $d x, d y, d z$ e $d p_{x}, d p_{y} \mathrm{e}$ $d p_{z}$. Para condensar a notação, trabalharemos com $d^{3} r$ referente às posições e $d^{3} p$ referente aos momentos, conforme a Fig. 2.11:

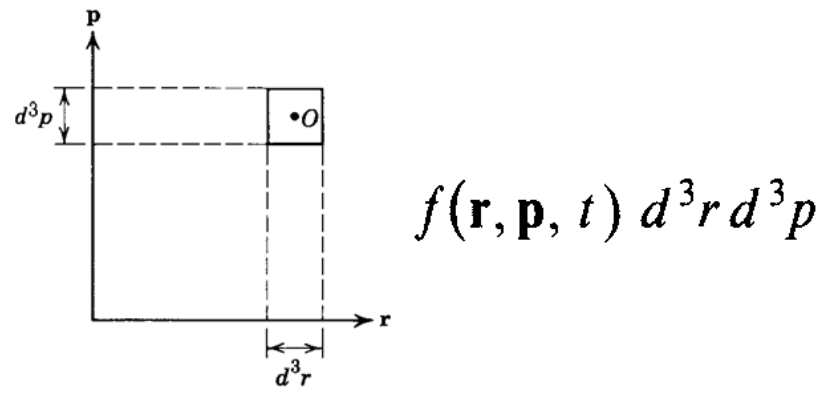

Figura 2.11 - Espaço de fase onde o ponto $O$ está contido no volume $d^{3} r d^{3} p$.

Desta forma, cada ponto neste espaço representaria uma distribuição possível das moléculas de um gás, ou seja, $f(r, p, t)$ representa a função de distribuição de posições e velocidades, onde $d^{3} r d^{3} p$ é o elemento infinitesimal do volume no espaço de fase, de forma que $f(r, p, t) d^{3} r d^{3} p$ representa o número de moléculas no elemento de volume.

Posteriormente, até chegar ao objetivo de determinar uma equação que fosse suficientemente sólida para explicar a entropia, Boltzmann passou seis anos num processo de maturação, aperfeiçoando as propostas de Maxwell. Em 1872, data da publicação de sua equação, Boltzmann contava somente com elementos mecânicos para sua tese, mantendo-se fiel às suas ideias já explicitadas em 1866, quando da publicação de seu primeiro artigo (os elementos probabilísticos seriam justificados mais tarde). Como consequência, conseguiu desenvolver uma equação íntegro-diferencial que simularia a evolução da função distribuição das velocidades das partículas. Desta forma, fundamentos mecânicos foram conectados com a $2^{\underline{a}}$ Lei da Termodinâmica.

A seguir condensaremos os passos matemáticos que levaram Boltzmann à sua famosa equação, ressaltando que nossa intenção com esta tese não é a de nos ater a detalhes de passagens matemáticas, que já foram estudadas exaustivamente (HUANG, 1987, p. 83; TOLMAN, 1979, p. 136; SALINAS, 2005), mas sim o de levantar os principais pontos onde as hipóteses 
físicas são de importância na tentativa de redução da termodinâmica macroscópica à mecânica das moléculas.

Para entender seu modelo (SKLAR, 1999; BRUSH, 1986, p. 443-7; HUANG, 1987), vamos considerar que, dentro de um determinado volume infinitesimal, partículas entrariam, colidiriam e sairiam, conforme representado na Fig. 2.12:

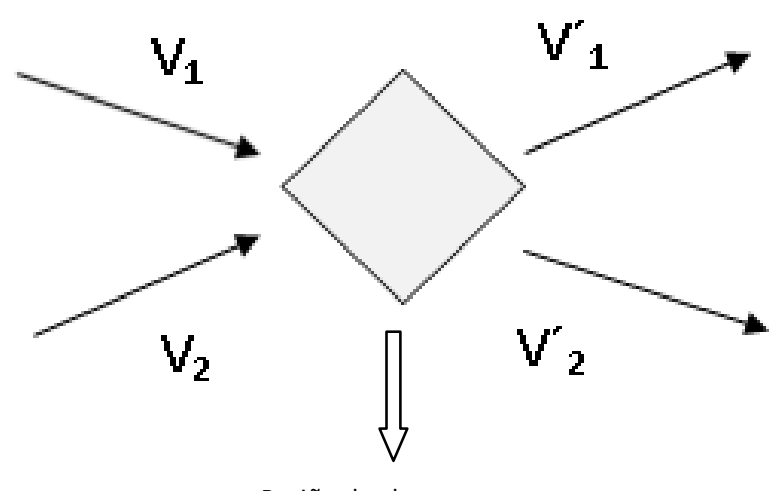

Região do choque

Figura 2.12 - Modelo da região de choque, contido na equação de Boltzmann.

O caminho adotado para chegar à sua equação de transporte passa por um elaborado cálculo de colisões entre esferas duras, considerando as respectivas conservações de momento e energia dentro da região de choque indicada na Fig. 2.12.

Originalmente Boltzmann escreveu sua equação cinética não em função da velocidade, como fazemos aqui, mas em função da energia cinética. $A$ grandeza essencial em sua equação é $f\left(\vec{r}, \vec{v}_{1}, t\right)$, que é a função de distribuição das moléculas de um gás ao longo de diferentes posições, diferentes velocidades, e ao longo do tempo. Um exemplo de uma distribuição de velocidades é a de Maxwell-Boltzmann, Fig. 2.10, que é uma distribuição de equilíbrio. O problema de Boltzmann era determinar como essa função variaria com o tempo, se o estado inicial fosse diferente do estado de equilíbrio.

Caso não haja colisão na região de choque, a equação se torna mais simples, assemelhando-se a uma equação de continuidade:

$$
\left\{\frac{\partial}{\partial t}+v_{1} \cdot \nabla_{r}+\frac{\vec{F}}{m} \cdot \nabla_{v 1}\right\} f\left(\vec{r}, \vec{v}_{1}, t\right)=0, \quad \text { onde: }
$$




$$
v_{1} \cdot \nabla_{r}=v_{x} \frac{\partial}{\partial x}+v_{y} \frac{\partial}{\partial y}+v_{z} \frac{\partial}{\partial z} \quad, \quad \frac{\vec{F}}{m} \cdot \nabla_{v 1}=1 / m\left(F_{x} \cdot \frac{\partial}{\partial x}+F_{y} \cdot \frac{\partial}{\partial y}+F_{z} \cdot \frac{\partial}{\partial z}\right) .
$$

Nas equações acima, $F$ é uma possível força externa agindo sobre as partículas.

Caso consideremos que o sistema apresenta colisões na região do choque, então o lado direito deixa de ser zero, assumindo a forma:

$$
\left(\frac{\partial f}{\partial t}\right)_{C o l}=\int d^{3} p_{2} d \Omega\left|v_{1}-v_{2}\right|\left(\frac{d \sigma}{d \Omega}\right) \cdot\left(F_{1^{\prime} 2^{\prime}}-F_{12}\right) .
$$

Aqui a variável $F$ representa uma função de correlação desconhecida (HUANG, 1987). Neste ponto iremos substituir, na integral, a função $F_{1,2}\left(r, v_{1}, v_{2}, t\right)$ por:

$$
F_{1,2}\left(r, v_{1}, v_{2}, t\right) \approx f\left(r, v_{1}, t\right) . f\left(r, v_{2}, t\right) .
$$

Esta condição, que pode ser interpretada como a exclusão de qualquer tipo de interação entre as partículas antes ou depois do choque, é a já mencionada suposição de independência estatística. A tentativa de achar uma justificativa física para esta suposição invocaria a hipótese conhecida como "caos molecular" (ver seção 2.6).

Podemos interpretar fisicamente o funcionamento da equação como uma forma de estabelecer que a quantidade de partículas que entram e que saem do elemento de volume é igual à variação do número médio de partículas no elemento de volume $d^{3} r d^{3} p$ num intervalo de tempo $d t$.

Agora podemos escrever a equação de Boltzmann na sua forma mais completa:

$\left\{\frac{\partial}{\partial t}+v_{1} \cdot \nabla_{r}+\frac{\vec{F}}{m} \cdot \nabla_{v 1}\right\} f\left(\vec{r}, \vec{v}_{1}, t\right)=\int d^{3} p d \Omega\left|v_{1}-v_{2}\right|\left(\frac{d \sigma}{d \Omega}\right)\left[f\left(\vec{v}_{2}, t\right) \cdot f\left(\vec{v}_{1}, t\right)-f\left(\vec{v}_{2}, t\right) \cdot f\left(\vec{v}_{1}, t\right)\right]$.

O termo $\sigma(\Omega)$ refere-se à seção de choque diferencial, que dependerá da natureza da interação. As velocidades antes e depois da colisão são respectivamente $v_{1}, v_{2}$ e $v_{1}^{\prime}, v_{2}^{\prime}$, conforme já salientamos na Fig. 2.9.

No processo de estruturação da equação, Boltzmann precisou dispor de 
algumas hipóteses, ou melhor, aproximações:

- $\quad$ As colisões serão somente binárias.

- $\quad$ alcance da força de interação entre as partículas é muito menor que o seu livre caminho médio.

- A função distribuição é homogênea no volume do alcance da interação.

- $\quad$ A equação é valida para baixa densidade dos gases.

Finalmente agora, depois de "subir" no ombro de gigantes, que eram seus contemporâneos, Boltzmann conseguiu propor e fundamentar uma equação que dita como um sistema caminha até seu equilíbrio, em função do tempo. Neste caso é necessário supor que, no equilíbrio do sistema, não há taxa de variação de $f(r, v, t)$, ou seja:

$$
\frac{\partial f(\vec{r}, \vec{v}, t)}{\partial t}=0
$$

Neste caso há uma igualdade das distribuições antes e depois do choque:

$$
f\left(r, v_{1}, t\right) \cdot f\left(r, v_{2}, t\right)=f\left(r, v_{i}^{\prime}, t\right) \cdot f\left(r, v_{2}^{\prime}, t\right)
$$

Tomando-se o logaritmo neperiano,

$$
\ln f\left(v_{1}\right)+\ln f\left(v_{2}\right)=\ln f\left(v_{1}^{\prime}\right)+\ln f\left(v_{2}^{\prime}\right)
$$

podemos notar que o resultado parece exprimir uma lei de conservação, como as de energia e momento. Um dos pontos de sucesso desta proposta foi o fato de que a equação íntegro-diferencial chega à distribuição de Maxwell no equilíbrio, através de uma equação de movimento, diferentemente do caminho adotado por Maxwell, que adotou o caminho da isotropia do espaço (SALINAS, 2007):

$$
f(\vec{r}, \vec{v}, \infty)=f(\vec{v})_{M A X W E L L}
$$


Sinteticamente podemos dizer que a equação de Boltzmann determina como um gás caminha para seu estado de equilíbrio, caso haja o rompimento de algum vínculo do sistema, como por exemplo, uma membrana separando diferentes densidades de gases numa caixa.

Para Boltzmann, agora o grande desafio era conectar sua equação cinética com a entropia, e para isso foi necessária a introdução de uma grandeza que originalmente foi chamada de "eta", e posteriormente de "agá" (H) (segundo Boltzmann este erro deveu-se a uma interpretação errônea do tipógrafo; ver CHAPMANN, 1937).

O teorema $\mathrm{H}$, como ficou conhecido, foi a proposta de Boltzmann para tentar reduzir a $2^{\underline{a}}$ lei da Termodinâmica à Mecânica Estatística de partículas. A expressão para H era:

$$
H(f)=\int f(\vec{r}, \vec{v}, t) \ln f(\vec{r}, \vec{v}, t) d^{3} r d^{3} v .
$$

Caso uma função de distribuição $f(r, v, t)$ satisfaça a equação cinética, então, substituída em $H$, fornece:

$$
\mathrm{d} H / \mathrm{dt} \leq 0 .
$$

Esta derivada é igual a zero somente na ocasião em que a função de distribuição seja a de Mawxell. Nota-se que $\mathrm{H}$ deve ser interpretado como a entropia com o sinal invertido, ou seja, $\mathrm{H}=-\mathrm{S} / \mathrm{k}_{\mathrm{b}}$. Assim o teorema pode ser expresso como:

$$
\mathrm{dS} / \mathrm{dt} \geq 0,
$$

sendo que a entropia $S$ cresce monotonicamente. Desta forma, foi atingida a meta de encontrar uma função que possui uma direção temporal privilegiada. Com isso, Boltzmann convenceu-se de ter estabelecido uma conexão direta e consistente entre o comportamento do mundo micro e os fenômenos do ambiente macro.

Com sua equação e teorema, conseguiu descrever qual a direção tomada por um estado inicialmente fora do equilíbrio, em direção ao equilíbrio. A taxa de variação de $\mathrm{H}$ com o tempo será sempre menor ou igual a zero $(d H / d t \leq 0)$. 
Após sua publicação, o Teorema sofreu duas sérias críticas que estiveram separadas por aproximadamente 20 anos. A primeira delas, surgiu em 1876, e ficou conhecida como o Paradoxo da Reversibilidade (Umkehreinwand) apresentada por J. Loschmidt quando da publicação de um artigo, que contestava as bases mecânicas que serviam de alicerce para o teorema H. Sabe-se que em 1876 Loschmidt já era um crítico da então nova $2^{\underline{a}}$ Lei da Termodinâmica:

O aterrorizante nimbus da segunda lei [...] que aparece como um princípio de destruição de toda vida no universo (Loschmidt, apud Müller, 2007, p.72).

Agora, sua crítica era fundamentada no fato de que os princípios mecânicos são reversíveis temporalmente. Assim, um gás que estivesse primeiramente contido numa metade de uma caixa, e depois evoluísse para um estado de equilíbrio após um tempo $\Delta t$, por princípios mecânicos teria a condição de voltar à primeira metade, invertendo os sinais das velocidades de todas as suas partículas, num novo intervalo de tempo $\Delta \mathrm{t}$. Assim, um sistema que estava com baixa entropia iria para uma configuração de máxima entropia (ocupando a caixa integralmente) para depois a reversibilidade levá-lo novamente a baixa entropia (ver Fig. 2.13). Um primeiro ponto levantado por Boltzmann era o fato de mesmo num pequeno volume, que contivesse poucas moléculas, a probabilidade de que todas tivessem seus sinais invertidos seria extremamente improvável.
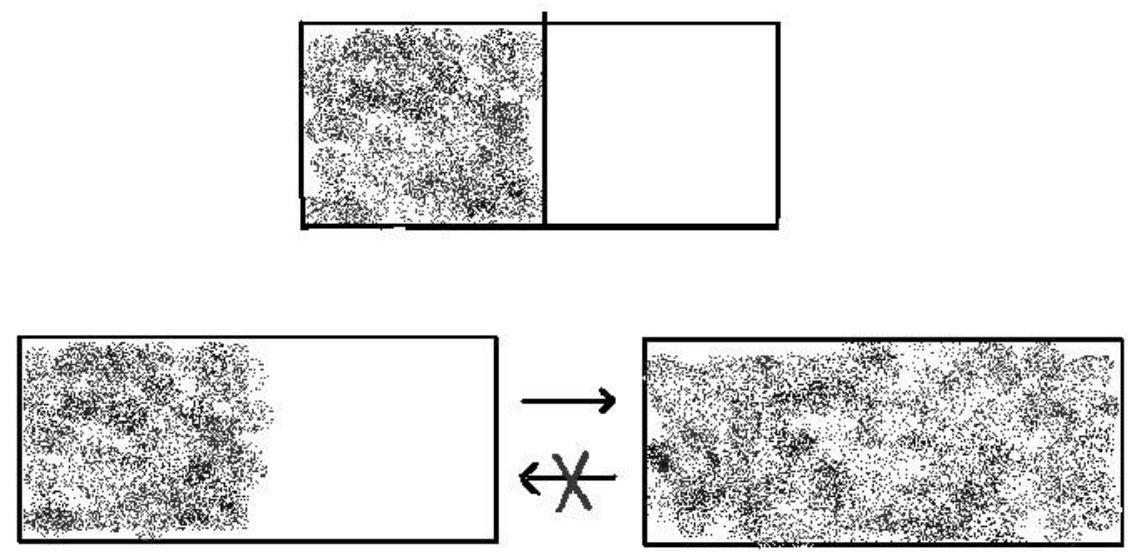

Figura 2.13 - Representação do comportamento de gases, primeiramente confinado no lado esquerdo da caixa. Posteriormente após o rompimento de um êmbolo o gás espalha-se pela integralidade da caixa. O " $X$ " mostra um movimento muito pouco provável do gás. 
A crítica de Loschmidt se mostrou correta, e o erro de Boltzmann foi não ter percebido a importância de sua suposição de independência estatística, ao considerar a função distribuição $f\left(x, v_{1}, v_{2}, t\right)=f\left(x, v_{1}, t\right) \cdot f\left(x, v_{2}, t\right)$. Uma maneira de justificar esta suposição é invocar uma hipótese de Caos Molecular. Isso garantiria que sistemas macroscópicos mantivessem sua irreversibilidade, pois haveria uma causa física que destruiria qualquer correlação entre as partículas antes e depois do choque. Como fazem parte agora de eventos independentes, após cada colisão as partículas seriam acometidas de alguma forma de "amnésia", ignorando de onde vieram, portanto sendo improvável sua reversão ao ponto inicial. Exploraremos a discussão sobre o conceito de Caos Molecular na seção 2.6.

\section{4 - Concepção Probabilista de Entropia}

A partir da crítica de Loschmidt, Boltzmann em 1877 propôs aquela que ficou conhecida como sua mais famosa fórmula, escrita por Planck da seguinte maneira, bem conhecida dos livros didáticos:

$$
S=k_{B} \cdot \ln \Omega .
$$

A entropia $S$ de um macroestado é proporcional ao logaritmo de $\Omega$, o número de estados microscópicos consistentes com 0 macroestado ("configurações", na terminologia de Boltzmann, ou "complexões", para Planck). A constante de proporcionalidade é a constante de Boltzmann $k_{B}$ (ver discussão em AURANI, 2009).

O exemplo mais simples envolve um gás ideal constituído por $N$ moléculas. Um macroestado do sistema é definido a partir dos valores de suas variáveis termodinâmicas, como energia interna, pressão, volume e temperatura. Para um certo macroestado definido pelos valores dessas variáveis, há um grande conjunto de microestados consistentes com eles (de forma a serem coerentes com as mesmas variáveis termodinâmicas), e o número de microestados neste conjunto define o valor da complexão $\Omega$. 
Podemos, de uma maneira mais caricatural, dizer que uma estante de livros, com variáveis macroscópicas volume e peso, seja o nosso macroestado; há obviamente muitas maneiras diferentes de dispor os livros na mesma, sem que a estante mude o seu tamanho ou peso.

O número de microestados associados ao sistema no estado final de equilíbrio é muitíssimo maior do que o número de microestados associados a um estado longe do equilíbrio. Supondo que a probabilidade de cada microestado é a mesma, então o sistema permanecerá no macroestado de equilíbrio por um tempo proporcional (em relação aos estados fora do equilíbrio) ao número de microestados associados. No entanto, há uma probabilidade finita de o sistema flutuar para fora de seu estado de equilíbrio.

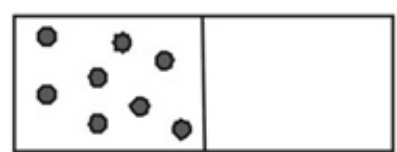

$$
\begin{aligned}
& \Omega=1 \text { arranjo } \\
& \Omega=8 \text { arranjos } \\
& \Omega=28 \text { arranjos } \\
& \Omega=70 \text { arranjos }
\end{aligned}
$$$$
00
$$$$
0
$$
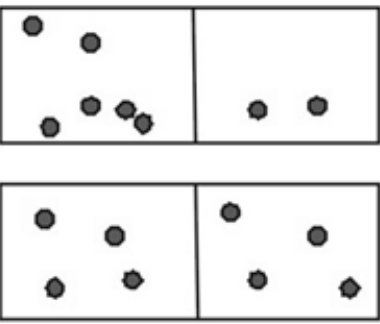

Figura 2.14 - Vários arranjos relativos a 8 bolinhas distribuídos entre dois compartimentos. Supõe-se que as bolinhas sejam distinguíveis.

Uma maneira didática de expor essas ideias inicia-se com a Fig. 2.14. Suponhamos uma caixa dividida pela metade, contendo 8 moléculas monoatômicas de um gás. Se houver $\mathrm{n}$ moléculas no compartimento da esquerda e $(8-n)$ no da direita, o número de estados diferentes associados com esta configuração é dado pela relação: 


$$
\Omega=\frac{8 !}{(8-n) ! n !} .
$$

$\mathrm{Na}$ Fig. 2.14, anota-se o número $\Omega$ para quatro arranjos diferentes. A disposição mais provável, ou seja, para a qual o número de arranjos é maior, é aquela em que as moléculas estão igualmente divididas pela caixa. Sabemos que esse corresponde ao estado de equilíbrio, então a ideia de associar o número de microestados ao estado de equilíbrio se mostra fecunda. À medida que o número de partículas aumenta, a probabilidade de o sistema se encontrar no estado de equilíbrio vai aumentando.

Se dispusermos de uma molécula em uma caixa, e probabilidade de encontrá-la, por exemplo, no lado esquerdo da mesma é de 1/2. Caso haja duas moléculas, a probabilidade de encontrar as duas é de $(1 / 2)^{2}$; se formos considerar $10^{23}$ moléculas, obviamente a probabilidade será baixíssima de encontrar todas num mesmo lado, por exemplo o esquerdo (Fig. 2.15). Quando em sala de aula o professor fala para os alunos que há uma probabilidade de todo $\mathrm{o}$ ar se concentrar em um canto da sala, levando todos a sufocarem, tal probabilidade é bastante ínfima, sendo bem menor do que $10^{-23}$ !

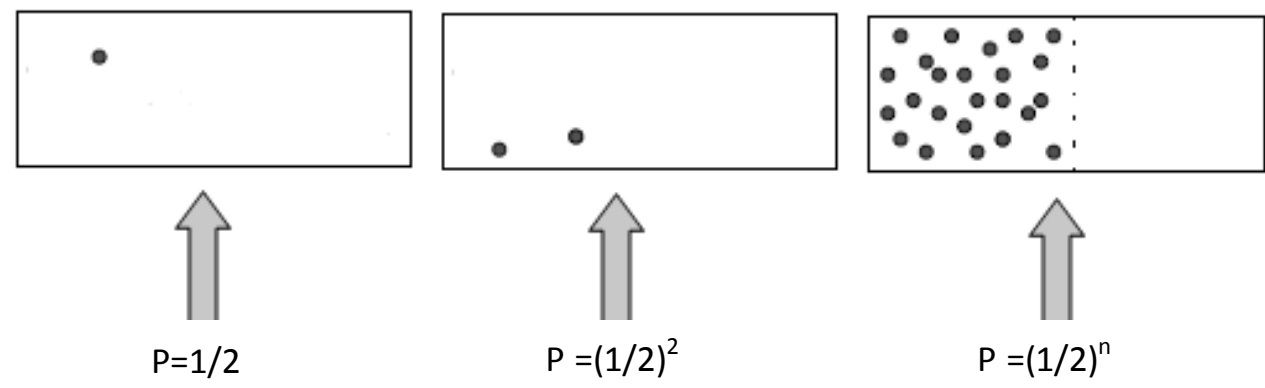

Figura 2.15 - À medida que aumenta o número $n$ de partículas, a probabilidade de todas ocuparem metade de um recipiente cai com $1 / 2^{\text {n }}$.

No entanto, para tornar o modelo mais realista, é preciso definir diferentes distintos macroestados. Uma possibilidade é introduzir um pistão (com peso desprezível) separando os dois compartimentos, e considerar diferentes posições deste pistão (REIF, 1967, pp. 315-20).

$\mathrm{Na}$ Fig. 2.16, isso é ilustrado para uma situação com quatro macroestados diferentes, cada um correspondendo a uma posição 
macroscópica diferente do pistão. No exemplo, há $n_{1}=2$ partículas do lado esquerdo do pistão, e $n_{2}=3$ do lado direito. Além disso, dado uma certa posição do pistão, há um número $N_{1}$ de microestados acessíveis para cada partícula do lado esquerdo, e $N_{2}$ do lado direito. Para calcular o número de microestados consistentes com o dado macroestado, basta usar a seguinte fórmula simples:

$$
\Omega=N_{1}^{n_{1}} \cdot N_{2}^{n_{2}} .
$$

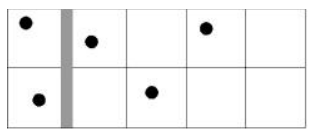

$\Omega_{1}=2^{2} .8^{3}=2048$ microestados

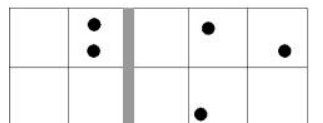

$\Omega_{2}=4^{2} \cdot 6^{3}=3456$

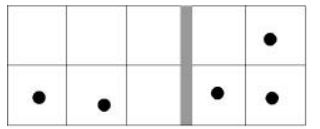

$\Omega_{3}=6^{2} \cdot 4^{3}=2304$
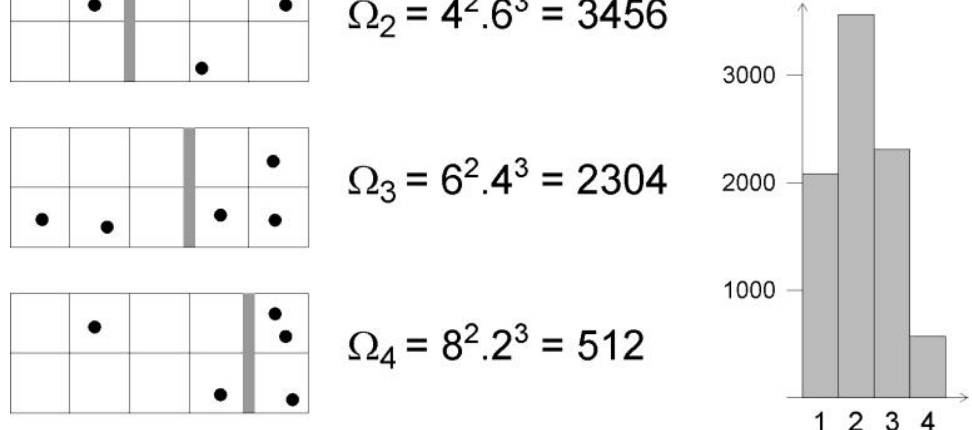

$\Omega_{4}=8^{2} \cdot 2^{3}=512$

Figura 2.16 - Quatro macroestados do gás separado por pistão.

Vemos claramente que o estado mais provável é $\Omega_{2}$, supondo-se que o sistema passa por todos os microestados acessíveis com igual probabilidade. Este é exatamente o estado em que a razão dos volumes de cada lado do recipiente é igual à razão do número de partículas, 2:3. E, de fato, esta conclusão se verifica em amostras reais de gases, onde o efeito de grandes números faz com que o pistão fique imóvel, dentro da resolução de nossas observações.

Para ilustrar o efeito dos grandes números, consideramos na Fig. 2.17 sistemas com 40 e 400 partículas, que indicam como os desvios do estado de 
entropia máxima são cada vez mais raros à medida que cresce o número de partículas.

$N_{1}=16$

$N_{2}=24$

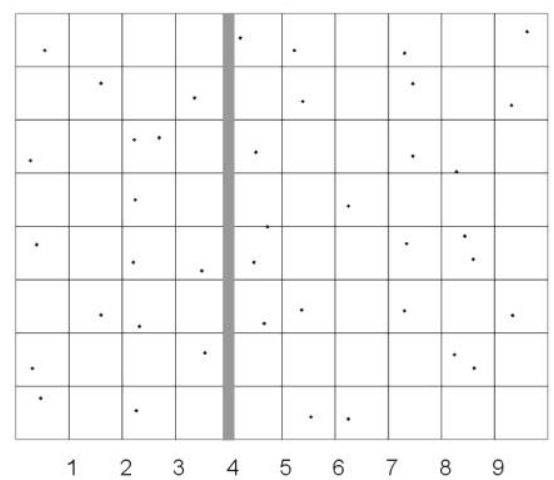

$\Omega_{j} \cdot 10^{62}$

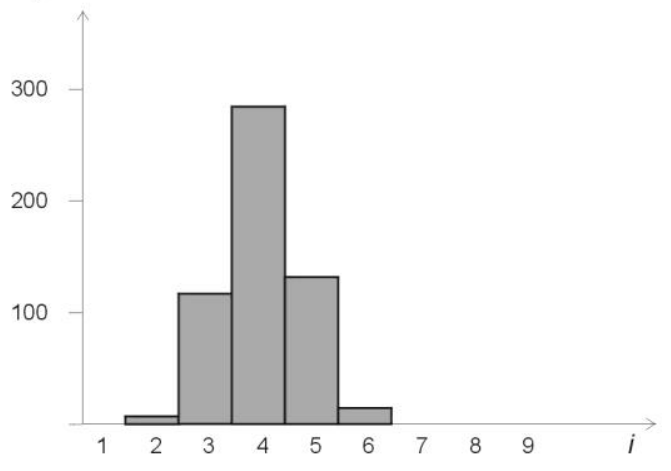

$N_{1}=160$

$\mathrm{N}_{2}=240$

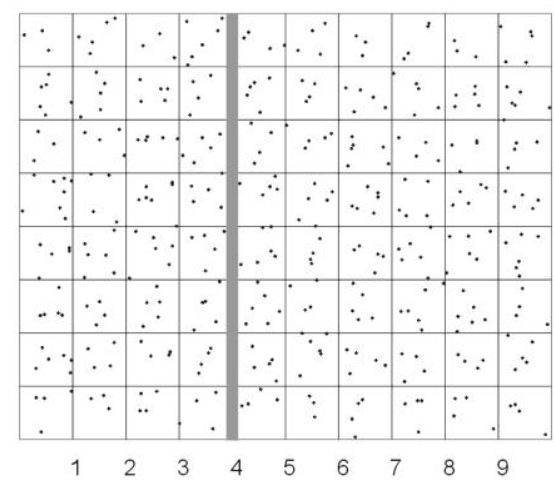

$\Omega_{i} \cdot 10^{642}$

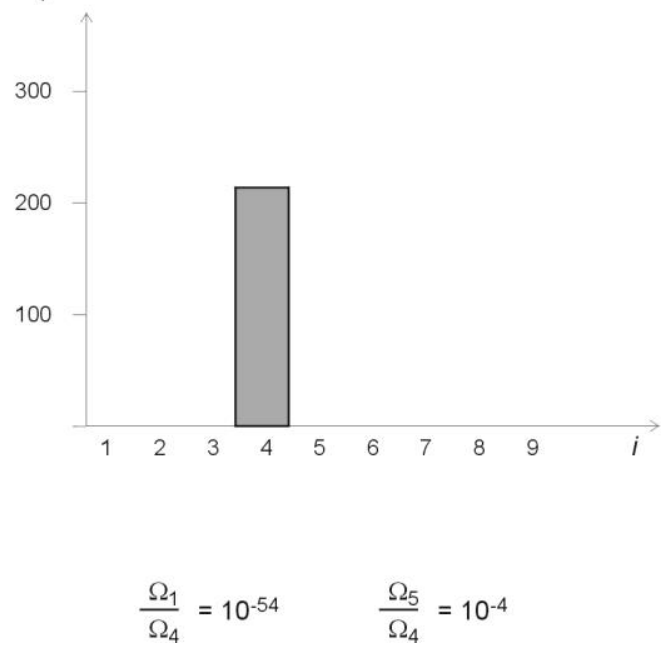

Figura 2.17 - llustração do efeito dos grandes números, comparando sistemas de pistão com 40 e 400 partículas. No primeiro, o macroestado mais provável corresponde a $\Omega_{4} \approx 300 \cdot 10^{62}$ microestados, e a razão $\Omega_{4} / \Omega_{5}=0,4$. Já no segundo caso, para 400 partículas, $\Omega_{4} \approx 200 \cdot 10^{642}$, e $\Omega_{4} / \Omega_{5}=10^{-4}$. Ou seja, à medida que o número de partículas cresce, as flutuações para fora do estado de maior entropia diminuem (PESSOA JR., 2014a, p. 146).

Vemos que para 400 partículas, a razão entre o estado de equilíbrio e 0 macroestado mais próximo caiu para $10^{-4}$. Para um mol de moléculas pode-se estimar grosseiramente que tal probabilidade caia para algo como $1 / 10^{10^{20}}$, ou seja, é uma situação que nunca observaremos em nossas vidas!

A definição probabilista de entropia da eq.(2.27) atribui ao estado mais 
provável o maior valor da entropia. Porém, um estado fora do equilíbrio passa a ter uma certa probabilidade de ocorrência, mesmo ínfima, diminuindo a entropia do sistema. Boltzmann substituiu assim a sua abordagem determinista associado ao teorema $\mathrm{H}$ por esta visão estatística. A $2^{\underline{a}}$ Lei da Termodinâmica deixa de ser uma lei estrita da Física, e passa a ser uma lei estatística.

Eis então algumas maneiras de apresentar didaticamente a concepção probabilista de entropia de Boltzmann. A hipótese de igual probabilidades dos microestados é um princípio fundamental da análise, e ela pode ser alterada fixando-se a "função de partição" do sistema, ou seja, como diferentes probabilidades são repartidas entre os diferentes microestados.

Com relação à definição do número $\Omega$ de "configurações" ou "complexões", podemos recordar a Fig. 2.11 que representa o espaço de fase de um sistema mecânico de muitas partículas, onde um ponto neste espaço representa um microestado do sistema. Boltzmann chamou inicialmente de "Monoden" as maneiras como o sistema macroscópico poderia ser representado por diferentes arranjos microscópicos. Como vimos, para cada macroestado, existe um conjunto de microestados numa determinada região do espaço de fase que é consistente com ele. Mais tarde Josiah Gibbs veio a chamar Monoden de "ensemble" (que significa "conjunto", em francês).

Com sua abordagem estatística, Boltzmann pôde resolver os paradoxos que minaram o seu teorema $\mathrm{H}$. Desta maneira pôde contornar a crítica de Loschmidt, aceitando que um processo reverso possa ocorrer, só que com uma probabilidade muito pequena.

Entretanto, as objeções à tentativa de Boltzmann de ligar o micro ao macro não pararam por aí. Em 1896, outra crítica pesada foi dirigida ao teorema $\mathrm{H}$, proposta pelo físico e filósofo Ernest Zermelo, ex-aluno de Max Planck (que certamente influenciou fortemente seu orientando, ver BRUSH, 1986, p. 632-44; KANGRO, 1976, p. 131).

Conhecida como paradoxo da recorrência (Wiederkehreinwand, em alemão), ele se baseou em um teorema fundamental da mecânica clássica, desenvolvido pelo matemático Henri Poincaré, no ano de 1890. Em linhas gerais, a tese de Poincaré afirmava que um sistema mecânico sob a ação de forças conservativas, no espaço de fase, obrigatoriamente passará após um tempo $t$ finito, tão próximo quanto se queira de ponto onde se encontrava em 
$t=0$. A seguir, na Fig. 2.18, podemos ver uma interpretação pictórica deste teorema:

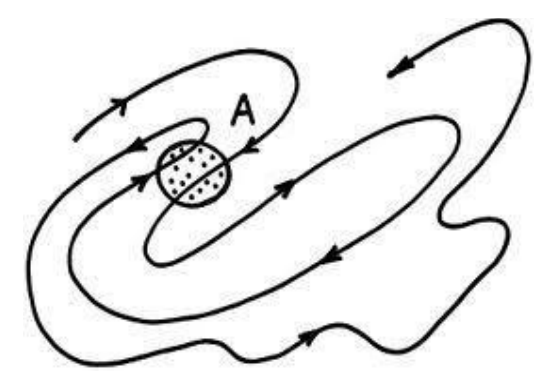

Figura 2.18 - Desenho mostrando o comportamento de um sistema mecânico sob a ação de forças conservativas, onde há uma recorrência muito próxima a seu estado inicial, representado por um ponto na região circular.

Deste modo, o teorema de recorrência mostrou a impossibilidade de fundamentar a irreversibilidade da Termodinâmica com base exclusivamente nos elementos da mecânica clássica, como pretendia o teorema H. Dado qualquer sistema termodinâmico isolado, mesmo que inicialmente em um estado fora do equilíbrio, ele voltaria a este estado inicial depois de um determinado tempo finito, de forma que a entropia acabaria diminuindo, o que claramente vai em direção contrária ao previsto pelo teorema $\mathrm{H}$. Novamente, foi a suposição de independência estatística que fez com que o teorema $\mathrm{H}$ não contemplasse a recorrência.

A essa altura, porém, Boltzmann já podia se servir de sua abordagem estatística, e fez uma estimativa do tempo de recorrência para um número de $10^{18}$ átomos num volume de $1 \mathrm{~cm}^{3}$ (Fig. 2.19). Quanto tempo levaria para que um ponto no espaço de fase retornasse a sua posição inicial? Neste caso, para $10^{18}$ partículas, o tempo de recorrência achado foi de $10^{10^{18}}$ segundos (HUANG, 1987, p. 90). 


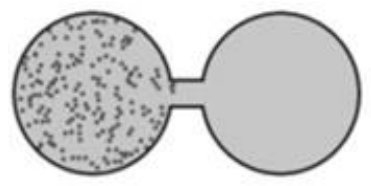

(1)

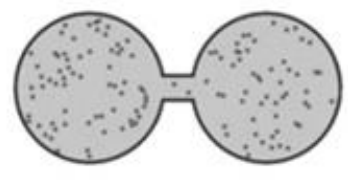

(2)

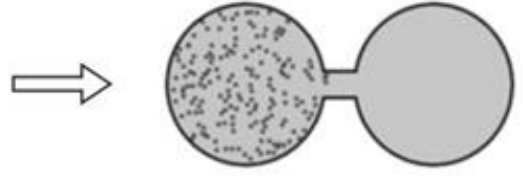

(3)

Figura 2.19 - O sistema (1) refere-se a todas as moléculas de gás dispostas inicialmente de um lado do bulbo. Em (2) elas estão uniformemente distribuídas, num estado de equilíbrio e portanto de máxima entropia. Em algum instante posterior, em (3), as moléculas voltam novamente para somente um lado do bulbo, conforme prediz o Teorema Mecânico da Recorrência de Poincaré.

Vemos assim que para um sistema perfeitamente isolado, é improvável que a entropia diminua conforme mostrado na Fig. 2.19: improvável, mas não impossível. Uma maneira didática de ilustrar o que a teoria estatística de Boltzmann prediz é a proposta de Paul e Tatiana Ehrenfest, formulada na primeira década do século $\mathrm{XX}$, comumente conhecida como o "modelo de urna". No capítulo 3 traremos esta proposta dos Ehrenfest como uma sugestão de exercício didático. Este modelo mostra o caráter "markoviano" da escolha das bolas, ou seja,o número sorteado anteriormente não tem ligação alguma com o sorteado posteriormente.

\section{5 - Novas Aproximações: a Hierarquia BBGKY}

Até hoje, a equação de Boltzmann, que possui caráter não linear, é objeto de estudos, pois ainda não sabemos se ela gera soluções com significado físico para todo o tempo $t$, independente das condições iniciais de $f_{0}$. Desde a época de Boltzmann, com o passar do tempo, novas técnicas foram desenvolvidas na constituição das equações cinéticas, como por exemplo, a análise de processos estocásticos markovianos e as equações mestras de Pauli.

No entanto, optamos por adotar um caminho que se cerca de fundamentos mecânicos, ou seja, formalismos que relatam a trajetória de partículas no espaço de fase, tratadas via equações de Hamilton, equação de Liouville e finalmente o foco desta seção, as equações acopladas, conhecidas 


\section{como BBGKY.}

Essa teoria fora desenvolvida paralelamente pelos cientistas que cederam suas iniciais: Bogoliubov, Born, Green, Kirkwood e Yvon, que a desenvolveram quase ao mesmo tempo. A grande contribuição deste método é analisar as interações de algumas partículas e descrever seu caminho até o equilíbrio.

Em 1935 Yvon introduziu a função de distribuição para S-partículas na mecânica estatística. Posteriormente, Bogoliubov, Kirkwood, Born e Green apresentam seus trabalhos em revistas diferentes no ano de 1946, sendo que os dois últimos autores trabalharam juntos no desenvolvimento de um cálculo estatístico das funções de distribuição.

Veja esquema a seguir:

leva a

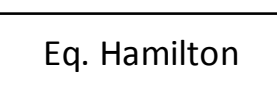

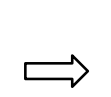

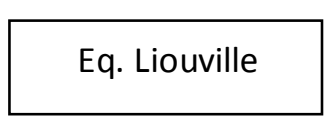

leva a

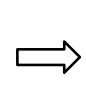

BBGKY

Para entendermos rapidamente os passos até a Hierarquia BBGKY, temos de tomar como partida a equação de Hamilton e a equação de Liouville.

As equações de Hamilton regem a evolução dos pontos contidos numa região do espaço de fase, por exemplo, de R para uma região R', conforme as equações:

$$
\dot{q}=\frac{\partial H}{\partial p} \quad ; \quad \dot{p}=-\frac{\partial H}{\partial q} .
$$

Adotando o volume dessas regiões como $\Omega$ e $\Omega$ ' respectivamente, é lícito dizer que uma transformação canônica que leva de $R$ para $R$ ' preserva o volume desta região. Como consequência, a evolução temporal desses pontos também preserva volume. 
Já a equação de Liouville descreve a evolução da densidade $\rho$ de pontos no espaço de fase, ou seja, a maneira como a função distribuição evolui temporalmente neste espaço. Abaixo a forma desta equação:

$$
\frac{d \rho(\vec{r}, t)}{d t}=\frac{\partial \rho(\vec{r}, t)}{\partial t}+\{H, \rho\}=0 .
$$

Um ponto bem importante, que devemos ressaltar, é que a mesma é invariante por reversão temporal, como esperado para sistemas mecânicos. Então por que não tratarmos a evolução de um sistema termodinâmico de maneira microscópica com a equação de Liouville?

A resposta está no grau de dificuldade em se tratar analiticamente a evolução da densidade $\rho$ de pontos. É aqui que entra a ideia da técnica que levou as equações acopladas de BBGKY.

Tratando agora de um número muito menor do que as $N$ partículas dispostas em $\rho$, a técnica basal de BBGKY envolve trabalhar com distribuições reduzidas de uma partícula, $f_{1}$, de duas partículas $f_{2}$ e assim por diante. Em outros termos, as funções de correlação $f_{s}$ fornecem a probabilidade de encontrar $s$ partículas com valores especificados de posições e momentos, nos sistemas formando um "ensemble" (HUANG, 1987, p. 65). A função $f_{1}$ é a função de distribuição que aparece na equação de Boltzmann.

As equações em sua forma integral se escrevem como:

$$
\left(\frac{\partial}{\partial t}+h_{S}\right) f_{S}(1, \ldots, s, t)=-\sum_{i-1}^{S} \int d z_{S+1} k_{i, S+1} \nabla_{p i} f_{S+1}(1, \ldots, s+1, t)
$$

onde $f_{\mathrm{S}}$ é o conjunto de $s$ funções, e $h_{s}$ representa o hamiltoniano que é dado por:

$$
\frac{\overrightarrow{p_{1}}}{m} \cdot \nabla_{r 1}+F_{1} \cdot \nabla_{p 1}
$$

No limite, levando em conta todas as equações, teremos a função de distribuição de Liouville novamente, que é a base da hierarquia BBGKY. Vemos que para calcular $f_{1}$, é preciso conhecer $f_{2}$, e para calcular $f_{2}$, é preciso conhecer $f_{3}$, e assim por diante. Na prática, o sistema de equações é truncado 
para um certo valor de $S$, constituindo uma estratégia de aproximação sucessiva.

Para termos uma boa noção desta cadeia de equações, iremos escrever as duas primeiras equações de uma sequência infinita:

$$
\begin{gathered}
\left(\frac{\partial}{\partial t}+\frac{p_{1}}{m} \cdot \nabla_{r 1}+\boldsymbol{F}_{1} \cdot \nabla_{p 1}\right) f_{1}\left(z_{1}, t\right)=-\int d z_{2} \cdot \boldsymbol{K}_{12} \cdot \nabla_{p 1} f_{2}\left(z_{1}, z_{2}, t\right) \\
{\left[\frac{\partial}{\partial t}+\frac{p_{1}}{m} \cdot \nabla_{r 1}+\frac{p_{2}}{m} \cdot \nabla_{r 2}+\boldsymbol{F}_{1} \cdot \nabla_{p 1}+\boldsymbol{F}_{2} \cdot \nabla_{p 2}+\frac{1}{2} \boldsymbol{K}_{12} \cdot\left(\nabla_{p 1}-\nabla_{p 2}\right)\right] f_{2}\left(z_{1}, z_{2}, t\right)=} \\
-\int d z_{3}\left(\boldsymbol{K}_{13} \cdot \nabla_{p 1}+\boldsymbol{K}_{23} \cdot \nabla_{p 2}\right) f_{3}\left(z_{1}, z_{2}, z_{3}, t\right) .
\end{gathered}
$$

Vemos que eq.(2.34), que descreve a evolução temporal da função distribuição $f_{1}$, aparece como dependente de $f_{2}$. Já a eq. $(2,35)$, que descreve a evolução de $f_{2}$, terá dependência de $f_{3}$, e assim por diante.

Os termos das equações têm dimensões de $f_{s} / t$, mas envolvem escalas temporais distintas: $\quad \boldsymbol{K} \cdot \nabla_{p} \sim 1 / \tau_{c}, \boldsymbol{F} \cdot \nabla_{p} \sim 1 / \tau_{e}, \frac{p}{m} \cdot \nabla_{r} \sim 1 / \tau_{s}$. O termo $\tau_{c}$ é a duração de uma colisão ( $\boldsymbol{K}$ exprime um potencial intermolecular), $\tau_{\mathrm{e}}$ é o tempo em que uma molécula atravessa a distância em que o potencial varia significantemente ( $\boldsymbol{F}$ é a força externa associada a este potencial), e $\tau_{\mathrm{s}}$ é o tempo para a molécula atravessar a distância em que a função de correlação varia significantemente. Temos também que $\tau_{c}<\tau_{s}<\tau_{e}$. Assim, os termos em $\boldsymbol{F} \cdot \nabla_{p} \sim 1 / \tau_{e}$ podem ser desprezados nas equações acima (ou seja, desprezamse os efeitos das forças externas). Além disso, pode-se considerar que a força intermolecular $\boldsymbol{K}$ atua só em um raio de interação menor do que um certo valor $r_{0}$, que para gases rarefeitos é da ordem de $10^{-10} \mathrm{~m}$ (1 Ångström).

O lado direito da eq.(2.34) representa a chamada integral de colisão, $(\partial f / \partial t)_{C O L}$, que descreve as abruptas mudanças de momento devido às colisões com outras partículas. Os termos em $(p / m)$ são chamados "streaming terms", e descrevem o movimento da partícula no potencial em questão, sem considerar choques. No caso da eq.(2.34), o lado esquerdo da equação corresponde a uma partícula única, não havendo portanto qualquer espalhamento intermolecular (HUANG, 1987, p. 68). 
Um dos grandes desafios do método BBGKY está em se quebrar algum vínculo, estabelecer condições de contorno que gerem respostas coerentes com o comportamento macroscópico dos gases. Para se obterem "equações cinéticas", é necessário quebrar a hierarquia das equações, usando alguma hipótese física para justificar tal quebra (MIZRAHI, 1994, p. 532).

No caso da eq.(2.35), pode-se truncá-la supondo que o lado direito da equação seja nulo. Obtemos assim duas equações simplificadas:

$$
\begin{gathered}
\left(\frac{\partial}{\partial t}+\frac{p_{1}}{m} \cdot \nabla_{r 1}\right) f_{1}\left(z_{1}, t\right)=\left(\frac{\partial f\left(z_{1}, t\right)}{\partial t}\right)_{C O L .} . \\
{\left[\frac{\partial}{\partial t}+\frac{p_{1}}{m} \cdot \nabla_{r 1}+\frac{p_{2}}{m} \cdot \nabla_{r 2}+\frac{1}{2} K_{12} \cdot\left(\nabla_{p 1}-\nabla_{p 2}\right)\right] f_{2}\left(z_{1}, z_{2}, t\right)=0 .}
\end{gathered}
$$

$\mathrm{Na}$ eq.(2.36), se anularmos o termo de colisão, $\left(\frac{\partial f}{\partial t}\right)_{C O L}=0$, deriva-se a distribuição de equilíbrio de Maxwell-Boltzmann (eq. 2.15). Para derivar a equação de Boltzmann (2.19), utiliza-se a eq.(2.37) da hierarquia BBGKY, com algumas suposições, como $\frac{\partial f_{2}}{\partial t}=0$, que supõe que $f_{2}$ atinge a situação de equilíbrio antes de $f_{1}$, e que $r_{0}$ tende a zero (ver detalhes em HUANG, 1987, p. 71).

A cadeia completa de equações BBGKY não nos dá um novo referencial a respeito da irreversibilidade temporal, uma vez que advinda de Liouville, a mesma é reversível temporalmente. Segundo padrões matemáticos, a série de equações é considerada como "não fechada", pois contém termos que vão além de $f_{s}$, ou seja, $f_{s+1}$. Para que a hierarquia venha a ser considerada uma equação cinética (isto é, represente algum fenômeno físico baseado neste modelo), é necessário quebrar algum vínculo ou "truncá-la", como exemplificado acima.

É interessante ressaltar que, dependendo da aproximação advinda do truncamento desta cadeia de equações, podemos gerar automaticamente uma evolução irreversível, que na prática descreve bem os processos irreversíveis medidos macroscopicamente. Isso é de certa forma surpreendente, pois uma solução aproximada descreve melhor sistemas experimentais do que a solução exata.

Já quando a densidade de moléculas não pode deixar de ser levada em 
consideração, devemos considerar as interações entre as mesmas, mas não suas correlações antes ou depois de cada choque, pois iremos supor que após certa distância, as moléculas não tenham mais nenhuma correlação. De certa maneira já "invocamos" esta forma de truncar a hierarquia, quando falamos da hipótese da independência estatística na equação de Boltzmann, também conhecida como caos molecular. Seu conceito está inserido na equação:

$$
\begin{gathered}
\left(\frac{\partial f_{1}}{\partial t}\right)_{\text {COL. }}=-\int d z_{2} \cdot k_{1.2} \cdot \nabla_{p 1} f_{1}\left(z_{1}, t\right) f_{1}\left(z_{2}, t\right), \\
\text { onde } f_{2}\left(z_{1}, z_{2}, t\right)=f_{1}\left(z_{1}, t\right) \cdot f_{1}\left(z_{2}, t\right) .
\end{gathered}
$$

Esta aproximação nos leva a uma conhecida equação cinética chamada de equação de Vlasov, muito usada no comportamento evolutivo das partículas carregadas eletricamente que constituem o plasma, e aplicável também a sistemas a altas temperaturas com partículas interagindo por potenciais de longo alcance.

A partir da hierarquia BBGKY deduz-se não só a eq. de Boltzmann, mas também, perturbativamente, termos de correção que resultam em equações derivadas por Chapman, Enskog, Prigogine, Grad, Klimontovich, Landau e outros (MIZRAHI, 1994, p. 532). A Fig. 2.20 mostra as formas de se obter as equações cinéticas da mecânica estatística.

No entanto há algo que esta equação carrega que é extremamente curioso. Ao contrário da aproximação que nos leva à equação de Boltzmann, cuja característica é a de retratar fenômenos irreversíveis, a equação de Vlasov é reversível temporalmente. Assim, essa equação descreve alguns aspectos do comportamento de um plasma diluído fora do equilíbrio, mas não é capaz de descrever a evolução temporal irreversível do plasma, rumo ao seu estado de equilíbrio (SALINAS, 2001, p. 326). 


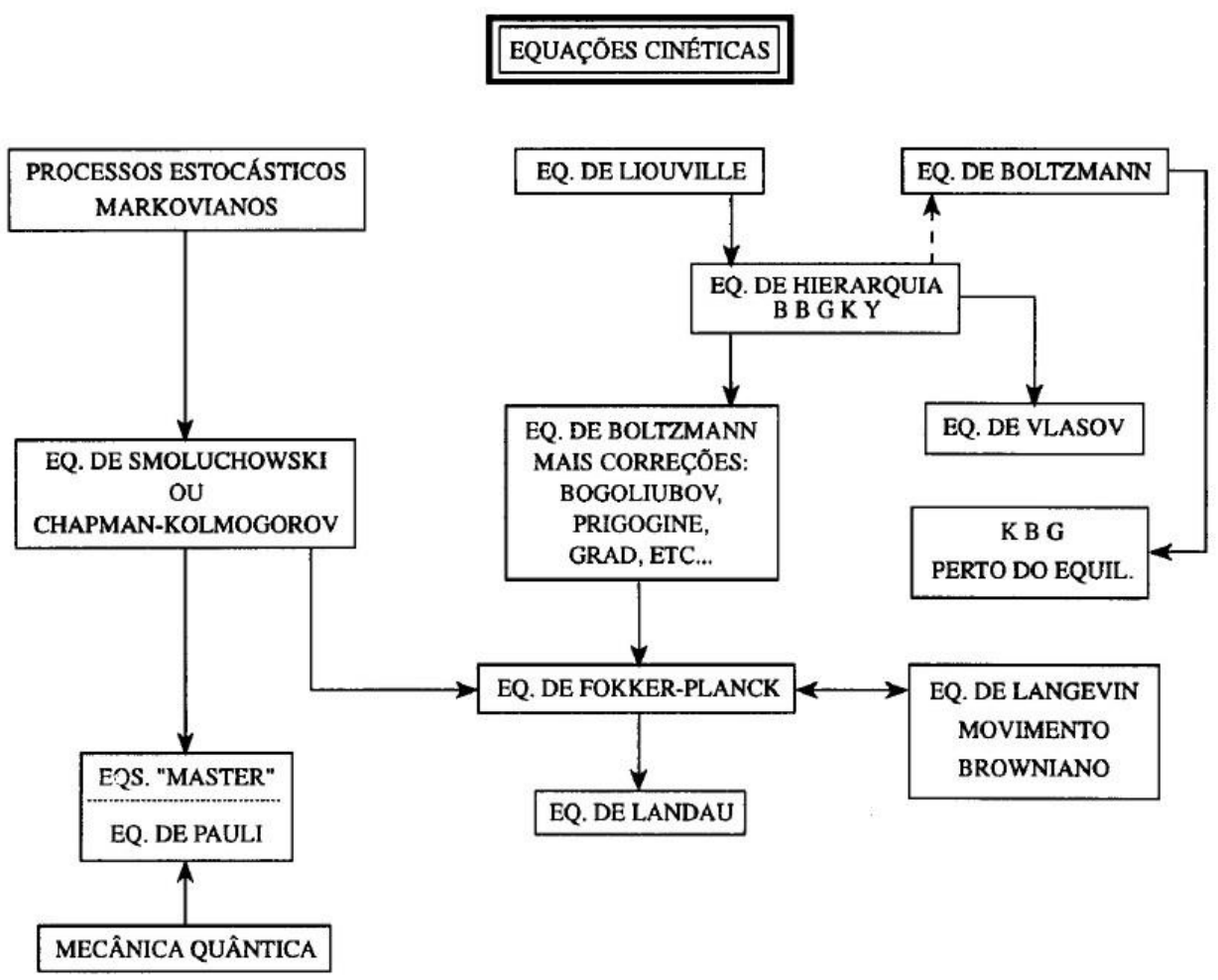

Figura 2.20. Fluxograma indicando o caminho de derivação de várias equações cinéticas da mecânica estatística (MIZRAHI, 1994, p. 532).

Neste capítulo como um todo, fica claro a luta de homens como Clausius, Maxwell e principalmente Boltzmann para conseguir relacionar o conceito macroscópico de entropia com o comportamento microscópico da matéria. No início foram adotados somente preceitos mecânicos, no entanto somente com estes encontraram-se dificuldade para explicar os problemas advindos dos paradoxos da reversibilidade e da recorrência. Foi necessário introduzir a suposição matemática da independência estatística nas colisões, justificada por uma hipótese física do caos molecular. Por outro lado, a concepção probabilista de entropia resolveu os paradoxos, ao preço de admitir que $\mathrm{o}$ ar de uma sala tem uma probabilidade finita de se juntar todo em um canto da sala (uma probabilidade, porém, que é ínfima). Vimos também a importância da escolha das aproximações em Física, exemplificada pelos diferentes truncamentos da hierarquia de BBGKY. 


\section{6 - A Hipótese do Caos Molecular}

Os trabalhos de Boltzmann despertaram interesse no Reino Unido, onde na década de 1890 vários físicos, como E.P. Culverwell, G.H. Bryan e S.H. Burbury examinavam a demonstração puramente mecânica do teorema $\mathrm{H}$, resultando em diversas publicações na Nature. Tornou-se claro para eles que algum princípio adicional teria que ser adicionado, quer de natureza estatística, quer uma interação com o éter luminífero. O próprio Boltzmann visitou uma reunião da British Association for the Advancement of Science, em Oxford em 1894, e passou a participar ativamente das discussões. Neste ano, Burbury publicou um trabalho na Nature sugerindo explicitamente que um processo físico, que chamou de "condição A" poderia ser responsável pelo fato de a entropia raramente diminuir:

Penso que a resposta para isso seria que qualquer sistema material recebe distúrbios de origem externa, cujos efeitos, vindos aleatoriamente, produzem a própria distribuição de coordenadas que é requerida para fazer $H$ diminuir. Assim, haveria uma tendência geral para $H$ diminuir, apesar de ser concebível que ela possa aumentar em casos particulares (Burbury, 1894, apud BRUSH, 1986, p. 621).

Culverwell passou a criticar todas as tentativas de defender o teorema $\mathrm{H}$, incluindo as soluções propostas para o paradoxo da reversibilidade. Neste ponto, em 1895, Boltzmann escreveu uma carta à Nature ressaltando a sua concepção probabilista, e admitindo que 0 valor de $H$ pode aumentar ocasionalmente acima do valor mínimo (ou seja, a entropia pode diminuir ocasionalmente). Assim o teorema $H$ não seria refutado, mas apenas ficaria clara a sua natureza probabilista (BRUSH, 1986, p. 623).

No primeiro volume de seu Vorlesungen über Gastheorie (1895), Boltzmann adotou o postulado A de Burbury, dizendo que o estado do gás está "desordenado molecularmente", e que tal suposição é fundamental não só para a derivação do teorema $\mathrm{H}$, mas também para cálculos de viscosidade, condutividade térmica etc., e para a fundamentação da distribuição de equilíbrio de Maxwell (BRUSH, 1986, p. 625).

Burbury continuaria insistindo em 1903 na necessidade de supor a 
aleatoricidade trazida pela hipótese da "desordem molecular" para derivar a irreversibilidade. Sua tese seria criticada no mesmo ano por James Jeans, que a considerou "ilógica" (BRUSH, 1986, p. 651).

Nesta altura, a concepção alternativa de Willard Gibbs abria uma nova perspectiva ao problema. Gibbs considerou que um ensemble (coletivo de estados) se aproxima do equilíbrio não devido a um elemento de aleatoricidade no comportamento molecular, mas para o fato de que o escoamento no espaço de fase produz uma mistura (mixing) que progressivamente impede 0 observador macroscópico de discernir os detalhes do sistema.

Gibbs lançou mão de uma analogia com um líquido transparente em que se joga uma gota de tinta colorida insolúvel. Ao misturar o líquido, a gota manteria o seu volume, mas iria se espalhando em finíssimos tentáculos, até desaparecer da vista do observador. Posteriormente, o casal Ehrenfest introduziu a distinção entre grão grosso (coarse graining) e grão fino (fine graining). Assim, a função $\mathrm{H}$ de Boltzmann, considerada em grão fino, envolveria uma constante de movimento, ao passo que considerada em grão grosso (conforme visto pelo observador macroscópico) decresceria como resultado do processo de mistura (BRUSH, 1986, p. 650).

É importante ressaltar a conexão entre a hipótese da desordem molecular e a hipótese usada por Boltzmann em sua derivação do teorema $H$, conhecida em alemão como Stosszahlansatz, ou "postulado sobre o número de colisões". Trata-se da suposição de independência estatística (eq. 2.18) de que nas colisões moleculares não há correlações entre as velocidades das moléculas, hipótese usada anteriormente por Maxwell. Ou seja, em qualquer instante, o número de colisões de moléculas com velocidades $v_{1}$ e $v_{2}$ dependerá apenas da proporção de moléculas do gás que possuem as respectivas velocidades, além de depender da densidade do gás e do volume percorrido por uma das moléculas (SKLAR, 1993, p. 33).

Para a derivação do teorema $H$, é preciso que o Stosszahlansatz seja aplicado a todo instante (ver SKLAR, 1993, p. 66). O que garantiria isso fisicamente? Seria algum processo físico que veio a se chamar de "desordem molecular" ou "caos molecular", como preferiam o casal Ehrenfest.

Burbury associou um agente físico a este caos molecular, que seriam as flutuações térmicas e de outra natureza provinda do ambiente externo. 
Assim, na prática, um sistema nunca estaria completamente isolado. Modernamente, tal concepção veio a se chamar de interpretação intervencionista, pois haveria uma intervenção constante por parte do ambiente (SKLAR, 1986, p. 296). Essas flutuações poderiam ser devidas a campos gravitacionais e eletromagnéticos de objetos próximos, radiação de fundo do Universo, flutuações do vácuo, etc. Na Física Quântica, Hans Dieter Zeh (1970) argumentou que quanto mais partículas estiverem presentes em um sistema, menor será a diferença de energia entre os níveis energéticos, e portanto maior será a influência do ambiente. Consequentemente, não haveria sistemas macroscópicos isolados, salvo o Universo como um todo (PESSOA, 2014a, p. 143).

Uma maneira diferente de interpretar a hipótese do caos molecular é supor que moléculas individuais têm uma instabilidade intrínseca, que pode estar associada a uma irreversibilidade nanoscópica. Esta é a posição do químico llya Prigogine (ver COURBAGE \& PRIGOGINE, 1983). O único exemplo comprovado de assimetria de reversão temporal é o decaimento de káons, medido em 1964, mas isso não é suficiente para explicar a irreversibilidade em casos gerais.

Examinaremos agora a análise feita por Kerson Huang (1987) sobre a noção de Stosszahlansatz, que ele chama de "hipótese do caos molecular" ( $p$. 62). Na Fig. 2.21, o valor de $\mathrm{H}$ é representado ao longo do tempo. Notamos que este valor nunca vai abaixo de um certo valor mínimo, e também que na maior parte do tempo o sistema flutua dentro de um "intervalo de ruído" (noise range). O sistema poderia, em princípio, flutuar para fora do intervalo de ruído, mas HUANG (1987, p. 88) afirma que "para todo fim prático $H$ nunca flutua espontaneamente para cima do intervalo de ruído". Se o sistema sair do equilíbrio, como no ponto $\boldsymbol{a}$, ele rapidamente retorna para o intervalo de ruído.

Na maior parte do tempo, o valor de $H$ flutua no intervalo de ruído, no qual $d H / d t$ é tão frequentemente positivo quanto negativo. (Isto não é uma contradição com o teorema $H$, porque o teorema $H$ requer apenas que quando o sistema está em um estado de "caos molecular", então $\mathrm{dH} / \mathrm{dt} \leq 0$ no instante seguinte.) (HUANG, 1987, p. 88) 


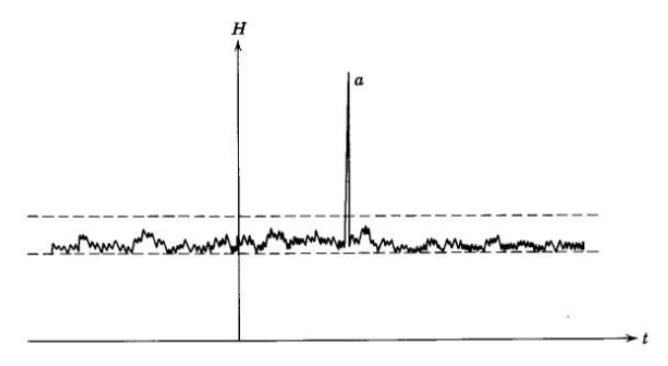

Figura 2.21. Representação esquemática das flutuações de $\mathrm{H}$ dentro do intervalo de ruído.

Assim, a hipótese do Stosszahlansatz (ou do "caos molecular", como prefere Huang) valeria em pontos que se encontram no topo de um pico de flutuação, pois são nestes pontos em que o valor de $d H / d t$ é sempre menor ou igual a zero, o que é justamente garantido pelo Stosszahlansatz. Nos outros pontos da curva serrilhada de flutuação não valeria tal hipótese.

$O$ físico sino-americano apresenta outra figura que ilustra 0 decrescimento monotônico da solução de Boltzmann de sua equação de transporte, representada pela curva tracejada da Fig. 2.22. Mas, além disso, Boltzmann reconheceu que o teorema $\mathrm{H}$ não descrevia flutuações estatísticas, o que é representado pela curva cheia serrilhada. No alto dos "dentes de serra" localizam-se pontos que são justamente aqueles nos quais $d H / d t \leq 0$, ou seja, onde valeria o Stosszahlansatz (ver também CATTANI \& BASSALO, 2008).

O estranho da Fig. 2.22 é que não parece haver um valor mínimo da linha de base de $\mathrm{H}$, que limita as flutuações, como ocorre na Fig. 2.21.

$H(t)$ apresenta o comportamento serrilhado no caso de calcularmos a função $f(r, v, t)$ através de simulação numérica, sem envolver a equação de transporte de Boltzmann. Quando $f(r, v, t)$ é determinado através da equação de transporte de Boltzmann, o comportamento de $H(t)$ seria descrito por uma curva (tracejada) que faria uma média entre os pontos dos picos, segundo Huang (ver também HILL,1956). 


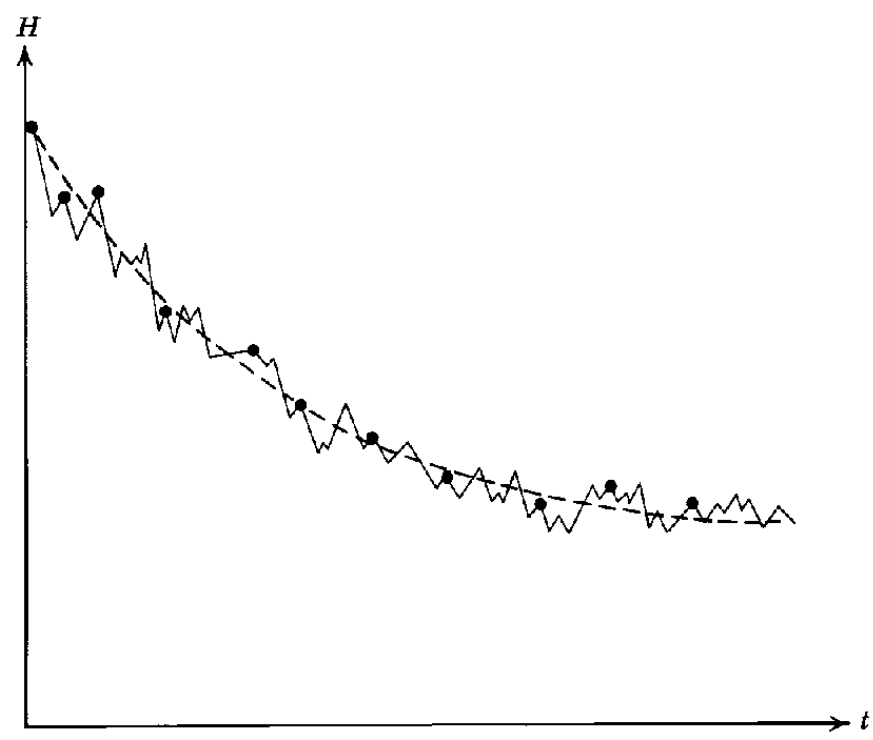

Figura 2.22 - Variação de H (inverso da entropia) com o tempo, partindo de um estado improvável. As linhas tracejadas representam a previsão do comportamento de um gás pela equação de transporte de Boltzmann. As linhas sólidas mostram 0 comportamento de $\mathrm{H}$ em um modelo mais realista. Os pontos pretos, apresentados no gráfico, são pontos de inflexão onde ocorreria o fenômeno do caos molecular (HUANG, 1987, p. 89).

A interpretação de independência estatística, hipótese que ajudou Boltzmann a fundamentar sua resposta ao problema dos movimentos moleculares sempre tenderem ao estado de máxima entropia, agora justificam as flutuações de entropia presentes em cálculos de primeiros princípios (EYRING et al., 1982), que não usam sua equação cinética, suprindo assim algo que até então o Teorema $\mathrm{H}$ não havia conseguido justificar.

Neste caso podemos argumentar que a Equação de Transporte de Boltzmann e, por conseguinte seu Teorema $\mathrm{H}$ tratam da descrição de um comportamento médio do sistema, não contemplando assim as variações de $\mathrm{H}$ nos curtos intervalos temporais.

Vale comparar o comportamento teórico da Fig. 2.22 com medidas de entropia, feitas por BANDI et al. (2006). 


\section{CAPÍTULO 3 \\ Filosofia da Ciência e Modelos}

O obscurecimento gradual dos tempos em que vivemos levou a Filosofia a perder sua luz e se converter num jogo dialético, num exercício retórico e racional, que não encontra aplicação fora de sua própria sistematização. (Federico GONZÁLEZ, 2003, p. 28)

\section{1 - Filosofia da Física}

A filosofia é de bastante importância para a ciência, como defendido consistentemente por alguns autores (BENTLEY \& GARRISON, 1991; MATTHEWS, 1998). No entanto, parece-me que na formação docente a filosofia da ciência é aplicada somente como um mero complemento, sem uma maior integração com os demais conteúdos presentes no currículo. Há disciplinas "conteudistas", onde se passam conteúdos de física sem maiores discussões conceituais, e disciplinas pedagógicas, onde o foco são as teorias e métodos de ensino. Em ambas, porém, as discussões de filosofia da ciência são praticamente ignoradas.

Supomos que uma das tarefas mais importantes da filosofia da física é "iluminar" os conceitos da física, verificar limites e até algumas inconsistências nesses conceitos. O ponto nevrálgico é que os professores muitas vezes apenas ficam apenas no formalismo matemático e não querem (ou não sabem) se aventurar pelos caminhos dos fundamentos conceituais (POMEROY, 2006).

Dentre as ciências, uma das que mais possui contribuições para a filosofia é a física, tanto que existe uma sub-área da filosofia da ciência chamada Filosofia da Física. "A filosofia da física é a área que discute os problemas não resolvidos da descrição física do mundo, sendo que muitos estão na fronteira da pesquisa física atual” (PESSOA, 2014b, p. 3).

A aproximação entre a filosofia e o ensino de ciências (ZANETIC, 
1989), ajudaria aos professores de física quando são desafiados por seus alunos a responderem questões como: "qual o início do tempo?", "o que é a vida e a consciência?", "qual será o fim do Universo?", etc. Para Pessoa (2014b, p. 2):

Quem estuda uma questão de filosofia da física pode inicialmente se frustrar com o fato de haver várias respostas e nenhuma maneira de decidir qual delas é a melhor. Mas depois se percebe algo curioso: o estudo de diferentes respostas permite uma melhor compreensão da pergunta.

Um futuro professor, cuja formação tenha sido influenciada também por questões filosóficas, será um profissional multifacetado, podendo adotar um posicionamento "plural". Um professor pluralista, cuja formação filosófica não seja desprezível, poderá fazer com que os alunos construam um significado mais amplo para assuntos específicos, relacionando-os com uma visão mais geral de mundo. Esta aproximação entre ciência e filosofia certamente amplifica o canal de comunicação entre professor e aluno.

Seria vantajoso se os professores de física soubessem qual é o estado atual do debate filosófico e se posicionar de maneira abrangente. Avaliamos que o ensino de física (dentro do ensino de ciências) se enriqueceria com professores que tenham cursado, pelo menos, uma disciplina de "introdução à filosofia da física". Isso permitiria aprofundar a abordagem conceitual simplificada que é usual, explorando os fundamentos dos conceitos (ERDURAN et al., 2007) e também os problemas não resolvidos.

Uma maneira de abordar questões de história e filosofia da ciência é através da leitura de textos originais passados ou da vanguarda da física hoje. Incentivar o futuro professor a estudar os meandros de artigos originais e se envolver com as questões conceituais pode contribuir para que este sinta-se parte desta história (MATTHEWS, 1994b, p.190).

Uma das questões cuja discussão é enriquecida pela filosofia da física é a abordagem explorada nesta tese, referente aos sistemas reversíveis e irreversíveis, e os modelos de explicação utilizados. A análise filosófica de um fenômeno físico permite que uma teoria muito matematizada possa ser melhor compreendida pelo professor e pelo aluno. Esse é também o caso da física 
quântica.

\section{2 - Sobre Modelos e Aproximações}

O intuito do Capítulo 2 foi o de estabelecermos os caminhos adotados pelos físicos a fim de reduzir uma teoria fenomenológica, como a Termodinâmica, a uma teoria construtivista, Mecânica Estatística. Nesse processo, simplificações teóricas foram introduzidas, tendo em vista facilitar os cálculos matemáticos. Tais simplificações são chamados "modelos". Nesta seção, explorarei um pouco deste tema, com o intuito de esclarecer as dificuldades encontradas na tentativa de redução da Termodinâmica.

Nesta empreitada, a necessidade da utilização de modelos, sejam eles com o viés didatizante, sejam com o intuito de capturar a estrutura do fenômeno estudado, aparece de forma bem clara. Um exemplo de modelo ocorre na tentativa de conectar uma variável macroscópica, como a temperatura, a variáveis microscópicas, como a média do quadrado das velocidades de moléculas. Para fazer isso, caracteriza-se o gás por bolinhas que ocupam um volume tendendo a zero em relação ao espaço que as contém. Este modelo do gás ideal é uma maneira de simplificarmos o objeto real.

Para a educadora Dominique Colinvaux:

[...] se as práticas dos cientistas envolvem elaboração de modelos, então é necessário que a educação em ciências trate também do tema modelos, seja em suas investigações, seja em suas práticas pedagógicas, formais ou informais (COLINVAUX, 1998, p.9).

Geralmente quando descrevemos um fenômeno natural pela primeira vez, tentamos estabelecer as relações entre este sistema e os elementos que o cercam, de maneira a encontrar uma regularidade ou uma lei envolvendo aquele fenômeno. Ao fazer isso, geralmente elaborarmos um modelo científico.

Por exemplo, no estudo de fenômenos optoeletrônicas em semicondutores, inicialmente considerou-se que os elétrons que se movem no material interagem de acordo com a lei de Coulomb de atração eletrostática. 
Em 1923, Debye \& Hückel elaboraram um modelo no qual os elétrons eram blindados pelo meio dielétrico, o que levou à introdução na lei de Coulomb de um decaimento exponencial (com a distância). Este modelo melhorado foi então adaptado para semicondutores. Conwell \& Weisskopf (1950) consideraram o espalhamento de elétrons em impurezas por meio de um modelo semiclássico (ou seja, parcialmente quântico). Outros modelos mais detalhados foram sendo elaborados, à medida que materiais mais complexos e dopagens mais sofisticadas foram sendo estudados experimentalmente. $O$ modelo de Takimoto (1959) introduziu correlações entre os elétrons, e desta forma obteve melhores ajustes de curvas aos dados experimentais (HALL, 1962). Tais modelos foram estudados em meu mestrado, considerando variações de temperaturas do material.

Vemos que um modelo deve se encaixar em uma teoria científica já conhecida, quer uma teoria clássica, quer uma teoria quântica. Um modelo é uma aplicação simplificada da teoria para facilitar a comparação com a realidade, já que geralmente o cálculo matemático é extremamente elaborado. Embora um modelo possa responder a certos questionamentos e gerar aplicações práticas, ele certamente será substituído por outros modelos mais adequado. Há assim uma evolução dos modelos para tratar de determinado fenômeno.

$\mathrm{Na}$ física, fala-se em "modelo padrão" ou "modelo do big bang", mas estas podem ser consideradas teorias. A distinção entre teoria e modelo não é rígida, já que teorias sempre trazem simplificações: há um contínuo entre modelos e teorias, e a tarefa de diferenciá-los, em muitos casos, leva a cenários confusos (DA COSTA \& FRENCH, 2000).

O texto abaixo é exposto no livro Historia universal da infâmia, onde o escritor e poeta argentino Jorge Luis Borges (1982, p. 117) expõe nesta parte as infinitudes e utilidades de um mapa.

Naquele império, a Arte da Cartografia alcançou tal Perfeição que o mapa de uma única Província ocupava uma cidade inteira, e o mapa do Império uma Província inteira. Com o tempo, estes Mapas Desmedidos não bastaram e os Colégios de Cartógrafos levantaram um Mapa do Império que tinha o Tamanho do Império e coincidia com ele ponto por ponto. Menos Dedicadas ao 
Estudo da Cartografia, as gerações seguintes decidiram que esse dilatado Mapa era Inútil e não sem Impiedade entregaram-no às Inclemências do Sol e dos Invernos. Nos Desertos do Oeste perduram despedaçadas Ruínas do Mapa habitadas por Animais e por Mendigos; em todo o País não há outra relíquia das Disciplinas Geográficas. (Suárez Miranda: Viajes de Varones Prudentes, Livro Quarto, Capítulo XIV, Lérida, 1658.)

A partir do relato desse belíssimo trecho do personagem Suárez Miranda, pode-se perguntar até que ponto modelos extremamente sofisticados têm lugar na ciência? É preciso sermos tão detalhistas para que tenhamos conhecimento dos fenômenos? À medida que uma teoria se aproxima da verdade, ela não se tornaria cada vez mais inútil, dada sua crescente complexidade? Talvez o conhecimento científico tenha que envolver simplificações, e é nesse sentido que os modelos se tornam essenciais para a ciência. Essa impossibilidade prática de descrever o real em todos os seus detalhes, introduzindo lacunas, está relacionada com a noção de "emergência", discutida no Cap. 1.

Independentemente da área considerada, o papel das aproximações em física sempre foi de fundamental importância para seu desenvolvimento. Isso implica que a descrição teórica de um fenômeno deixa de lado muitos detalhes, e é em cima de tais descrições que funciona o método científico.

Nos anos 1980 existia uma figura na televisão, vulgarmente conhecida como o "homem do tempo". A acurácia de suas previsões era péssima, e ele frequentemente errava suas previsões para 0 dia seguinte, ou até para 0 mesmo dia. A opinião pública até aquela época não acreditava em quase nada da meteorologia. Hoje, a previsão do tempo é "quase certa", e alguém pode perguntar: "O que mudou?". A resposta é direcionada aos algoritmos de cálculo, que foram substancialmente melhorados nos modelos mais elaborados de meteorologia.

No caso da mecânica estatística, a própria inclusão da palavra "estatística" se dá devido à impossibilidade de tratarmos cada ente microscópico correspondente a uma variável termodinâmica. Os modelos estatísticos contabilizam sucessos decorrentes de suas aproximações, tal como o modelo cinético de Boltzmann. 
Em suma, devido à grande complexidade que a natureza apresenta, os cientistas utilizam-se de modelos aproximados que servem de "sustentáculos" para a confirmação de suas teorias.

Para Pozo \& Crespo (2006, p. 20):

[...] a ciência não é um discurso sobre 'o real', mas um processo socialmente definido de elaboração de modelos para interpretar a realidade.

Podemos concordar que a ciência seja um processo social de elaboração de modelos para interpretar a realidade, mas isso não significa que a ciência não seja um discurso sobre o real. Adotando uma postura filosoficamente mais realista do que a de Pozo \& Crespo, podemos dizer que a ciência refere-se ao real através de teorias e modelos. Modelos seriam representações simplificadas da realidade, podendo ser expressos de várias formas, tamanhos e estilos. Muitas vezes estão presentes dentro das teorias, como uma maneira de representar parte daquela teoria, ajudando-a a manter certa coerência interna. Os modelos também podem surgir antes do surgimento de uma teoria mais completa, por exemplo, o modelo atômico de Bohr. Existe várias propostas de tipos de modelos na literatura: modelos heurísticos, explicativos, teóricos, fenomenológicos, icônicos, matemáticos, de escala, imaginários, formais, etc. Às vezes nomes diferentes são usados para sentidos bastante próximos.

\section{3. - Filosofia da Ciência e Modelos}

O filósofo Peter Achinstein (1977, p. 355), consegue apresentar um interessante panorama sobre a discussão dos modelos na ciência:

O termo "modelo" se aplica a diversos tipos inteiramente diferentes de concepções nas ciências. Um uso do termo é para referir-se a uma representação física tridimensional de um objeto - sendo a representação tal que, ao estudá-la, podem-se afirmar certos fatos a respeito do original. Essa classe inclui os modelos pau-ebola de moléculas, modelos do sistema solar que encontramos em museus, assim como os chamados 
modelos analógicos, tal como um modelo de circuito elétrico para um sistema acústico. Em outro uso do termo "modelo" se refere a um conjunto de pressuposições idealizadas sobre a estrutura interna, composição ou mecanismo de um objeto ou sistema. Os exemplos seriam o modelo de Bohr para o átomo e o modelo dos elétrons livres para os metais. Em um terceiro uso ainda, o termo se refere a um conjunto de suposições sobre um sistema que deveriam mostrar como o sistema poderia ser, se ele satisfizesse certas condições, mas que não se pretende que sejam tomadas como suposições satisfeitas por qualquer sistema real. Um exemplo é o modelo de Poincaré de um mundo não-euclidiano que deveria mostrar como seria um mundo físico, se ele satisfizesse a geometria de Lobatchevsky. O filósofo da ciência continuará a esclarecer cada uso do termo "modelo," isto é, cada um desses tipos de modelos. Ele fará isso ao considerar suas características e também, talvez, ao contrastá-los com analogias com as quais eles são às vezes identificados, mas das quais eles deveriam ser distinguidos (ACHINSTEIN, 1977, p. 355).

A importância dos modelos na ciência é vista de maneira distinta por diferentes tradições filosóficas. Frigg \& Hartmann (2012) resumem a visão das duas grandes escolas logicistas da filosofia da ciência.

A abordagem sintática desenvolvida pelos empiristas lógicos, como Rudolf Carnap, concebe uma teoria científica como sendo um sistema de axiomas. Modelos seriam uma interpretação alternativa ao conjunto de axiomas, por exemplo, quando a teoria cinética dos gases é interpretada como se aplicando para bolas de bilhar, diz-se que tais bolinhas de bilhar são um modelo da teoria. Nesse sentido, modelos seriam supérfluos para a ciência, tendo valor apenas didático ou psicológico.

Já para a abordagem semântica, defendida por autores como van Fraassen, Giere, Suppe e Suppes, os modelos passam a ter mais importância do que o conjunto de axiomas lógicos. Basicamente interpretam as teorias científicas como "famílias de modelos", sendo estes últimos imprescindíveis à teoria.

Essas duas escolas interpretam "modelos" como entidades lógicosemânticas, mas o que nos interessa aqui são os chamados "modelos físicos" ou "representacionais", explorados por autores como Mary Hesse (1966) e, na tradição semântica, Ronald Giere (1988). Um modelo físico representa o comportamento e estrutura de um sistema físico, sendo que os dois 
compartilham de uma estrutura semelhante. Por exemplo, um modelo de paue-bola da molécula de água procura capturar a estrutura espacial real da molécula de água, alterando porém os objetos relacionados e seu tamanho (MORRISSON \& MORGAN, 1999, p. 5).

Podemos considerar diferentes tipos de modelos, no sentido representacional, seguindo Dutra (2005, p. 221):

Modelos Icônicos: Modelos que podem ser entendidos como uma representação da natureza de um sistema físico, apresentando semelhanças estruturais com os entes físicos. Por exemplo, quando temos em mão o modelo de plástico de um determinado avião.

Modelos Matemáticos: As equações presentes numa teoria poderiam ser encaradas como uma forma de representação matemática do objeto da teoria.

Modelos Nômicos: Podem ser entendidos como representações verbais que descrevem, estruturalmente ou em detalhe, o comportamento de outras estruturas ou sistemas.

Hesse (1966, p. 8), retoma o trabalho do físico e filósofo inglês Norman Campbell, em um suposto diálogo com o também físico e filósofo francês Pierre Duhem, que desvalorizava o uso de modelos na ciência. Para Campbell, segundo Hesse, o modelo físico (icônico) e o sistema real podem apresentar analogias positivas (como a estrutura espacial, no exemplo do modelo molecular), analogias negativas (em que não há correspondência, como o material de que são feitas as bolas do modelo) e analogias neutras (onde a semelhança não é conhecida). São estas últimas que possibilitam fazer novas previsões a respeito de um sistema.

No ensino de ciências, Harrison \& Treagust (2000, p. 355) apresentam uma tipologia de modelos analógicos. Para eles, tais modelos referem-se a representações de teorias e objetos científicos, que podem ser concretas, abstratas ou misturadas, e que são usados em livros didáticos, por professores e pelos alunos. Entre o modelo analógico e o alvo (objeto, entidade ou teoria) há um mapeamento entre os atributos compartilhados. Geralmente os modelos são muito simplificados, para deixar claro o mapeamento entre o modelo e 0 alvo. Modelos analógicos podem ser modelos de escala, modelos moleculares, modelos icônicos/simbólicos (como uma fórmula química), modelos 
matemáticos, modelos teóricos ou modelos de um processo ou conceito (como os modelos de ácidos e bases, na química).

Já vimos no Cap. 2, e veremos em outros exemplos neste capítulo, que os modelos que abordam a Mecânica Estatística têm a característica de reduzir o número de partículas (em relação ao número de moléculas em um mol de gás real), e estão acoplados a um formalismo matemático com alto grau de sofisticação e abstração. Tais modelos matemáticos são generalizáveis a diversos fenômenos em diferentes áreas científicas.

O filósofo Gaston Bachelard tece um comentário sobre o uso de modelos matemáticos geométricos visualizáveis, e modelos matemáticos mais abstratos:

\begin{abstract}
Mais cedo ou mais tarde, na maioria dos domínios, é forçoso constatar que essa primeira representação geométrica, fundada num realismo ingênuo das propriedades espaciais, implica ligações mais ocultas, leis topológicas menos nitidamente solidárias com as relações métricas imediatamente aparentes, em resumo, vínculos essenciais mais profundos do que os que se costuma encontrar na representação geométrica [...]. O papel da matemática na física contemporânea supera pois, de modo singular, a simples descrição geométrica. (BACHELARD, 1996, p. 7).
\end{abstract}

O projeto reducionista utiliza modelos simplificados e um forte uso do formalismo matemático, como foi indicado no Cap. 2, onde mostramos um dos caminhos adotados pelos físicos para explicarem formalmente uma possível redução da $2^{\text {a }}$ Lei da Termodinâmica à Mecânica Estatística. Na Mecânica Estatística, o modelo matemático é um componente do modelo físico. Além disso, examinamos algumas estratégias de aproximação, como na abordagem de BBGKY, para tratar das dificuldades do formalismo.

Para o filósofo da ciência Ronald Giere (2004, p. 747), "o que é especial sobre modelos é que eles são construídos de maneira que os elementos do modelo possam ser identificados com características do mundo real". Ele apresenta o seguinte esquema para se entenderem os modelos baseados em teorias científicas: 


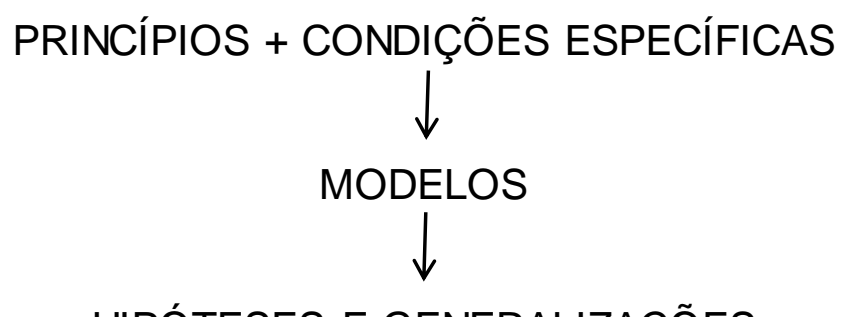

HIPÓTESES E GENERALIZAÇÕES

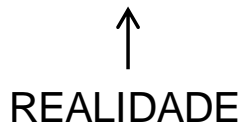

Neste esquema, os cientistas constroem os modelos utilizando-se de princípios e condições específicas. A tentativa de aplicar modelos ao mundo gera hipóteses sobre o ajuste dos modelos específicos aos objetos do mundo, hipóteses essas que posteriormente podem ser generalizadas.

Neste esquema, os princípios devem atuar como moldes gerais para a construção de objetos abstratos específicos, que são os "modelos": eles são abstratos mas contêm condições específicas que restringem seu escopo de aplicação. Para Giere, os fenômenos da natureza são associados a modelos, e é uma série ou família destes que constituem uma "teoria científica".

No caso da representação feita por um mapa, em relação a um território geográfico, podemos estabelecer uma regra de correspondência entre as características geográficas do local e o modelo em escala menor que o mapa representa. É usual que alguns detalhes deste mapa não contenham informações sobre a topografia local, tipos de estrada, locais de descanso, regiões perigosas, etc. Porém, levando em consideração o publico a que esse mapa se destina, esses detalhes poderiam ser adicionados pelo cartógrafo. Assim, os modelos são construídos também incorporando as características sociais dos indivíduos que os apresentam (SARKAR, 2005).

Uma espiral torcida conectada por pequenos pedaços de madeira pode ser considerado um modelo da molécula de DNA. Talvez o ângulo entre as moléculas do modelo sejam diferentes dos ângulos da molécula real, mas isso não tem importância dependendo da finalidade do modelo, por exemplo se se tratar de uma representação da molécula de DNA para crianças do $6^{\circ}$ ano.

No entanto um novo fator surge quando tentamos modelar a entropia, pois ao contrario dos modelos planetário, atômico, nuclear e celular, os quais relacionamos com uma entidade física através de uma relação de semelhança, 
os modelos de entropia não representam diretamente um sistema real, pois envolvem abstrações baseadas em regras estatísticas. O modelo da urna não representa um gás real, mas esclarece muito bem a natureza da entropia, tanto que pode ser estendido para ambientes não físicos, como a teoria econômica de mercados.

Os dois modelos comentados há pouco expõem o esforço de explicar os conceitos básicos que fundamentam microscopicamente a entropia, e por isso mostram um esforço em reduzir ontologicamente a $2^{\underline{a}}$ Lei da Termodinâmica a processos microscópicos.

O modelo físico simplificado é importante não só no ensino de ciências, mas também em discussões de questões da filosofia da ciência, como sobre a natureza da irreversibilidade macroscópica. O modelo da urna de Ehrenfest sugere uma solução para este problema da irreversibilidade, em sintonia com a concepção probabilista da entropia de Boltzmann. Mas como saber se o modelo não está simplificando "demais" uma teoria? Em que sentido o modelo poder ser considerado um argumento a favor da concepção reducionista de Boltzmann? Quais os limites explicativos de um modelo? Pode ser de fato usado em domínios diferentes, como o mercado de capitais, ou em um sistema físico mais complexo? Isso significa que também em tais domínios o argumento reducionista é plausível?

\section{4 - Três Modelos de Física Térmica}

Para o químico e educador Áttico Chassot (2001, p. 259):

[...] mudam os modelos, mas não a realidade. Temos na verdade uma nova ideia de átomo, ou seja, um novo átomo, para explicar uma realidade que não mudou. A mudança que ocorre é no nosso conhecimento sobre a realidade.

Esta afirmação de Chassot indica uma certa liberdade no uso de modelos: mesmo modelos muito simplificados podem capturar aspectos importantes de um sistema física. Vamos considerar três modelos que exploram a relação entre mecanismos e estruturas microscópicas (melhor seria 
dizer nanoscópicas) e o sistema visto de maneira macroscópica. O primeiro modelo apresentado refere-se à difusão do calor através de duas barras metálicas em contato, representando-se um número pequeno de "fônons". O segundo ao chamado "modelo de urna" apresentado pelo casal Paul Ehrenfest e Tatiana Ehrenfest-Afanaseva, sendo que ambos os modelos fazem alusão ao aumento global da entropia. O terceiro é o modelo do vento e da árvore, também apresentado pelo casal Ehrenfest, que esclarece o significado da "suposição de independência estatística" e do "caos molecular".

\subsection{1 - Modelo dos Fônons na Barra}

No primeiro modelo, imagine duas barras de cobre $A$ e $B$ de mesmo tamanho, mas com temperaturas diferentes, por exemplo, a barra $A$ com temperatura de $60^{\circ} \mathrm{C}$ e a B com $20^{\circ} \mathrm{C}$. Caso as coloquemos em contato, não será uma tarefa das mais difíceis chegarmos à conclusão de que ambas entrarão em equilíbrio térmico, tendo em vista a $2^{-}$Lei da Termodinâmica (desprezam-se perdas de calor ao ambiente).

Um modelo físico envolvendo "fônons" é de grande valia para justificar esse comportamento do calor. Por fônon designamos um quantum de vibração da rede cristalina, mas iremos associar este quantum de vibração a átomos individuais. Iremos supor que a temperatura de um corpo é proporcional ao número de fônons no material.

Será que a entropia do sistema final em equilíbrio, após o contato das duas barras, é maior do que a entropia do sistema inicial com as barras separadas? Usemos o modelo simplificado dos fônons para verificar isso, conforme a Fig. 3.1 (LIENHARD, 2013). Nesta figura, a estrutura constituinte de cada barra contém apenas quatro átomos. A $20^{\circ} \mathrm{C}$ representamos apenas um único fônon, ao passo que a barra a $60^{\circ} \mathrm{C}$ possuiria cinco quanta de energia vibracional. Modos coletivos de vibração são ignorados. 

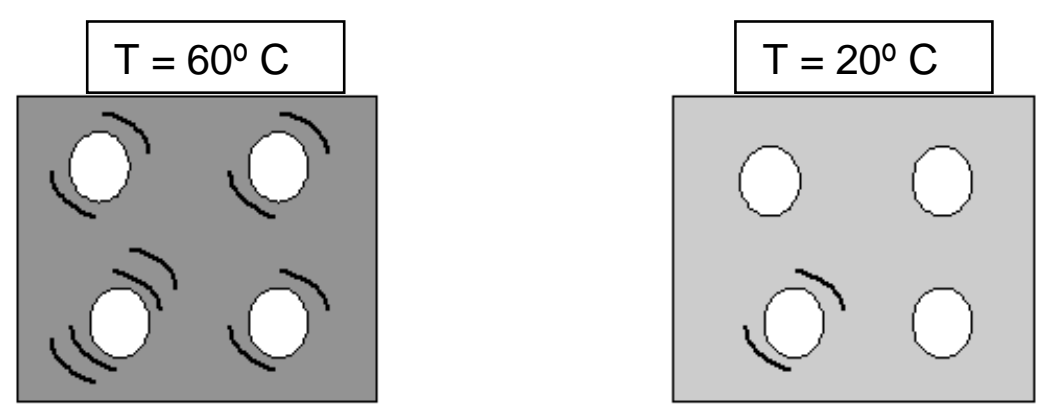

Figura 3.1 - A barra $A$, com $T=60^{\circ} \mathrm{C}$ possui 5 quanta de energia de vibração, representados pelas linhas curvas, já a barra $B$ com $T=20^{\circ} \mathrm{C}$ possui apenas um quantum, uma vez que possui menor temperatura.

No Cap. 2 foi visto que a definição probabilista de entropia proposta por Boltzmann estipula que a entropia $S$ é proporcional ao logaritmo do número $\Omega$ de estados possíveis do sistema (ou "configurações"): $S=k \cdot \ln \Omega$. Assim, para estimarmos as entropias nos modelos de fônons, precisamos contar o número de configurações para cada barra separada (antes do contato entre elas) e o número de configurações após estabelecido o contato (em equilíbrio).

Antes do contato, a barra $A$ mais fria, a $20^{\circ} \mathrm{C}$, possui 4 estados possíveis, correspondendo a um único fônon estando presente em um dos quatro átomos. Assim, $\Omega_{\mathrm{FRIA}}=4$. Para a barra B mais quente, a $60^{\circ} \mathrm{C}$, há $r=5$ quanta de energia que podem ser distribuídos entre $n=4$ átomos. Usando a fórmula combinatória $(n+r-1)$ ! / [ $(n-1)$ ! $r$ ! ] , obtemos $\Omega_{\text {QUENTE }}=56$.

A entropia total inicial é a soma das entropias inicias de cada subsistema. Como os valores da entropia em cada sistema são $S_{A}=k \ln 4=$ $k \cdot 1,39$ e $S_{B}=k \ln 56=k \cdot 4,02$, o valor total da entropia inicial é $\mathbf{S}_{\mathrm{Ti}}=\boldsymbol{k} \cdot \mathbf{5 , 4 1}$.

Após serem colocadas em contato, o equilíbrio térmico é estabelecido, e as duas barras possuirão a mesma temperatura de $40^{\circ} \mathrm{C}$.

Os fônons movem-se livremente no sistema composto. Há $r=6$ quanta de energia distribuídos entre $n=8$ átomos, o que fornece $\Omega_{\mathrm{FINAL}}=1716$. Fazendo o cálculo da entropia total final, obtém-se $\mathbf{S}_{\mathrm{Tf}}=\boldsymbol{k} \cdot \mathbf{7 , 4 5}$. 


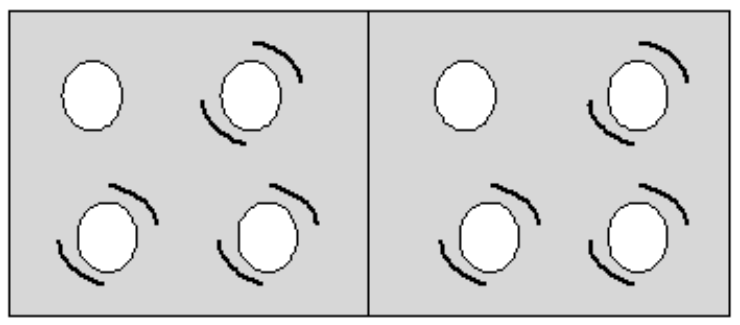

Figura 3.2 - Sistema em equilíbrio, onde na média o número de quanta de energia é distribuído de forma igualitária entre as barras em contato. Não seria correto impor que essa distribuição se mantivesse fixa, já que poderia ocorrer uma flutuação no número de fônons em cada lado.

Vemos assim que a variação total da entropia, neste processo espontâneo, é positiva, o que está de acordo com a $2^{2}$ Lei.

Vemos assim como um modelo, por mais simplificado que seja, pode fazer uma "analogia positiva" (como diria Campbell) com o caso real estudado na física. A analogia positiva se dá ao postular bolinhas para representar átomos, sendo que tais bolinhas vibram em suas posições de equilíbrio de maneira discreta, em analogia com os fônons. A "analogia negativa" envolveria as diversas propriedades da barra metálica real não incorporada no modelo, como o número e tamanho dos átomos, as vibrações da rede cristalina como um todo, etc.

\subsection{2 - Modelo da Urna de Ehrenfest}

Examinemos agora outro modelo, conhecido como Modelo da Urna (ou "modelo dos cachorros pulguentos"), cujo viés matemático é fundamental para exprimirmos a essência da concepção probabilista de entropia, apresentada nesta tese no Capítulo 2, cujas bases apresentam o caráter estatístico da $2^{\underline{a}}$ Lei da Termodinâmica. Proposto pelos físicos Paul e Tatiana Ehrenfest em 1906, este modelo evidencia a tendência ao equilíbrio da distribuição de calor entre dois corpos e o consequente aumento da entropia global.

Consideremos duas caixas A e B, uma delas (A) completamente preenchida de bolinhas e a outra vazia. Vamos agora numerar as bolinhas, de 1 até o número $N$ de bolinhas, que pode ser 20, conforme indicado na Fig. 3.3. 


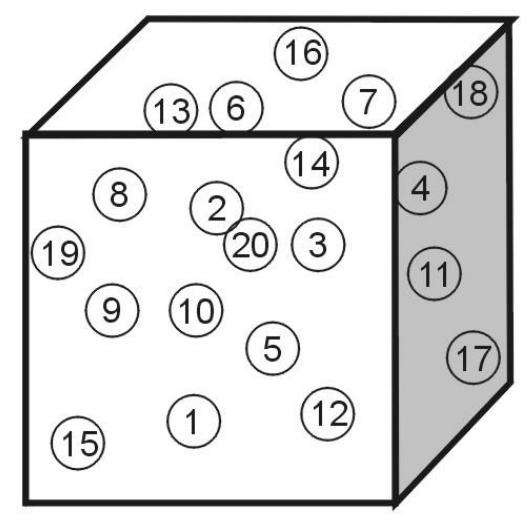

A

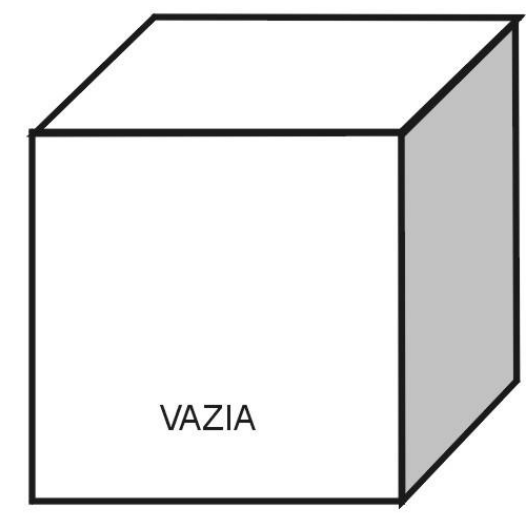

B

Figura 3.3 - Modelo da Urna de Ehrenfest.

Em seguida, munidos de um gerador de números aleatórios, que é facilmente encontrado na web, podemos sortear números de 1 a 20 em intervalos de tempo $\tau$. O processo consiste em retirar a bolinha correspondente ao número sorteado e trocá-la de caixa: caso esteja em $A$, colocá-la em $B$, se estiver em B, colocá-la em A.

De início há um número maior de bolinhas em $\mathrm{A}$, mas com o passar do tempo há uma tendência de as caixas conterem aproximadamente o mesmo número de bolinhas. $\mathrm{O}$ número exato de bolinhas em cada urna estará sujeita a flutuações.

Apesar de este modelo não ser determinista, como Boltzmann supôs inicialmente na derivação do Teorema $\mathrm{H}$, vê-se claramente que a probabilidade destas bolinhas voltarem ao seu estado inicial é ínfima, ou mais especificamente, o tempo de recorrência é muito alto. Isso foi mostrado por KAC (1947, p. 386), que derivou o tempo médio de recorrência $T_{R}$ para o caso de condição inicial arbitrária, e que em nosso caso é simplesmente $T_{R}=\tau \cdot 2^{N}$, onde $\tau$ é o tempo entre cada sorteio e $N$ o número total de bolinhas.

Desta maneira podemos estimar o tempo médio de recorrência para 20 bolinhas contidas primeiramente na Urna A, conforme a Fig. 3.3, da ordem de 1.048.576 segundos (com intervalo de tempo entre os sorteios de 1 segundo). Ficaríamos aproximadamente 12 dias esperando para que as bolas saíssem de $A$, atingissem o equilíbrio $\left(N_{A}=N_{B}\right)$ e retornassem à urna $A$ novamente. 
Caso queiramos extrapolar esse cálculo, podemos considerar um número maior de bolas na caixa, por exemplo, 20.000, e com $\tau=1 \mathrm{~s}$, teremos um tempo de recorrência de $2^{20.000} \mathrm{~s}$, ou $10^{6.000}$ anos!

Vemos que esse modelo esclarece a questão levantada por Zermelo, quando este se utilizou do fenômeno da recorrência para criticar o Teorema $\mathrm{H}$ de Boltzmann. A crítica à derivação original de Boltzmann era válida, pois ao usar a hipótese do Stosszahlansatz Boltzmann concluiu que não haveria recorrência, já que a irreversibilidade derivada seria estrita. Mas ao adotar a sua concepção probabilista de entropia, Boltzmann pôde transformar sua noção de "impossibilidade" de recorrência em uma noção de "alta improbabilidade" de recorrência.

O modelo da urna de Ehrenfest tem o mérito de permitir entender esta questão de maneira bastante simples. Isto pode ser usado como uma atividade didática em sala de aula, demonstrando a relação entre o tempo de recorrência e o número de bolas utilizadas.

$\mathrm{Na}$ Fig. 3.4, apresentamos o gráfico referente a uma rodada do jogo da urna, com 6 bolas dispostas inicialmente em uma única urna, que pode ser usada em sala de aula. O tempo entre cada sorteio é de $5 \mathrm{~s}$. Se cada aluno realizar uma rodada deste "jogo da urna", espera-se que na média o tempo de recorrência seja de 320 segundos.

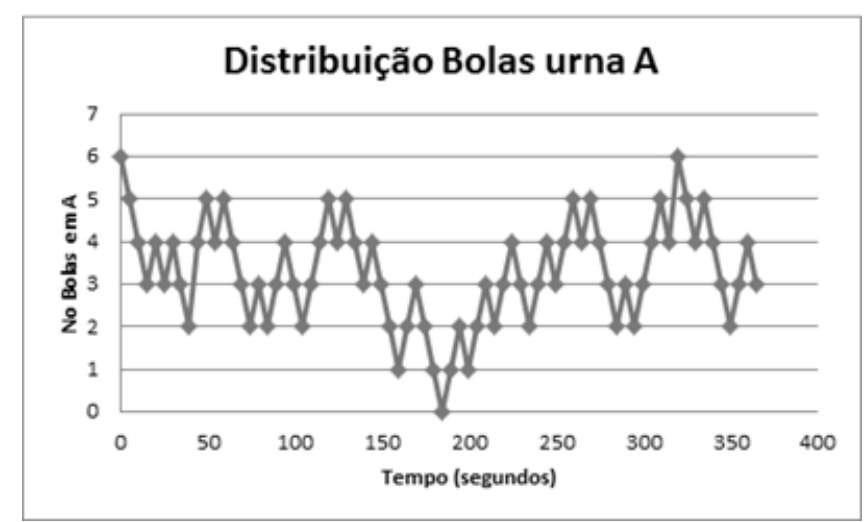

Figura 3.4 - Exemplo de gráfico referente ao tempo de recorrência de 6 bolas, todas presentes inicialmente em uma única urna, denominada $A$. Os sorteios ocorrem com intervalos de 5 segundos. 
A seguir apresentamos na Fig. 3.5 um gráfico referente a este experimento, envolvendo agora 20 bolas numeradas e um tempo entre sorteio de 5 segundos aproximadamente, onde realizamos 50 jogadas. Primeiramente colocamos todas as bolas na caixa A, conforme a Fig. 3.4.

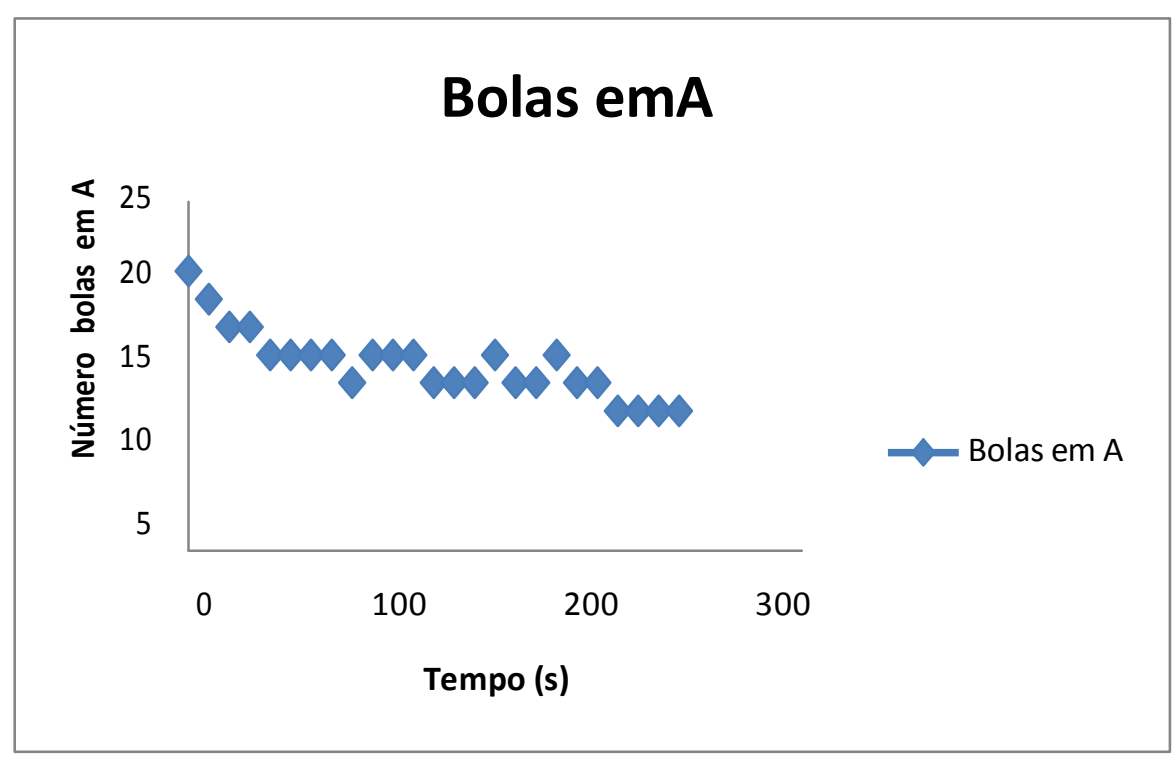

Figura 3.5 - Gráfico referente ao número de bolinhas na Urna A em relação ao tempo. O intervalo dos sorteios é de $5 \mathrm{~s}$, mas os pontos indicados marcam cada $10 \mathrm{~s}$ (o que explica os pontos sucessivos com igual número de bolas).

Podemos notar que de inicio é pequena a probabilidade de que uma bola de $B$ venha para $A$, pois é determinada pela razão $1 / N$. Já a probabilidade de que uma de $A$ venha para $B$ é de $1-1 / N$, ou seja, muito maior. Devido ao pequeno número de bolas, podemos observar flutuações bem proeminentes em torno do ponto de equilíbrio, que é o número igual de bolas nas duas caixas. No entanto para um número maior de bolinhas, as flutuações começam a diminuir.

Este modelo, que de início fora proposto com a finalidade de explicar a dissipação do calor (difusão molecular), acabou por ultrapassar os limites de sua aplicação inicial, servindo de base teórica para sistemas mais complexos presentes na área da química, biologia e economia (GARIBALDI \& PENCO, 2000). Esta grande abrangência de aplicações sugere que o modelo da urna é mais do que um simples modelo físico, pois ele parece capturar um aspecto matemático presente em variados sistemas. 
Qual é, afinal, a natureza dos modelos na ciência? Para tentarmos responder a esta pergunta, vamos nos ater agora a como os modelos estão ligados a uma teoria científica.

\subsection{3 - Modelo do Vento e da Árvore dos Ehrenfests}

Um outro modelo desenvolvido pelo casal Tatiana \& Paul Ehrenfest faz uma anologia entre um gás chocando-se com obstáculos fixos e o vento batendo em árvores fixas (ver RECHTMAN et al., 1991). O propósito do modelo é ilustrar a noção de caos molecular, que exploramos na seção 2.6.

O modelo do vento e da árvore tem uma evolução microscópica totalmente determinística, em duas dimensões (por exemplo, em um plano). Há dois tipos de "moléculas": a molécula $Q$ é fixa, e tem a forma de um quadrado, ao passo que a molécula $P$ é redonda e móvel, e não interage com outras moléculas $P$. Conforme se vê na Figura 3.6, as moléculas $P$ incidem a $45^{\circ}$ das faces de uma molécula $Q$, sendo assim desviada em $90^{\circ}$. Disso resulta que as moléculas $P$ só se movem em duas direções $x$ e y, em ambos os sentidos. Cada choque com $\mathrm{Q}$ faz uma $\mathrm{P}$ mudar a direção de seu movimento.

Quando uma molécula $P$ se move no sentido $+x$, atribui-se a ela o valor 0 ; no sentido $+y$, o valor 1 ; no sentido $-\mathrm{x}$, o valor 2 ; e no sentido $-\mathrm{y}$, o valor 3 . A fração das moléculas com valores $0,1,2$ e 3 é dado respectivamente por $f_{0}, f_{1}$, $f_{2}$, e $f_{3}$. Para qualquer distribuição de velocidades inicial, espera-se que eventualmente as distribuições oscilem em torno do estado de equilíbrio com $f_{0}=f_{1}=f_{2}=f_{3}=1 / 4$. Pode-se derivar a evolução temporal das quatro funções de distribuição. Para isso, é razoável supor que o número de P's indo no sentido i (por exemplo, $+\mathrm{x}$ ) que desvia para $\mathrm{i}+1$ (por exemplo, $+\mathrm{y}$ ) é igual, por simetria, ao número de $\mathrm{P}$ 's (vindos por $+\mathrm{x}$ ) que desviam para $\mathrm{i}-1$ (no caso, $-\mathrm{y}$ ) (ver Fig. 3.6b). Impondo esta condição perfeitamente razoável:

$$
N_{i, i+1} \delta t=N_{i, i-1} \delta t=k f_{i} \delta t .
$$

deriva-se uma equação analítica que fornece a evolução temporal das distribuições de velocidade, que tende à situação de equilíbrio mencionada (a 
constante $k$ depende dos tamanhos de $\mathrm{P}, \mathrm{Q}$ e da densidade dos $\mathrm{Q}$ ) (ver RECHTMAN et al., 1991).

No entanto, há algo errado, pois o sistema deveria exibir recorrência, além de estar sujeito à objeção do paradoxo da reversibilidade. Com efeito, para este sistema de distribuição de velocidades, pode-se escrever a função $H$ de Boltzmann, $H(t)=\Sigma f_{i}(t) \ln f_{i}(t)$, e obter uma equação bastante simples, que tende ao valor mínimo, conforme esperado pelo teorema $\mathrm{H}$, sem flutuações. Como foi possível derivar tal resultado?

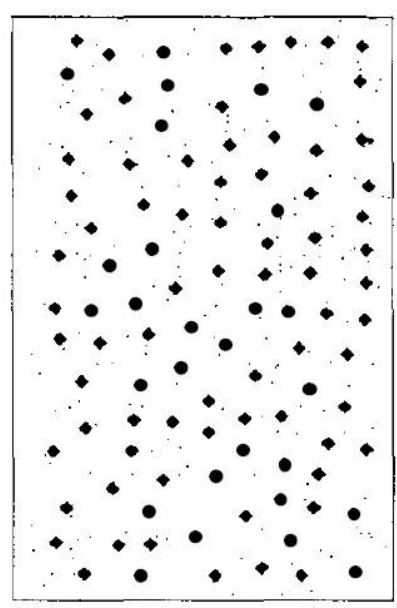

(a)

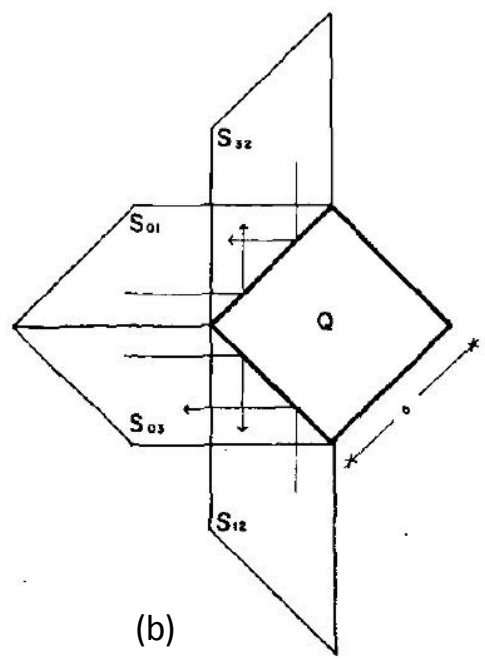

(b)

Figura 3.6: Modelo do vento e da árvore do casal Ehrenfest (RECHTMAN et al., 1991), em duas dimensões. À esquerda (a), uma disposição possível das moléculas $P$ (quadradas e fixas) e das $Q$ (redondas e móveis). À direita (b), ilustração de como uma molécula $P$, ao se chocar elasticamente com uma $Q$, necessariamente tem um desvio de $90^{\circ}$.

A chave está na suposição da eq.(3.1), que nada mais é do que a versão, no modelo do vento e da árvore, da hipótese da independência estatística (Stosszahlansatz), que Rechtman et al. (1991) chamam de "caos molecular" (seguindo Huang e outros físicos).

Em uma simulação com 2000 moléculas $P$, a cada intervalo mínimo de tempo utilizado, há um pequeno desvio da condição estipulada na eq.(3.1), de $2 \%$, segundo Rechtman et al. (1991, p. 31). O que isso deve significar é o seguinte: supondo 500 moléculas rumando no sentido $+x$, o Stosszahlansatz estipularia que exatamente 250 desvia para $+y$ e 250 desvia para $-\mathrm{y}$; no entanto, em média, esta distribuição (para este sistema em particular) seria 
algo como 255 e 245.

Tomando este modelo como um representante de um sistema analisado por Boltzmann em seu teorema $\mathrm{H}$, o que temos é que Boltzmann teria imposto (com o Stosszahlansatz) que o desvio mencionado nunca sairia de 250/250, em nenhum intervalo de tempo.

Outro ponto interessante do sistema mecânico determinista do modelo da árvore e do vento é que, supondo paredes que refletem elasticamente de $+x$ para $-x$ (e vice-versa), e o mesmo para $y$, temos que cada molécula $P_{i}$ individual tem um período de recorrência constante $T_{i}$, oscilando eternamente com este período (RECHTMAN et al., 1991, p. 31). Podemos estimar que o tempo de recorrência do sistema como um todo seria da ordem do produto de todos os períodos $T_{i}$ mencionados.

Vemos assim como o uso de um modelo tem valor didático e científico, ajudando a esclarecer uma questão complexa, como aquela envolvida na violação da hipótese da independência estatística. 


\section{CAPÍTULO 4 \\ Implicações para o Ensino de Ciências}

\section{1 - História e Filosofia no Ensino de Ciências}

Um dos fins básicos do Ensino de Ciências é possibilitar que os estudantes atinjam uma "adequada" compreensão da Natureza da Ciência (PETRUCCI \& DIBAR URE, 2001). Diversos estudos, entretanto, têm apontado que os egressos da educação científica mantêm uma série de concepções distorcidas sobre o tema, tais como a ideia de uma ciência imutável, cumulativa, linear e desenvolvida por semideuses contempladores (AIKENHEAD \& RYAN, 1992; LEDERMAN, 2002; CANAVARRO, 2000; entre outros).

Para Popper (1974, p. 119; uso a tradução de MARTINS, 2006, p. 12):

A ciência não está fundamentada sobre um leito rochoso. A estrutura ousada de suas teorias se eleva, por assim dizer, sobre um pântano. É como um edifício erguido sobre palafitas. As estacas são cravadas de cima para baixo no pântano, mas não atingem nenhuma base natural 'dada'. Se paramos de empurrar as estacas mais para baixo, não é porque tenhamos alcançado um solo mais firme. Simplesmente paramos quando aceitamos que elas estão suficientemente estáveis para suportar a estrutura, pelo menos por enquanto.

Nas últimas décadas, tem-se salientado a importância da História e Filosofia da Ciência (HFC) no ensino e na formação de professores. Tal perspectiva aparece em documentos oficiais da área de Educação, como os PCNs (Parâmetros Curriculares Nacionais). 
Michael Matthews tem sido um pioneiro na aproximação entre a HFC e o ensino. Segundo ele, no ensino médio, a abordagem "contextualista" da história da ciência melhora o ensino porque:

1) motiva e interessa os alunos; 2) humaniza os conteúdos; 3) proporciona uma melhor compreensão dos conteúdos científicos mostrando seu desenvolvimento e aperfeiçoamento; 4) a compreensão de episódios cruciais na história da ciência tem valor intrínseco, como a revolução científica, o darwinismo etc.; 5) demonstra que a ciência é mutável e dinâmica e que, consequentemente, o conhecimento científico atual é suscetível de ser transformado; o que 6) desta maneira, combate a ideologia cientificista; e finalmente, 7) a história permite o conhecimento mais rico do método científico e mostra as fases de mudança das metodologias aceitas (MATTHEWS, 1994a, p. 259).

Apesar do consenso retratado nas pesquisas, dificilmente tal abordagem chega às salas de aula na educação básica. Por quê? Muitas são as dificuldades envolvidas, tais como a falta de bons materiais disponíveis, além da ausência de reflexões sobre o tema nos cursos de formação inicial e continuada de professores (MARTINS, 2007).

Mas que tipo de história tem sido utilizada no ensino? Allchin (2000), ao discutir como não devemos ensinar a História da Ciência, salienta graves problemas neste ensino. Por exemplo, a tendência a se apresentar apenas os produtos da ciência passada, ignorando o processo de construção; a dificuldade em expor os erros cometidos pelos cientistas do passado; a apresentação do método científico como um algoritmo, capaz de conduzir à verdade, etc. Muitas vezes, no afã de incluir um pouco de $\mathrm{HC}$ em sala de aula, muitos propedeutas caem na chamada "interpretação whig da História", sinônimo de História da Ciência anacrônica, consistindo em "estudar o passado com os olhos do presente" (BUTTERFIELD, 1965).

Nesse momento, partindo do pressuposto de que "o estudo cuidadoso da História da Ciência pode ajudar bastante a entender a natureza da Ciência" (SILVA \& MARTINS, 2003), seria importante sublinhar que: 
- Uma observação significativa não é possível sem uma expectativa pré-existente.

- A natureza não fornece evidências simples o suficiente que permitam interpretações sem ambiguidade.

- Teorias científicas não são induções, mas sim hipóteses que vão necessariamente além das observações.

- O conhecimento científico não é estático e convergente, mas sim mutável e sem fim.

- Uma formação prévia dentro de um mesmo paradigma é uma componente essencial para que haja acordo entre os cientistas.

- O pensamento científico não se constrói sem influência de fatores sociais, morais, espirituais e culturais.

- Os cientistas não constroem deduções incontestáveis, mas sim julgamentos complexos e especializados.

- O desacordo é sempre possível (SILVA \& MARTINS, 2003, p. 54).

Resumidamente, esta chamada "visão adequada" seria aquela que mostraria toda a complexidade do fazer ciência, abordando o conhecimento do ponto de vista epistemológico e histórico, influenciado por um contexto social. Isso nos levará ao debate da historiografia "internalista" vs "externalista":

Segundo Ledermann \& Zeidler (1987, p. 721):

[...] a "natureza da ciência" comumente refere-se aos valores e suposições inerentes ao desenvolvimento do conhecimento científico.

Para Cibelle Silva \& Roberto Martins, é possível que ajudemos os estudantes a compreender melhor a NdC quando nos utilizamos de aspectos históricos e sociais, sem que façamos uso de tecnicidades, abstrações matemáticas ou elaborações mais complexas, que seriam aspectos "internalistas" a determinada área. Essa abordagem que enfatiza mais os aspectos sociais, históricos e institucionais é chamada de aspectos "externalistas" da História da Ciência. No entanto, os autores criticam o uso exclusivo dessa abordagem: 
[...] se o objetivo é ensinar Ciência através da História da Ciência, será impossível evitar os detalhes técnicos (SILVA \& MARTINS, 2003, p. 55).

Não seria contraproducente frisarmos os detalhes técnicos para vislumbrarmos a evolução de uma determinada teoria, pois estes seriam integrados aos aspectos externalistas junto à HC. Por outro lado, de acordo com Beltran, Saito \& Trindade (2014, p. 38):

Uma historiografia centrada apenas na análise interna de um documento é anacrônica e não permite que sejam avaliadas as condições próprias de uma época na qual aquele conhecimento foi produzido.

Porém:

a perspectiva externalista não privilegia o debate entre diferentes teorias que envolveram estudiosos de um determinado período e elimina toda a complexidade envolvida no processo do fazer da ciência (BELTRAN, SAITO \& TRINDADE, 2014, p. 38).

Nesta tese o enfoque foi principalmente "internalista", explorando as facetas de uma ciência autônoma, com dinâmica própria e com suas especificidades técnicas. Porém, por vezes buscaram-se elementos externalistas, como na controvérsia envolvendo Weinberg e Anderson. Nosso trabalho entende que as duas abordagens são complementares, e mais, fundamentais para que se atinja aquilo que foi chamado de uma visão "adequada" da $\mathrm{NdC}$.

Como consequência desta abordagem de $\mathrm{NdC}$, levantamos a importância do caráter dialógico interdisciplinar, que requer um mínimo de conhecimento das características básicas que cada disciplina possui (como aquelas tratadas aqui nesta tese: Termodinâmica e Mecânica Estatística). 


\section{2 - Uma Proposta de Curso}

Como parte do trabalho de tese, desenvolvi uma proposta de curso abordando a Termodinâmica e a Mecânica Estatística, de um ponto de vista histórico e filosófico. Essa proposta foi pensada para ser desenvolvida em um contexto de um curso de graduação em Física, bacharelado ou licenciatura. A inclusão dos bacharéis aqui se faz porque, mesmo aqueles que não seguirem a licenciatura, acabarão se tornando muitas vezes docentes nos cursos universitários. Poderia ser um curso de extensão ou uma disciplina optativa.

As atividades elaboradas para este minicurso levam em consideração aspectos históricos (tanto em uma perspectiva internalista quanto externalista) e filosóficos da Ciência, fundamentadas em leitura, discussões e reflexões sobre os temas. Seu título poderia ser "Tópicos de História e Filosofia da Termodinâmica e Mecânica Estatística". A Tabela 4.1 apresenta uma síntese do curso.

O curso se inicia com a aplicação de um questionário baseado naquele usado por Lederman et al. (2002), sobre as concepções sobre a natureza da Ciência (ver Tabela 4.2). Nas quatro aulas seguintes, os tópicos de redução e emergência são explorados, incluindo a discussão sobre o debate político entre Weinberg e Anderson, e também o exemplo de redução envolvendo a Teoria Cinética dos Gases. No apêndice A fazemos um resumo das atividades 1, 2 e 3 bem como no apêndice $B$ sintetizamos as atividades 4, 5, 6 e 7 através de slides. Após duas aulas sobre os elementos de Mecânica Estatística, trabalhase o papel das aproximações e dos modelos na ciência. Por fim, explora-se o modelo da urna de Ehrenfest, encerrando-se o curso com uma nova aplicação do questionário e a realização de um júri simulado. Tal recurso é recomendado por diversos autores (CRUZ SILVA \& MARTINS, 2009; BERNARDO et al., 2013) quando os temas discutidos são controversos.

Vale a pena salientar que este é apenas um guia inicial, podendo o professor utilizar-se do curso na ordem em que the seja mais conveniente, algo que certamente será ponderado a partir do diálogo com os alunos. 


\begin{tabular}{|c|c|c|}
\hline & $\begin{array}{l}\text { Momentos da } \\
\text { proposta }\end{array}$ & Atividades sugeridas \\
\hline \multirow{12}{*}{ 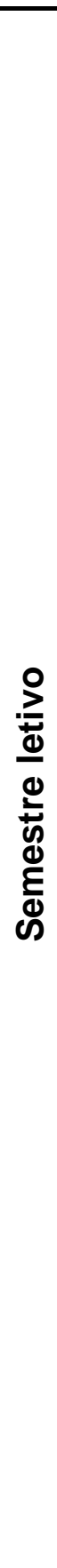 } & $\begin{array}{l}\text { Levantamento das } \\
\text { concepções iniciais } \\
\text { sobre a Natureza da } \\
\text { Ciência }\end{array}$ & $\begin{array}{c}\text { Questionário adaptado a partir de } \\
\text { VNOS - Form C (LEDERMAN et al., 2002). }\end{array}$ \\
\hline & \multirow{10}{*}{$\begin{array}{l}\text { Desenvolvimento do } \\
\text { Curso }\end{array}$} & Atividade 1 - Redução. \\
\hline & & Atividade 2 - Emergência. \\
\hline & & $\begin{array}{c}\text { Atividade } 3 \text { - A face política da discussão. } \\
\text { Síntese (Apêndice A). }\end{array}$ \\
\hline & & $\begin{array}{l}\text { Atividade } 4-\text { O projeto reducionista: a teoria cinética da } \\
\text { matéria. }\end{array}$ \\
\hline & & $\begin{array}{l}\text { Atividade } 5 \text { - A equação de Boltzmann, o Teorema H e } \\
\text { os desafios teóricos. }\end{array}$ \\
\hline & & $\begin{array}{c}\text { Atividade } 6 \text { - O determinismo em cheque: nasce a } \\
\text { Mecânica Estatística. }\end{array}$ \\
\hline & & $\begin{array}{l}\text { Atividade } 7 \text { - O papel das aproximações. } \\
\text { Síntese (Apêndice B). }\end{array}$ \\
\hline & & Atividade 8 - Os modelos em Ciência. \\
\hline & & Atividade 9 - Modelo de Urna dos Ehrenfest. \\
\hline & & $\begin{array}{c}\text { Atividade } 10 \text { - Novo levantamento de concepções sobre } \\
\text { a Natureza da Ciência. }\end{array}$ \\
\hline & Avaliação Final. & Atividade 11 - Júri Simulado. \\
\hline
\end{tabular}

Tabela 4.1 - Plano de aulas do curso de "Tópicos de História e Filosofia da Termodinâmica e Mecânica Estatística". 
1) Na sua opinião, qual é a diferença entre ciência e outras áreas de atividade humana, como a filosofia, religião, arte, etc.?

2) $\mathrm{O}$ que é um experimento? O conhecimento científico exige experimentos? Explique.

3) Qual a diferença entre um fato e uma teoria? Os fatos podem mudar? Uma teoria pode mudar?

4) Um mesmo conjunto de dados experimentais podem ser explicados igualmente bem por diferentes teorias? Dê um exemplo.

5) O que é um modelo científico?

6) A ciência reflete valores sociais e culturais (de uma certa sociedade) ou ela é universal (não dependendo da cultura em que ela ocorre)?

7) Há um único método científico, ou há vários métodos? Descreva esse método ou esses métodos. Eles podem ser usados de maneira mecânica, ou a atividade científica envolve criatividade e imaginação?

8) Pode-se fazer uma observação neutra de pressupostos teóricos, ou toda observação é carregada de pressupostos teóricos?

Tabela 4.2: Questionário VNOS adaptado

A seguir apresentam-se com mais detalhes cada uma das atividades do curso:

\section{ATIVIDADE 1 - Redução}

\begin{tabular}{|l|l|}
\hline Objetivos & Compreender o conceito de redução na Ciência. \\
\hline Materiais & $\begin{array}{l}\text { Texto da seção } 1.2 \text { desta tese. } \\
\text { Analisando a face da redução. } \\
\text { WEINBERG (1994), Sonhos de uma teoria final, cap. } 3 .\end{array}$ \\
\hline Questões para reflexão & $\begin{array}{l}\text { Reduzir é diminuir? } \\
\text { A visão reducionista é uma visão limitada de ciência? }\end{array}$ \\
\hline Tempo previsto & 2 horas aula. \\
\hline
\end{tabular}




\section{ATIVIDADE 2 - Emergência}

\begin{tabular}{|l|l|}
\hline Objetivos & Compreender o conceito de emergência na Ciência. \\
\hline Materiais & $\begin{array}{l}\text { Texto da seção 1.3. } \\
\text { Analisando a face da Emergência. } \\
\text { Artigo “More is different" - Philip ANDERSON (1972). } \\
\text { Artigo de KIM (1999), "Making sense of emergence”. }\end{array}$ \\
\hline Questões para reflexão & $\begin{array}{l}\text { Se imaginarmos a ciência como um quebra-cabeças, } \\
\text { estariam faltando peças quando dizemos que em } \\
\text { determinado ponto de uma teoria houve uma } \\
\text { emergência? } \\
\text { Onde termina a química e começa a bioquímica? }\end{array}$ \\
\hline Tempo previsto & 2 horas aula. \\
\hline
\end{tabular}

ATIVIDADE 3 - A face política da discussão

\begin{tabular}{|l|l|}
\hline Objetivos & Explorar aspectos externalistas do debate. \\
\hline Materiais & $\begin{array}{l}\text { Texto do Capítulo 1.1- A face política da discussão. } \\
\text { Slides 1 - Weinberg x Anderson: a síntese de uma disputa. }\end{array}$ \\
\hline Questões para reflexão & $\begin{array}{l}\text { Quais questões poderíamos levantar para questionar tanto } \\
\text { os argumentos de Weinberg quanto os de Anderson? } \\
\text { Quais outros debates na ciência que suplantam o campo } \\
\text { científico? }\end{array}$ \\
\hline Tempo previsto & 2 horas aula. \\
\hline
\end{tabular}

ATIVIDADE 4-O projeto reducionista: a teoria cinética da matéria

\begin{tabular}{|l|l|}
\hline Objetivos & $\begin{array}{l}\text { Analisar as relações entre variáveis termodinâmicas com } \\
\text { seus respectivos entes microscópicos. }\end{array}$ \\
\hline Materiais & $\begin{array}{l}\text { Texto da seção 2.1 - O conceito da Entropia e versões da } \\
\text { 2a lei. } \\
\text { Texto livro BRUSH (1986), seção 5.4. } \\
\text { Tese de SILVA (2013). }\end{array}$ \\
\hline Questões para reflexão & $\begin{array}{l}\text { Qual a necessidade em aproximar a termodinâmica a } \\
\text { Mecânica Estatística? }\end{array}$ \\
\hline Tempo previsto & 2 horas aula. \\
\hline
\end{tabular}




\section{ATIVIDADE 5 - A equação de Boltzmann e o Teorema H} e os desafios teóricos

\begin{tabular}{|l|l|}
\hline Objetivos & $\begin{array}{l}\text { Mostrar os desafios enfrentados por vários cientistas em } \\
\text { busca da explicação microscópica da Entropia }\end{array}$ \\
\hline Materiais & $\begin{array}{l}\text { Texto do seção 2.3 - A equação de Boltzmann e o Teorema } \\
\text { H. } \\
\text { Artigos de DAHMEN (2006), “A obra de Boltzmann em } \\
\text { Física", e BORGES (1999), "Irreversibilidade, desordem e } \\
\text { incerteza". }\end{array}$ \\
\hline Questões para reflexão & $\begin{array}{l}\text { Por que a necessidade de encontrar elementos mecânicos } \\
\text { microscópicos para a Entropia? } \\
\text { A hipótese de Independência Estatística, coloca em cheque } \\
\text { o caminho para a Redução? }\end{array}$ \\
\hline 2 horas aula. \\
\hline Tempo previsto & \\
\hline
\end{tabular}

ATIVIDADE 6 - 0 determinismo em cheque: nasce a Mecânica Estatística

\begin{tabular}{|l|l|}
\hline Objetivos & $\begin{array}{l}\text { Facilitar o entendimento de um elemento novo, como a } \\
\text { estatística, na seara do determinismo. }\end{array}$ \\
\hline Materiais & $\begin{array}{l}\text { Texto da seção 2.4 - Concepção probabilista de Entropia. } \\
\text { MIZRAHI (1994) e SKLAR (1993), Physics and chance, cap } \\
\text { II. }\end{array}$ \\
\hline Questões para reflexão & $\begin{array}{l}\text { Quando elementos estatísticos são "invocados" na teoria } \\
\text { de Boltzmann, podemos falar em Emergência? }\end{array}$ \\
\hline Tempo previsto & Horas aula \\
\hline
\end{tabular}

ATIVIDADE 7 - 0 papel das aproximações

\begin{tabular}{|l|l|}
\hline Objetivos & $\begin{array}{l}\text { Discutir o peso das aproximações e suas consequências } \\
\text { para o entendimento da NdC }\end{array}$ \\
\hline Materiais & $\begin{array}{l}\text { Texto da seção } 2.5 \text { - Novas aproximações. } \\
\text { Slides 2 - Termodinâmica e Mecânica Estatística. A } \\
\text { estratégia da hierarquia BBGKY }\end{array}$ \\
\hline Questões para reflexão & Aproximar, sempre é um ato de redução? \\
\hline Tempo previsto & 2 horas aula \\
\hline
\end{tabular}




\section{ATIVIDADE 8 - Os modelos em Ciência}

\begin{tabular}{|l|l|}
\hline Objetivos & A influência dos modelos para a compreensão da NdC. \\
\hline Materiais & $\begin{array}{l}\text { Textos das seções 3.2 e 3.4. } \\
\text { HESSE (1966), Models and analogies in science. } \\
\text { GIERE (2004), How models are used to represent reality. }\end{array}$ \\
\hline Questões para reflexão & $\begin{array}{l}\text { A partir do trecho do personagem Suárez Miranda, de J.L. } \\
\text { Borges (seção 3.2), pergunta-se até que ponto modelos } \\
\text { extremamente sofisticados têm lugar na ciência? } \\
\text { É preciso sermos tão detalhistas para que tenhamos } \\
\text { conhecimento dos fenômenos? } \\
\text { À medida que uma teoria se aproxima da verdade, ela não } \\
\text { se tornaria cada vez mais inútil, dada sua crescente } \\
\text { complexidade? }\end{array}$ \\
\hline Tempo previsto & 2 horas aula \\
\hline
\end{tabular}

ATIVIDADE 9 - Modelo de Urna dos Ehrenfest

\begin{tabular}{|l|l|}
\hline Objetivos & $\begin{array}{l}\text { Apresentação de um modelo físico, que dá suporte ao } \\
\text { Teorema H. Trazendo noções de tendência dos sistemas ao } \\
\text { equilíbrio, periodicidade e reversibilidade. }\end{array}$ \\
\hline Materiais & $\begin{array}{l}\text { Descrição experimental. } \\
\text { Gerador de números aleatórios (pode ser uma lista } \\
\text { telefônica de uma grande cidade). }\end{array}$ \\
\hline Questões para reflexão & \\
\hline Tempo previsto & 2 horas aula \\
\hline
\end{tabular}

\section{ATIVIDADE 10 - Júri Simulado}

\begin{tabular}{|l|l|}
\hline Objetivo & $\begin{array}{l}\text { Desenvolver capacidade argumentativa dos futuros } \\
\text { professores. }\end{array}$ \\
\hline Materiais & $\begin{array}{l}\text { 3 grupos: 1 reducionista, 1 emergentista e 1 neutro. } \\
\text { Artigo de CRUZ SILVA \& MARTINS (2009). }\end{array}$ \\
\hline Questões para reflexão & $\begin{array}{l}\text { Afinal, foi a 2a Lei da Termodinâmica reduzida à Mecânica } \\
\text { Estatística? }\end{array}$ \\
\hline Tempo previsto & 2 horas aula. \\
\hline
\end{tabular}


Pretende-se aplicar este roteiro de curso no início de 2017, possivelmente na UNESP de Bauru, uma vez que o objetivo geral da pesquisa era o desenvolvimento de uma proposta de formação a partir das discussões sobre redução e emergência, buscando levar as reflexões sobre a natureza da ciência para a sala de aula. Os "slides" mencionados nas Atividades 3 e 7 (Apêndice A e B) foram preparados, a partir de seminários e apresentações em congressos, e trazem conteúdos presentes nesta tese.

\section{3 - As implicações para o Ensino de Ciências}

Podemos concluir este capítulo apontando que há muitas implicações positivas do presente estudo em História e Filosofia da Termodinâmica e Mecânica Estatística para o ensino de ciências. Além da revisão de história da ciência, foram trazidas discussões filosóficas a respeito do debate reducionismo vs. emergentismo, e do uso de modelos nesta área da Física. Em sala de aula, essas questões podem ser levantadas não só em aulas expositivas, como em discussões na classe, incluindo um júri simulado, e também com atividades envolvendo modelos de mecânica estatística, como a urna de Ehrenfest. Julgamos que isso contribuirá para uma melhor compreensão da natureza da Ciência entre os estudantes. 


\section{CAPÍTULO 5 \\ Conclusões}

As discussões apresentadas nesta tese surgem como uma reação a um ensino tradicional, baseado na mera exposição de fórmulas e modelos desconectados. Neste sentido buscou-se uma abordagem que levasse em conta aspectos da História e Filosofia da Ciência (HFC) como fios condutores para a elaboração de uma proposta de formação, que permitisse a construção de uma visão adequada de Natureza da Ciência ( $\mathrm{NdC})$. Optamos por retratar as conexões entre a Termodinâmica e Mecânica Estatística, explorando diversos modelos, visando seu uso em sala de aula.

No cap. 2, abordou-se o esforço de Boltzmann na tentativa de tornar seu Teorema-H compatível com os fenômenos macroscópicos irreversíveis e a consequente vinculação da Mecânica à Estatística. A abordagem BBGKY foi introduzida como um exemplo das técnicas de aproximação em Mecânica Estatística.

É importante salientar que o uso de modelos não se restringiu ao Cap. 3, mas também fez-se presente nos capítulos 1 e 2. No cap. 3. Depois de discutir os aspectos filosóficos do uso de modelos na ciência, examinamos o modelo dos fônons na barra, o modelo da Urna dos Ehrenfests e o modelo do Vento e da Árvore. No Cap. 2, na exposição didática sobre o desenvolvimento da Teoria Cinética dos Gases e da Mecânica Estatística, foram apresentados diversos modelos de gás ideal, por meio de um pequeno número de bolinhas elásticas. $\mathrm{Na}$ apresentação da definição probabilista da entropia, foram explorados o modelo de um gás separado por um pistão e a lei dos grandes números. No Cap 1, na discussão do debate reducionismo vs. emergentismo, utilizou-se o exemplo da flambagem de uma barra, o que não deixa de ser um modelo simplificado.

Além da análise sobre modelos e sua importância no Ensino de Física, manifestou-se também a oposição filosófica entre redução e emergência e seus reflexos fora da seara acadêmica, através do debate entre os físicos Steven Weiberg e Philip Anderson. Ainda no Cap.1, apresentaram-se formas 
distintas de reducionismo e emergentismo, com o intuito de evitar uma análise superficial ao referencia determinado objeto, fenômeno ou propriedade de uma teoria.

Ademais, ainda que os tópicos redução e emergência permeiem os debates científicos em Mecânica Estatística e outras áreas, como na Biologia Molecular, eles se encontram ausentes dos currículos escolares e universitários. Defende-se, o valor educacional dessa reflexão para a formação do futuro professor e dos futuros cidadãos, mostrando como a ciência de fato é construída, revelando aspectos para os quais não há uma visão de consenso único.

Este trabalho não tem a pretensão de colocar um ponto final no debate entre reducionistas e emergentistas, pois questões complexas, sejam elas de cunho filosófico ou técnico, estão ainda em discussão atualmente, mesmo quanto à questão da redução ou não da Teoria Termodinâmica à Mecânica Estatística. Trata-se de otimizar essas ideias, intencionando seu uso como contrapartida à visão ingênua da construção científica.

Ao final da tese, apresenta-se uma proposta de curso, desenvolvida por intermédio das reflexões anunciadas nos capítulos anteriores, a fim de buscar contribuições para o enriquecimento dos estudos sobre a NdC. 


\section{Referências Bibliográficas}

ACHINSTEIN, P. History and philosophy of science: a reply to Cohen. In: Suppe, F. (org.). The structure of scientific theories. Urbana: University of Illinois Press, p. 350-60, 1977.

AIKENHEAD, G.S. \& RYAN, A.G. Student's preconceptions about epistemology of science. Science Education, v. 76, p. 559-80. 1992.

ALLCHIN, D. How NOT to teach history in science. In: Finley, F.; Allchin, D.; Rhees, D. \& Fifield, S. (eds.). Proceedings of the Third International History, Philosophy, and Science Teaching Conference, vol. 1. Minneapolis: University of Minnesota Press, p. 13-22, 1995.

ANDERSON, P. W. More is Different. Science, v. 177, p. 393-396,1972.

AURANI, K.M. As origens da relação entre o conceito de entropia e de probabilidade de estado. Enseñanza de las Ciencias, v. extra, p. 15991603, 2009.

BACHELARD, G. A formação do espírito científico: contribuição para uma psicanálise do conhecimento. $5^{\mathrm{a}}$ ed. Trad. E.S. Abreu. Rio de Janeiro: Contraponto, 1996. Orig. em francês: 1938.

BANDI, M.M; GOLDBURG, W.I. \& CRESSMAN JR., J.R. Measurement of entropy production rate in compressible turbulence. Europhysics Letters, v. 76, n. 4 , p. $595-601,2006$.

BATTERMAN, R.W. The devil in the details: asymptotic reasoning in explanation, reduction and emergence. Oxford: Oxford University Press, 2001.

BELTRAN M.H.R.; SAITO, F. \& TRINDADE, L.S.P. História da Ciência para a formação de professores. São Paulo: Livraria da Física, p .38. 2014.

BENTLEY, M.L. \& GARRISON, J.W. The role of philosophy of science in science teacher education. Journal of Science Teacher Education, v. 2, n. 3, p. 67-71, 1991.

BERNARDO, J.R.R.; VIEIRA, R.D.; GUIMARÃES, H.C. \& MELO, V.F. O júri simulado e a alternância de papeis em uma discussão sociocientífica: uma possibilidade para o desenvolvimento de habilidades argumentativas de professores. Atas do IX Encontro Nacional de Pesquisa em Educação em Ciências (ENPEC). Águas de Lindóia, SP, 10-14/11/2013. Online: http://www.nutes.ufrj.br/abrapec/ixenpec/atas/resumos/R15551.pdf 
BOGOLIUBOV, N.N. Kinetic Equations. Journal of Experimental and Theoretical Physics, v. 1, n. 16, p. 691-702, 1946.

BOLTZMANN, L. Lectures on gas theory. Trad. Stephen Brush. Berkeley: University of California Press, 1964. Original de 1896-98.

- Escritos populares. Trad. e notas A.A. Passos Videira. Novo Hamburgo, Ed. Unisinos, 2005. Seleção do original em alemão de 1905.

BORGES, E.P. Irreversibilidade, desordem e incerteza: três visões da generalização do conceito de entropia. Revista Brasileira de Ensino de Física, v. 21, p. 453-63, 1999.

BORGES, J.L. Sobre o rigor na ciência. In: História universal da infâmia. Trad. José Bento. Lisboa: Assírio e Alvim, 1982.

BORN, M. \& GREEN, H.S. General kinetic theory of liquids I. The molecular distribution functions. Proceedings of the Royal Society of London A, v. 188, p. 10-18, 1946.

BRUSH, S. The kind of motion we call heat: a history of the kinetic theory of gases in the $19^{\text {th }}$ century. 3a. ed. New York: Elsevier, 1986.

BUTTERFIELD, H. The whig interpretation of history. New York: Norton, 1965.

CACHAPUZ, A.F. Linguagem metafórica e o ensino das ciências. Revista Portuguesa de Educação, v.2, n.3, p.117-129,1989.

CANAVARRO, J.M. O que se pensa sobre a ciência. Coimbra: Quarteto, 2000.

CATTANI, M. \& BASSALO, J.M.F. Entropia, reversibilidade, irreversibilidade, equação de transporte e teorema $\mathrm{H}$ de Boltzmann e o teorema do retorno de Poincaré. Revista Brasileira de Ensino de Física, v. 30, n. 2, p. 2301-1 a 2301-9, 2008.

CHALLEY, J.F. Carnot, Sadi. Trad. Y.S. Figueiredo. In: Gillispie, C.C. (org.). Dicionário de biografias científicas. Editor brasileiro: C. Benjamin. Rio de Janeiro: Contraponto, vol. 1, pp. 414-20, 2007. Orig. em inglês: 1980.

CHAPMAN, S. Boltzmann's $H$-theorem. Nature, v. 139, p. 931, 1937.

CHASSOT, A. Alfabetização científica. ljuí: Ed. Unijuí, 2001.

CHIBENI, S.S. Tipos de teorias. Online: http://www.unicamp.br/ chibeni/ textosdidaticos/tiposdeteorias.pdf 
CLAUSIUS, R. The mechanical theory of heat: with its applications to the steam engine and to physical properties of bodies. 1a ed. Trad. J. Tyndall, org. T.A. Hirst. London: John van Voorst, 1867.

COLINVAUX, Dominique. Modelos e educação em ciências. Rio de Janeiro: Ravil, 1998.

COURBAGE, M. \& PRIGOGINE, I. Intrinsic randomness and intrinsic irreversibility in classical dynamical systems. Proceedings of the National Academy of Science U.S.A., v. 80, p. 2412-6, 1983.

CLAUSIUS, R. The mechanical theory of heat. Londres: John Van Hoorst,1867. Orig. em alemão: 1865.

CRUZ SILVA, B.V. \& MARTINS, A.F.P. Júri simulado: um uso da história e filosofia da ciência no ensino da óptica. Física na Escola, v. 10, n. 1, p. 17-20, 2009.

DA COSTA, N. \& FRENCH, S. Models, theories, and structures: thirty years on. Philosophy of Science, v. 67, Supplement, p. S116-127, 2000.

DAHMEN, S. A obra de Boltzmann em Física. Revista Brasileira de Ensino de Física, v. 28, n. 3, p. 281-95, 2006.

DENG, F.; CHEN, D.-T.; TSAI, C.-C. \& CHAI, C.-S. Students' views of the nature of science: a critical review of research. Science Education, v. 95, p. 961-999, 2011.

DIRAC, P.A.M. Quantum mechanics of many-electron systems. Proceedings of the Royal Society of London A, v. 123, p. 714-733, 1929.

DRIESCH, H. The history and theory of vitalism. London: Macmillan, 1914.

DRIVER, R.; LEACH, J.; MILLAR, R. \& SCOTT, P. Young people's images of science. Bristol (PA): Open University Press, 1996.

DUPRÉ, J. Reductionism. In: Newton-Smith, W.H. (org.), A companion to the philosophy of science. Oxford: Blackwell, p. 402-4, 2000.

DUTRA, L.H.A. Os modelos e a pragmática da investigação. Scientiae Studia, v. 3, n. 2, p. 205-32, 2005.

ERDURAN, S.; ADURIZ BRAVO, A. \& MAMLOK-NAAMAN, R. Developing epistemologically empowered teachers: examining the role of philosophy of chemistry in teacher education. Science and Education, v. 16, p. 97589, 2007. 
ESTANY, A. Modelos de cambio científico. Barcelona: Crítica, 1990.

EYRING, H.; HENDERSON, D.; STOVER, B.J. \& EYRING, E.M. Statistical mechanics and dynamics. New York: Wiley, 1982.

FRIGG, R. \& HARTMANN, S. Models in science. Stanford Encyclopedia of Philosophy, online, 2012.

GALILEI, G. Duas novas ciências [Discorsi]. Trad. L. Mariconda \& P. Mariconda. São Paulo: Ched/Nova Stella/Instituto Italiano di Cultura, 1985. Orig. de 1638.

GARIBALDI, U. \& PENCO, M.A. Ehrenfest's urn model generalized: an exact approach for market participation models. Statistica Applicata, v. 12, n. 2, p. 249-72, 2000.

GEORGESCU-ROEGEN, N. (1971). The entropy law and the economic process. Cambridge (MA): Harvard University Press, 1971.

GIERE, R. How models are used to represent reality. Philosophy of Science, v. 71, n. 5, p. 742-52, 2004.

GIL-PÉREZ, D. Contribuición de la historia y la filosofía de las ciencias al desarrollo de um modelo de enseñanza/aprendizaje como investigación. Enseñanza de las Ciencias, v.11, n. 2, p. 197-212, 1993.

GONZÁLEZ, F. Introducción a la ciencia sagrada, Programa Agartha. Revista Symbolos, n. 25-26, Buenos Aires, 1985. Online: http://introduccionalsimbolismo.com/Programa_Agartha.pdf

HAAPARANTA, L. The analogy theory of thinking. Dialectica, v. 46, n. 2, p. 16983, 1992.

HALL, G.L. Ionized impurity scattering in semiconductors. Journal of Physics and Chemistry of Solids, v. 23, p. 1147-51, 1962.

HARMAN, P.M. Energy, force, and matter: the conceptual development of nineteenth-century physics. Cambridge (Ingl.): Cambridge University Press, 1982.

HARRISON, A.G. \& TREAGUST, D.F. Learning about atoms, molecules, and chemical bonds: a case study of multiple-model use in grade 11 chemistry. Science Education, v. 84, n. 3, p. 352-81, 2000.

HAWKING, S.W. A brief history of time. $2^{\mathrm{a}}$ ed. New York: Bantam Books, 1998. 
- Gödel and the end of physics, 2002. Online: http://www.damtp.cam.ac.uk/events/strings02/dirac/hawking/

HESSE, M.B. Models and analogies in science. Notre Dame: University of Notre Dame Press, 1966.

HILL, T.L. Statistical mechanics. New York: McGraw-Hill,1956.

HOFFMANN, R. O mesmo e o não-mesmo. Trad. R. Leal Ferreira. São Paulo: UNESP, 2007. Orig. em inglês: 1995.

HUANG, K. Statistical mechanics. 2a ed. New York: Wiley, 1987.

KAC, M. Random walk and the theory of Brownian motion. American Mathematical Monthly, v. 54, p. 369-91, 1947.

KANGRO, H. Early history of Planck's radiation law. London: Taylor \& Francis, 1976.

KIM, J. Making sense of emergence. Philosophical Studies, v.95, p. 3-36, 1999.

KIRKWOOD, J.G. Statistical mechanical theory of transport process. I. General theory. Journal of Chemical Physics, v. 14, p. 180-201, 1946.

LABARCA, M. \& BEJARANO, N. Química e filosofia: rumo a uma frutífera colaboração. Química Nova, v. 8, p.1256-66, 2013.

LANGE, F. A. The history of materialism. London: Routledge \& Kegan Paul, 1957. Orig. em alemão: 1866.

LAUGHLIN, R.B. \& PINES, D. The theory of everything. Proceedings of the National Academy of Science, v. 97, p. 28-31, 2000.

LEDERMAN, N.G. Students' and teachers' conceptions of the nature of science: a review of the research. Journal of Research in Science Teaching, v. 29, 331-359, 2002.

LEDERMAN, N.G.; ABD-EL-KHALICK, F.; BELL, R.L. \& SCHWARTZ, R.S. Views of nature of science questionnaire: toward valid and meaningful assessment of learners' conceptions of nature of science. Journal of Research in Science Teaching, v. 39, n. 6, p. 497-521, 2002. 
LEDERMAN, N.G. \& ZEIDLER, D.L. Science teachers' conceptions of the nature of science: do they really influence teacher behavior? Science Education, v. 71, n. 5, p. 721-734, 1987.

LEGGETT, A.J. On the nature of research in condensed-state physics. Foundations of Physics, v. 22, n. 2. p. 23-45, 1992.

LIENHARD, J. (2013). Entropy. Vídeo do Teaching and Learning Laboratory, Massachusetts Institute of Technology, acessado em 17/11/2015: http://ocw.mit.edu/resources/res-tll-004-stem-concept-videos-fall2013/videos/governing-rules/entropy/ (ver em 10:20 min)

LOMBARDI, O. \& LABARCA, M. The ontological autonomy of chemical world. Foundations of Chemistry, v. 7, p.125-48, 2005.

MARTINS, André F.P. História e Filosofia da ciência no ensino: há muitas pedras nesse caminho. Cadernos Brasileiros de Ensino de Física, v. 24, n. 1, p. 112-131, 2007.

MARTINS, Roberto A. A Torre de Babel científica. Scientific American Brasil, edição especial, v. 6, "Erros da Ciência", p. 6-13, 2006.

MATTHEWS, M.R. Historia, filosofia e enseñanza de las ciencias: la aproximación actual. Trad. A.M. González. Enseñanza de las Ciencias, v.12, n.2, p. 255-277, 1994a. Original em inglês: Science \& Education, v.1, p. 11-47, 1992.

. Science teaching: the role of history and philosophy of science. New York: Routledge, 1994b.

In defense of modest goals for teaching about the nature of science. Journal of Research in Science Teaching, v. 35, n. 2, p.161-74, 1998.

MAXWELL, J.C. Illustration of the dynamical theory of gas. Philosophical Magazine, v.19, p.19-32, 1860.

. Theory of heat. $9^{\mathrm{a}}$ ed. Mineola (NY): Dover, 2001. Original: $1^{\underline{a}}$ ed., $1871 ; 9^{\text {a }}$ ed., 1888.

McEVILLEY, T. The shape of ancient thought. New York: Allworth, 2002.

MILL, J.S. A system of logic. Honolulu: University Press of the Pacific, 2002. Orig. 1845. 
MILLER, R.C. \& KUSCH, P. Velocity distributions in potassium and thallium atomic beams. Physical Review, v. 99, p.1314-18, 1955.

MIZRAHI, S.S. (1994), Química Nova, v. 17, n. 6, p. 527-35.

MORRISON, M. \& MORGAN, M.S. Introduction. In: Morgan \& Morrison (orgs.), Model as mediators: perspectives on natural and social science. Cambridge: Cambridge University Press, p. 1-9, 1999.

MÜLLER, I. History of thermodynamics. Berlin: Springer, 2007.

NAGEL, E. The structure of science: problems in the logical scientific explanation. New York: Harcourt, Brace \& World, 1961.

NUSSENZVEIG, H.M. Curso de física básica, v.2. São Paulo: Edgar Blücher, 1997.

O'CONOR, T. \& WONG, N.Y. Emergent properties. Stanford Encyclopedia of Philosophy, 2012. Online: http://plato.stanford.edu/archives/ spr2012/entries/properties-emergent/

OLENICK, R.P.; APOSTOL, T.M. \& GOODSTEIN, D.L. The mechanical universe. Vol. 1: Introduction to mechanics and heat. Cambridge: Cambridge University Press, 1985.

PESIC, P. Introduction. In: Maxwell, J.C. Theory of heat. $9^{\text {a }}$ ed. Mineola (NY): Dover, 2001.

PESSOA JR., O. Fisicalismo redutivo e sondas epistemológicas. In: Barra, E.S.O.; Calazans, A. \& Calazans, V.F.B. (orgs.). Anais do III encontro da rede paranaense de pesquisa em história e filosofia da ciência. Curitiba, SCHLA/UFPR, p. 179-90, 2005.

Filosofia da física clássica. Notas de aula da disciplina de Filosofia da Física, Universidade de São Paulo, 2014a. Online: http://www.fflch.usp.br/df/opessoa/FiFi-14.htm.

. O que é a filosofia da física. ComCiência - Revista Eletrônica de Jornalismo Científico, n. 156, LabJor/SBPC, Unicamp, Campinas, 10/03/2014b. Online: http://www.comciencia.br/comciencia/?section=8\& edicao $=97 \&$ id $=1186$

PETRUCCI, D. \& DIBAR URE, M.C. Imagen de la ciencia en alumnos universitarios: una revisión y resultados. Enseñanza de las Ciencias, v. 19, n. 2, p. 217-229, 2001. 
PFEUTY, P. \& TOULOUSE, G. Introduction to renormalization group and to critical phenomena. London: Wiley, 1977.

PHILIBERT, J. One and a half century of diffusion: Fick, Einstein, before and beyond. Diffusion Fundamentals, v. 4, artigo 6, p. 1-19, 2006.

POMEROY, D. Implications of teachers' beliefs about the nature of science: comparison of the beliefs of scientists, secondary science teachers, and elementary teachers. Science Education, v. 77, p. 261-278, 2006.

POZO, J.I. \& CRESPO, M.A.G. A aprendizagem e o ensino de ciências: do conhecimento cotidiano ao conhecimento científico. $5^{\underline{a}}$ ed. Porto Alegre: Artmed, 2006.

POPPER, K. Lógica da pesquisa científica. Trad. L. Hegenberg \& O. Silveira da Mota. São Paulo: Cultrix/EDUSP, 1972. Orig. em alemão: 1934.

RECHTMAN, R.; SALCIDO, A. \& CALLES, A. The Ehrenfests' wind-tree model and the hypothesis of molecular chaos. European Journal of Physics 12, p. 27-33, 1991.

REIF, F. Fundamentals of statistical and thermal physics. New York: McGrawHill, 1965.

ROTHMAN, M.A. The science gap: dispelling the myths and understanding the reality of science. Buffalo (NY): Prometheus, 1992.

RUSSELL, B. Theory of knowledge. London: Chapmann \& Hall, 2002. Orig. 1926.

SALINAS, S.R.A. Introduction to statistical physics. New York: Springer, 2001.

SARKAR, S. Molecular models of life. Cambridge (MA): MIT Press, 2005.

SCERRI, E.R. The ambiguity of reduction. International Journal for Philosophy of Chemistry, v. 19, p. 67-81, 2007.

- Has chemistry been at least approximately reduced to quantum mechanics? In: Hull, D.; M. Forbes, M.; Burian, R. (orgs.). PSA 1994, vol. 1. East Lansing (MI): Philosophy of Science Association, p.160-70, 1994.

- Popper's naturalized approach to the reduction of chemistry. International Studies in the Philosophy of Science, v.12, p. 33-44, 1998. 
SILVA, Cibelle C. \& MARTINS, Roberto A. A teoria das cores de Newton: um exemplo do uso da História da Ciência em sala de aula. Ciência \& Educação, p. 53-65, 2003.

SILVA, Djalma N. Ensino e aprendizagem da termodinâmica: questões didáticas e contribuições da história da ciência. Tese (Doutorado), Universidade de São Paulo, Faculdade de Educação, Instituto de Física, Instituto de Química e Instituto de Biociências, São Paulo, 2013.

SKLAR, L. Types of inter-theoretic reduction. British Journal for the Philosophy of Science, v. 18, p. 109-24, 1967.

_. Physics and chance. Cambridge: Cambridge University Press, 1993.

- The reduction(?) of thermodynamics to statistical mechanics. Philosophical Studies, v. 95, p. 187-202, 1999.

SCHWEBER, Silvan S. Physics, community and the crisis in physical theory. Physics Today 46 (11): 34-40, nov. 1993.

TOLMAN, R. C. The principles of statistical mechanics. New York: Dover, 1979. Orig. 1938.

TREAGUST, D.; DUIT, R.; JOSLIN, P. \& LINDAUER, I. Science teachers' use of analogies: observations from classroom practice. International Journal of Science Education, v.14, n. 4, p. 413-22, 1992.

VILLANI, A. Filosofia da ciência e ensino de ciência: uma analogia. Ciência \& Educação, v. 7, n. 2, p. 169-81, 2001.

WEINBERG, S. Sonhos de uma teoria final: a busca das leis fundamentais da natureza. Rio de Janeiro: Rocco, 1994. Orig. em inglês: 1992.

. Facing up: science and its cultural adversaries. Cambridge (MA): Harvard University Press, 2003.

WILSON, K. The renormalization group and critical phenomena. Reviews of Modern Physics, v. 47, p. 583-600, 1975.

YVON, J. La théorie statistique des fluides et l'équation d'état. Actualités Scientifiques et Industrielles, n. 203, 1935.

ZANETIC, J. Física também é cultura. Tese de Doutorado em Educação, Faculdade de Educação, Universidade de São Paulo, São Paulo, 1989.

ZEH, H.D. On the interpretation of measurement in quantum theory. Foundations of Physics, v. 1, p. 69-76, 1970. 
ZYLBERSZTAJN, A. Teoria final, unificação e reducionismo: opiniões da comunidade brasileira de física. Revista Brasileira de Ensino de Física, v. 25, n. 1, p. 1-17, 2003. 


\section{Apêndice A}

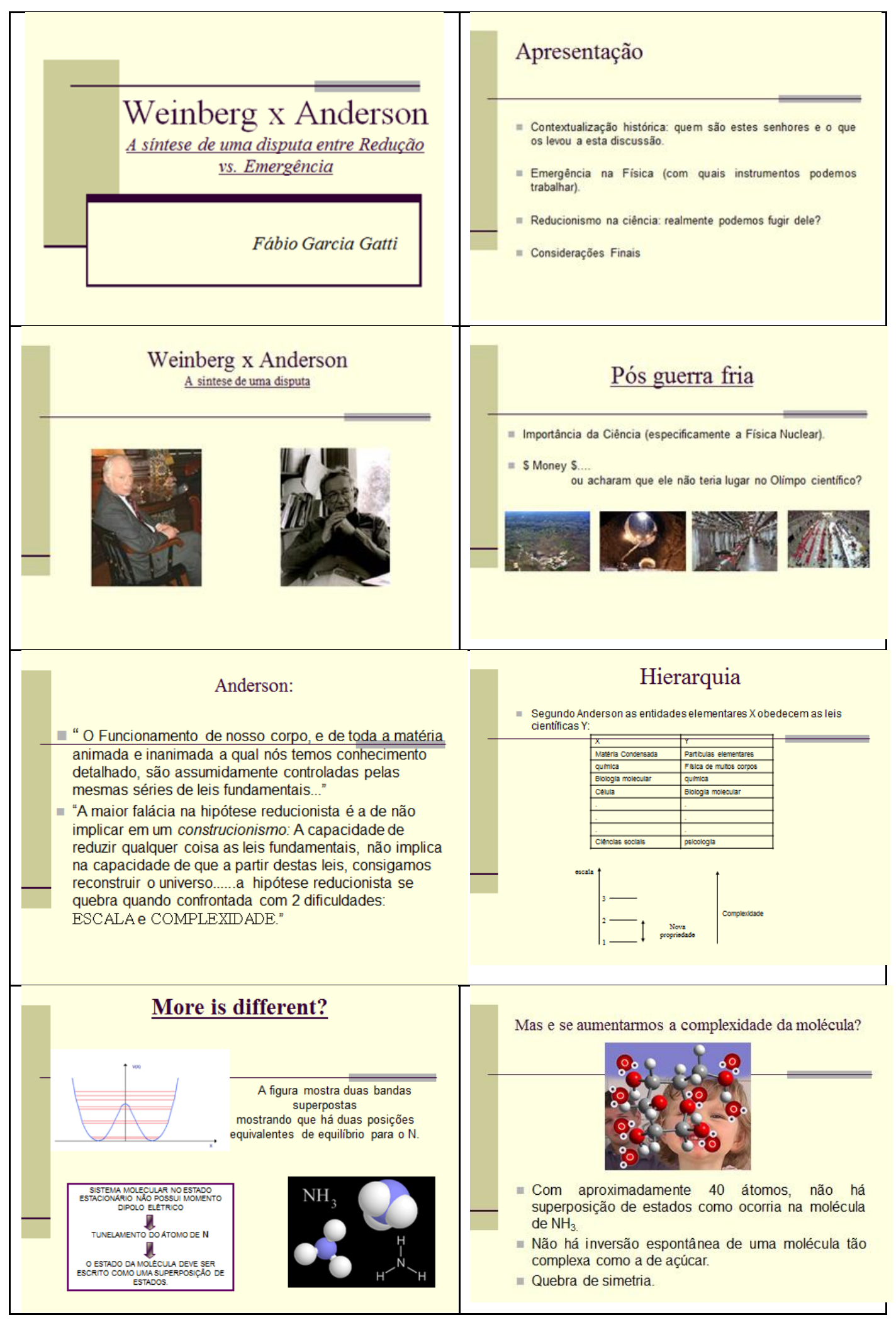


Quebra de simetria (sempre que ocorre em Física, algo importante acontece). Neste ponto, para esta escala, podemos falar de leis independentes de um nivel hierárquico mais básico.

II Anderson propóe um desafio: a Reconstrução.

- Pergunta: Conseguimos a partir das leis fundamentais da Física, prever os fenômenos até então obtidos, por exemplo, na Física da matéria condensada?

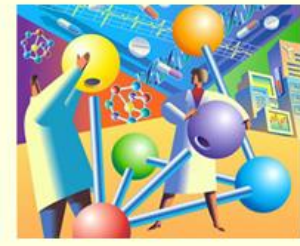

A reconstrução não contempla:

n Em supercondutores, o Efeito Meissner

Existência de cristais em 3D

* Existência de cristais líquidos em 3D

* Existência de um ponto triplo (sólido/liquido/gás)

Emergência $=$ mudança qualitativa a partir de incrementos quantitativos

Mas podemos realmente descrever o Macro sem considerar o micro?

- Sim, de certa forma já o fizemos isso várias vezes durante nossa história cientifica:

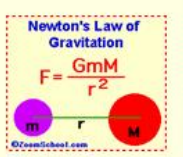

Não nos importa quais os elem

- Comportamento universal.
"Não há nenhuma leifíisca que imponha restriçõ̃es para que algum dia modelos eferramentas." (Facingup)
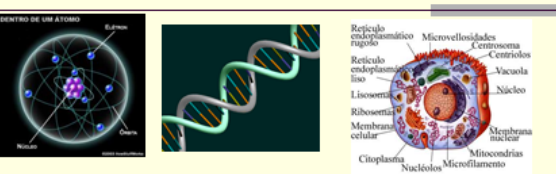

'Reducionismo não é uma prescrição geral para o progresso da ciência, mas uma correta." (Facing up)

\section{Considerações Finais}

Alguns reducionistas:

Vicktor Weisskopf, Leon Lederman, Robert Wilson, Abdus

Alguns emergentistas:

James Krumhansl, Leon Kadanoff, Kenneth Wilson, e um
biólogo do quilate de Ernst Mayr

Gerald Hooft, propõe uma "Lei Básica" ao invés de Lei de

Tudo.

A questão que estamos tratando é a questão se existe ou não uma lei final e se seremos capazes de descobri-la. A questão não é se seremos capazes de usar essa lei para explicar qualquer coisa que gostariamos de ter explicado. Quase certamente, nossa leis dinâmicas serão inúteis para isto, devido à tremenda quantidade de complexidade, presumivelmente ja em escalas um pouco maiores do que a escala de Planck".
Existe uma lei autonoma que possamos chamar de Fundamental em níveis mais complexos?

n Não podemos ter uma boa previsão do clima com mais de 10 dias, pois as equações envolvidas no modelo são de tipo não lineares...Mas alguém acredita que os trovões, humidade e ventos possam ser chamados de fundamentais???
Quando nos satisfazemos (cientificamente) com uma resposta? Se fenômenos de niveis mais complexos possuem suas próprias leis, poderiamos dizer que qualquer mudança ao nivel microscópico as mudaria?

- Modelos são aproximações, geralmente ignoramos a 3 ou quarta ordem numa série.

= hipótese psicológica:

Acredito que grande parte dos ataques "amigos" em relação ao reducionismo, deve-se ao fato de que uma natureza reducioniso, deve-se ao fato de que una "atheza real posição que um ser divino teria neste universo.

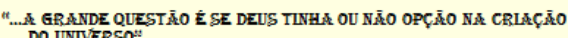




\section{Apêndice B}

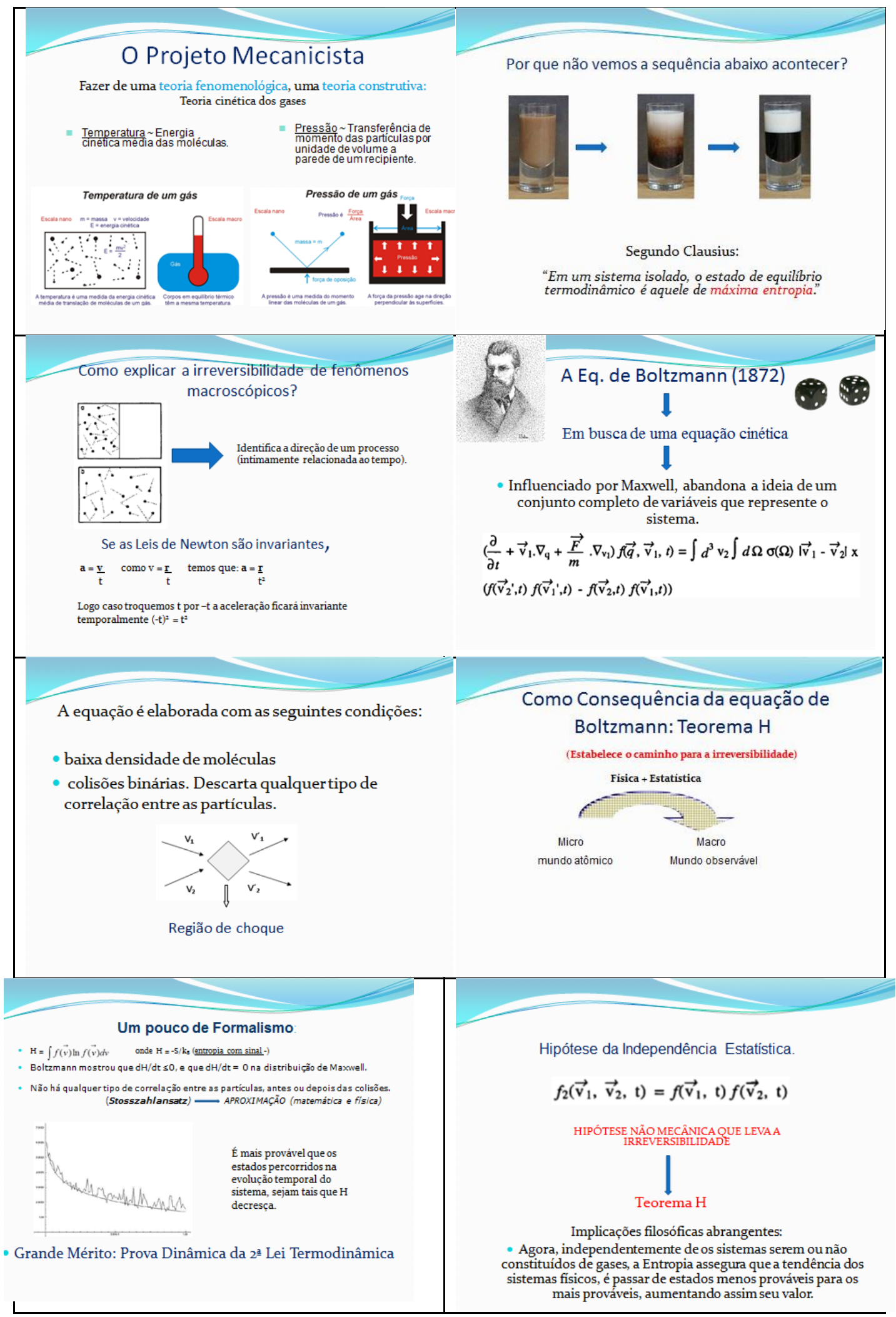




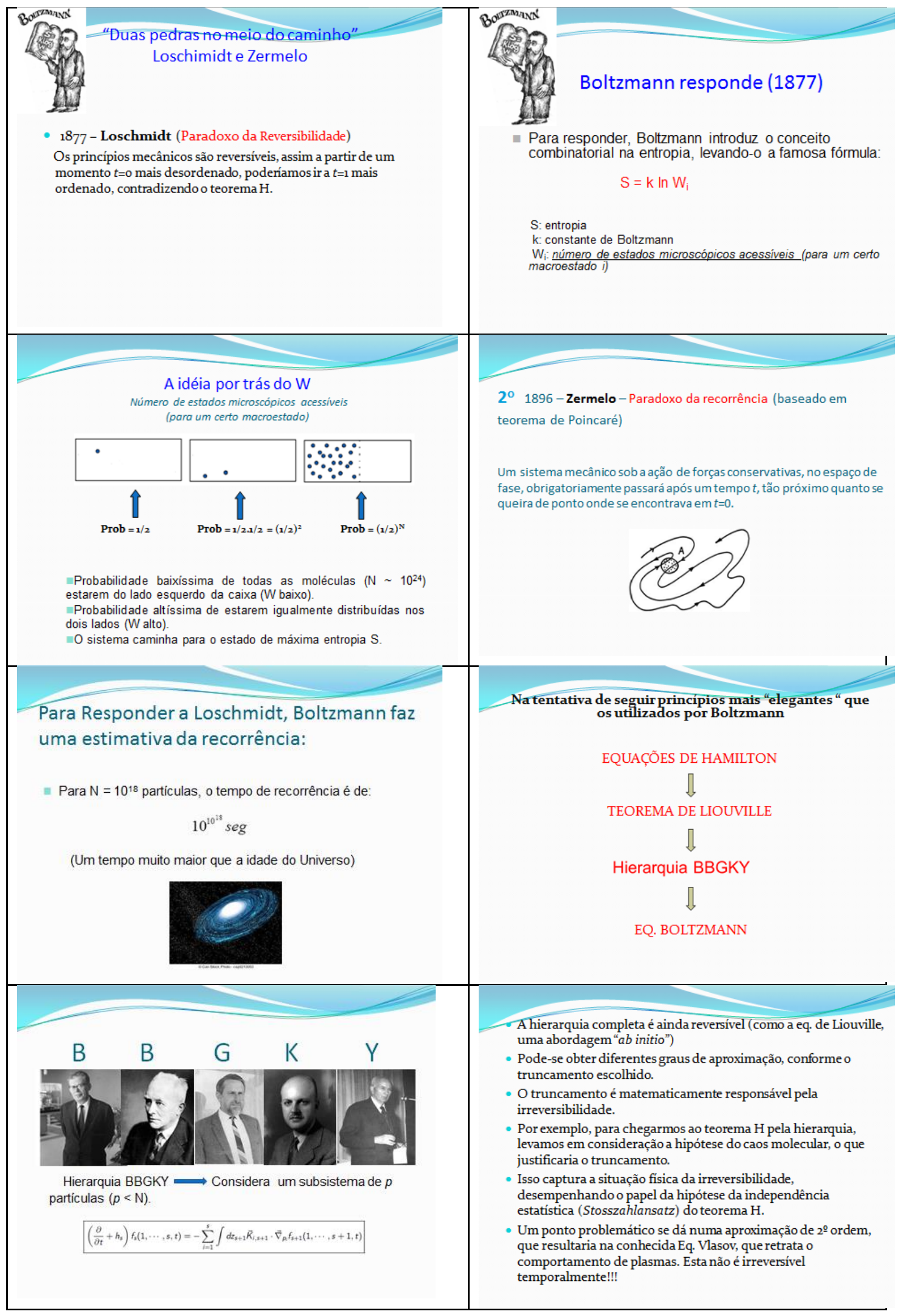

